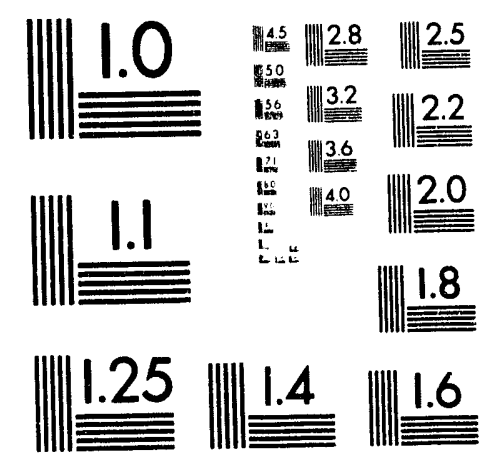



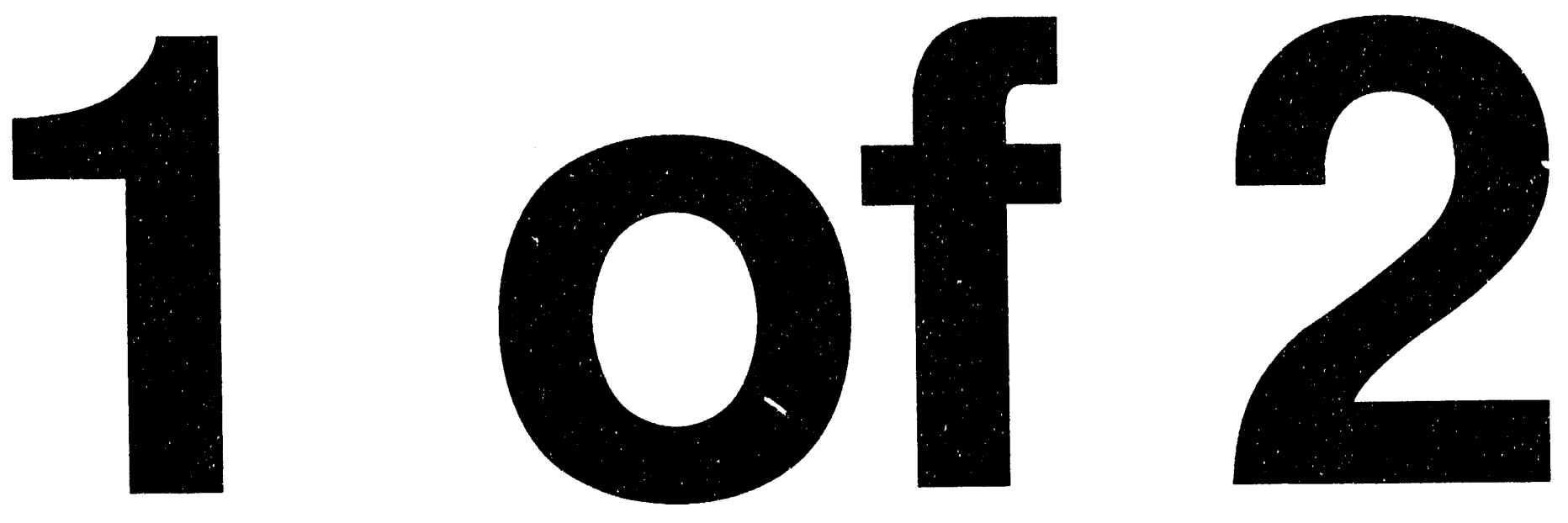


\title{
A NOVEL DUAL-SCREW COAL FEEDER FOR PRODUCTION OF LOW SULFUR FUEL
}

\author{
L. Lin, S. J. Khang and T. C. Keener
}

Engineering College

University of Cincinnati

Cincinnati, OH 45220

June 15,1993 


\section{CONTENTS}

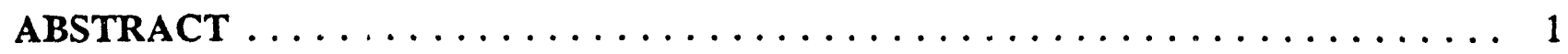

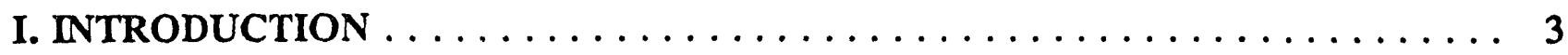

I. BACKGROUND $\ldots \ldots \ldots \ldots \ldots \ldots \ldots \ldots \ldots \ldots \ldots \ldots \ldots$

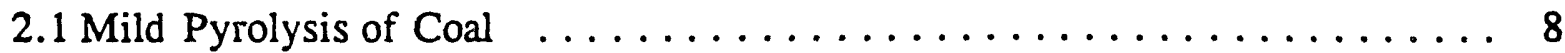

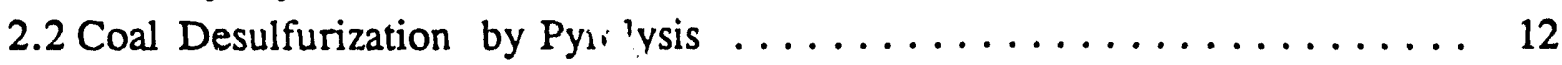

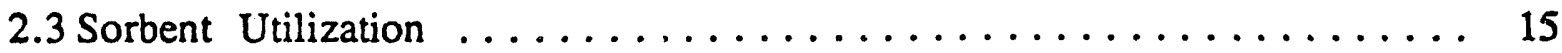

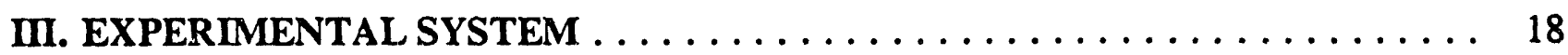

4.1 Design and Construction of the Dual-Screw Feeder Reactor ....... 18

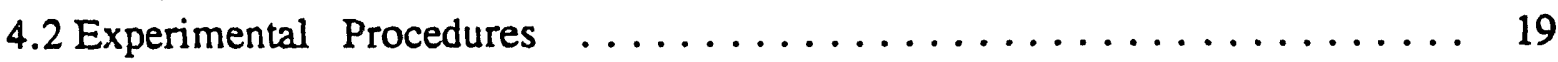

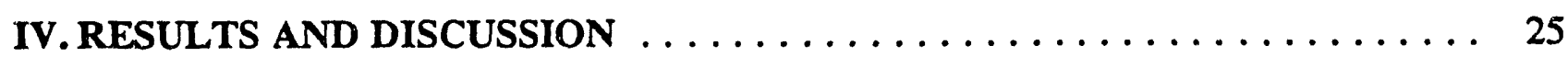

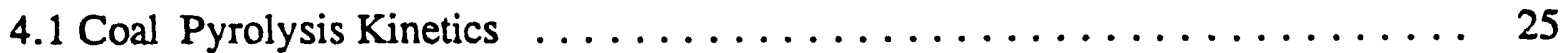

4.2 Coal Desulfurization by Pyrolysis $\ldots \ldots \ldots \ldots \ldots \ldots \ldots \ldots \ldots \ldots \ldots$

4.3 The Combustion Characteristics of The Pyrolyzed Products ......... 41

V.SIMULATION OF THE DUAL-SCREW FEEDER REACTOR $\ldots \ldots \ldots \ldots, 44$

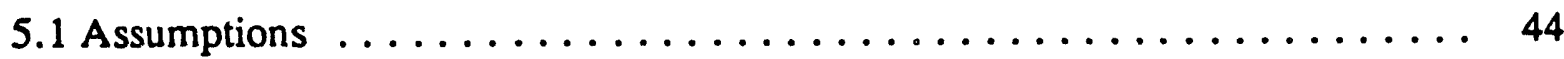

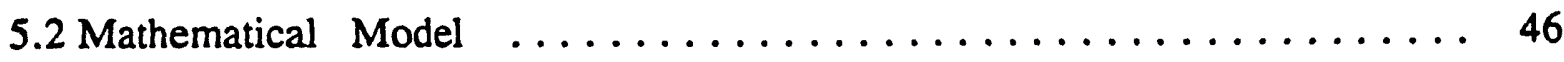

5.3 Estimation of the Parameters $\ldots \ldots \ldots \ldots \ldots \ldots \ldots \ldots \ldots$

(1) Specific Heat of Coal and Char .................. 49

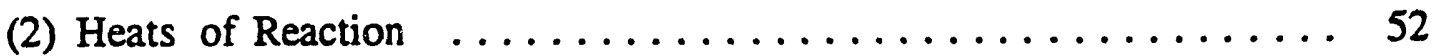

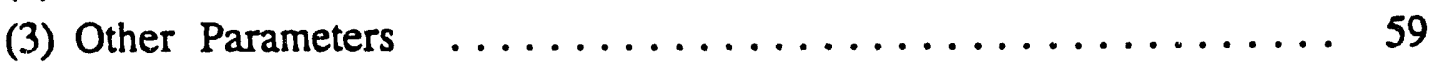

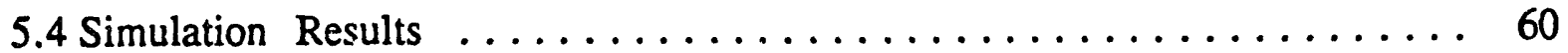

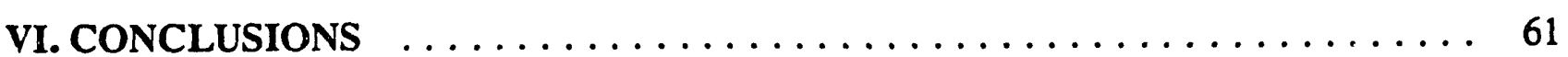

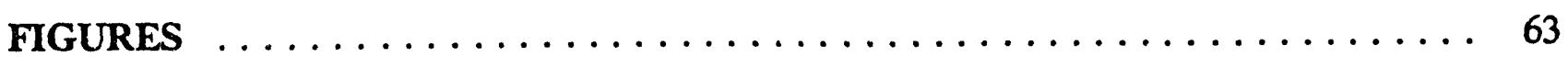

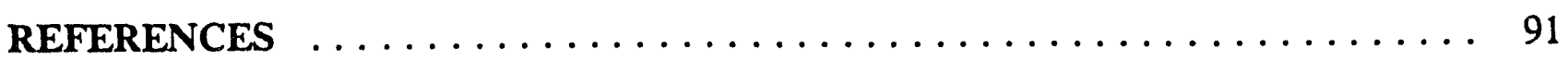




\section{LIST OF TABLES}

TABLE 2.1 Temperature Regions in Coal Pyrolysis

TABLE 2.2 Proposed Organic Sulfur Release Mechanism

at Different Temperature

TABLE 3.1 The Proximate Analysis of Ohio \#8 Coal

TABLE 3.2 The Elemental Analysis of Ohio \#8 Coal (d.a.f.base)

TABLE 4.1 Pyrolysis Product Distribution of OHIO \#8 Coal (8-16 mesh) in The Dual-Screw Feeder Reactor

TABLE 4.2 Kinetic Parameters for Coal Devolatilization 29

TABLE 4.3 Effect of Coal Particle Size on Pyrolysis 30

TABLE 4.4 Sulfur Content in Char 33

TABLE 4.5 $\mathrm{H}_{2} \mathrm{~S}$ Concentration in Pyrolysed Gas

TABLE 4.6 Sulfur Distribution in Pyrolysis Products of Ohio \#8 Coal (8-16 mesh)

TABLE 4.7 Limiting Desulfurization Conversion of Ohio \#8 Coal in Tube Oven

TABLE 4.8 Kinetic Parameter for Ohio \#8 Coal Desulfurization

TABLE 4.9 Effect of Coal Particle Size on Desulfurization

TABLE 4.10 The Sulfur Removal Efficiency of $\mathrm{CaO}$ pellets in Dual-Screw Feeder

TABLE 4.11 Sulfur Balance on Reactor

TABLE 4.12 The Organic Sulfur Content(wt\%) In Char Produced Under Different Pyrolysis Conditions

TABLE 4.13 The Organic Sulfur Removal efficiency(wt\%) 40

TABLE 4.14 Combustion Characteristics of The Pyrolyzed Products 42

TABLE 4.15 Elemental Analysis of Char Product (wt\%, d.a.f) 42

TABLE 5.1 Pyrolysis Gas Composition 56

TABLE 5.2 Thermodynamic Properties of $\mathrm{CO}_{2}$ and $\mathrm{CH}_{4} \quad 57$

TABLE 5.3 Values of $\mathrm{a}, \mathrm{b}$ and $\mathrm{c}$ at Different Temperatures 58 


\begin{abstract}
This report summarizes the three and half years of research on a dual-screw coal feeder reactor for desulfurization of coal. This reactor consists mainly of two concentric screw tubes, the inner tube acting as a coal pyrolyzer and the outer tube acting as a desulfurizer with hot calcined lime pellets or other renewable sorbent pellets. The objective of this project is to study the feasibility of an advanced concept of desulfurization.
\end{abstract}

In this project, the following tasks have been performed: 1) Setting up the Dual-Screw feeder reactor, 2) Determination of the pyrolysis product and the sulfur distribution in char, tar and gas based on experimental data, 3) Study of the devolatilization and the desulfurization kinetics and obtaining the basic kinetic parameters, 4) Study of the sulfur removal eificiency of lime pellets fed into the outer tube of the dual-screw feeder reactor, 5) Study of the effect of the coal particle size on pyrolysis and desulfurization, 6) Study of the coal pyrolysis using a TGA (Thermal Gravimetric Analyzer), 7) Study of the coal desulfurization using a tube oven, 8) Setting up a combustor, 9) Study of the combustion characteristics of the pyrolysis products from the dual-screw feeder reactor, 10) Process simulation of the dual-screw feeder reactor.

The experimental results of devolatilization and desulfurization of an Ohio \#8 coal demonstrate that an increasing the temperature in mild coal pyrolysis leads to the increase of both the devolatilization yield and the desulfurization yield. Under the experimental 
conditions, mainly the organic sulfur releases in the form of $\mathrm{H}_{2} \mathrm{~S}$. Both the devolatilization and the desulfurization processes can be described by using the first-order-reaction model which gives the activation energy values for pyrolysis and desulfurization of $170,021 \mathrm{~kJ} / \mathrm{mol}$ and $78,783 \mathrm{~kJ} / \mathrm{mol}$, indicating the sulfur is easier to release than volatiles. The outer screw region of $\mathrm{CaO}$ pellets also demonstrated almost a complete removal of hydrogen sulfide from volatiles. At a temperature of $475^{\circ} \mathrm{C}$ and a residence time of 6 minutes, $73.1 \%$ of the organic sulfur was removed in the screw feeder reactor. The investigation of the combustion characteristics of the pyrolysis products showed a negligible reduction of the total heating value of the char and volatile products.

The simulation results shows that the mild pyrolysis of Ohio \#8 coal (dry base) is possibly an exothermic process when the sensible heat and the heats of evaporation of moisture are not considered. However, the overall heat requirement is still endothermic. The heat transfer coefficient is about $341.7 \mathrm{~W} / \mathrm{m}-\mathrm{K}$ indicating a good heat transfer performance of the dual-screw feeder reactor. The results of this research suggest that a temperature between 500 and $600^{\circ} \mathrm{C}$ is favored for releasing more organic sulfur from coal during pyrolysis. A larger demonstration-scale equipment is recommended before full-scale commercial applications are attempted. 


\section{INTRODUCTION}

Coal is the most abundant domestic fossil fuel and reserve in the United States ${ }^{[11}$. In 1991, the total coal production in the United States is 998 million tons ${ }^{[2]}$. Most of the U.S. coal is used as a fuel for the production of electricity. In 1991, about 776 million tons of coal which amounts to $87 \%$ of the total annual domestic consumption was burned in coal-fired electric utility boilers ${ }^{[2]}$. Interest in the utilization of high-sulfur coal continues to grow throughout the world as other economical sources of energy are depleted while the demand for energy climbs unabated. However, the utilization of high-sulfur coals causes many problems such as corrosion and large amount of sulfur dioxide $\left(\mathrm{SO}_{2}\right)$ emission. It is known that the presence of sulfur dioxide in the atmosphere is directly related to the formation of acid rain. The air pollution problem caused by sulfur in coal has become more and more critical as the demand for coal is increasing. It has led to Federal Legislation that restricts sulfur dioxide emissions from coal-fired plants. The passage of acid rain legislation has been estimated to threaten the existence of over 12,000 jobs in the State of Ohio alone ${ }^{[3]}$ because of utilities switching to lower sulfur fuels in order to meet $\mathrm{SO}_{2}$ emission regulations. Some preliminary analyses ${ }^{[4]}$ have shown that there are over 1,000 existing boilers in the United States would receive permits to emit specific tonnages of $\mathrm{SO}_{2}$; over 600 of these boilers are candidates to be controlled(or purchase permits to emit the increment). Environmental concerns are putting new pressures on our ability to use coal. It is evident that the new $\mathrm{SO}_{2}$ emission regulation will have a severe economic impact on the national coal industry if new and innovative $\mathrm{SO}_{2}$ control methods are not found and implemented. Utilizing high-sulfur 
coal without damaging the environment presents a great challenge.

To increase the utilization of coal, especially high-sulfur coal, and to meet the regulations, a variety of technologies have been developed to remove or reduce sulfur from coal. These technologies fall into three categories depending upon their point of application: either precombustion, during combustion, or post-combustion. A typical example of the postcombustion coal desulfurization technology is the Flue Gas Desulfurization (FGD) process which is widely used in industry currently. In this process, the stack gas which contains $\mathrm{SO}_{2}$ is fed into a reactor to react with a wet sorbent. Because of its high capital and/or operating cost, this process is economically applicable only for large industrial and power plants. Another technology which is now in use is the Dry Injection process. It involves the reaction of $\mathrm{SO}_{2}$ with a dry solid sorbent during combustion. This process appears to offer economic benefits over conventional wet-sorbent scrubbing processes in terms of a lowering of capital cost requirements $^{[s]}$. However, the higher operating cost due to poor sorbent utilization may make it uneconomical for high sulfur coal application ${ }^{[6]}$. Additionally, low sorbent utilization can significantly increase the waste management problems associated with coal ash, limiting the ability of existing particulate control equipment to function efficiently.

An attractive alternative of removing sulfur from stack gas is the production of a low cost, low sulfur, coal-derived solid fuel before combustion. A novel dual-screw coal feeder reactor was designed and constructed in this project to remove the sulfur containing in the coal before combustion. Two basic concepts are involved in the development of this reactor: (1) 
coal desulfurization by mild pyrolysis, during which the total heating value of coal does not significantly decrease, and (2) the reaction of $\mathrm{H}_{2} \mathrm{~S}$ with calcium based sorbent, which will result in a higher sorbent utilization. This feeder reactor consists mainly of two concentric tubes, the inner tube acting as a coal pyrolyzer and the outer tube acting as a desulfurizer with hot calcined limestone. It combines the coal pyrolysis and the sulfur removal processes in one reactor. During the mild pyrolysis of coal, the sulfur-compounds are converted into gaseous forms, mainly $\mathrm{H}_{2} \mathrm{~S}$. When the volatiles go through the outer tube, $\mathrm{H}_{2} \mathrm{~S}$ reacts with the lime pellets.

Compared with the $\mathrm{SO}_{2}$ concentration in the stack gas (about $0.3 \%$ for a coal containing $3 \%$ of sulfur), the $\mathrm{H}_{2} \mathrm{~S}$ concentration in the pyrolysis gas is much higher (about 1-5\%). It is expected that the sulfur removal rate would be faster in this reactor than in conventional FGD reactors. Kinetically speaking, the higher the reaction rate is, the smaller the reactor volume is needed for a process. Therefore, the total volume of this dual-screw feeder reactor will be smaller than that of the conventional FGD reactors for the same sulfur removal percentage. Furthermore, because this proposed reactor is compact, the thermal energy could be utilized efficiently.

The sorbent utilization, which is important for lowering the operating cost, can be enhanced in this dual-screw feeder reactor. Being different from the conventional FGD reactors in which $\mathrm{SO}_{2}$ reacts with $\mathrm{CaO}$ or $\mathrm{Ca}(\mathrm{OH})_{2}$ producing $\mathrm{CaSO}_{4}$, the proposed reactor will produce $\mathrm{CaS}$ by the reaction of $\mathrm{H}_{2} \mathrm{~S}$ with $\mathrm{CaO}$. Because of the smaller molar volume of $\mathrm{CaO}$ 
compared to that of $\mathrm{CaSO}_{4}$, the formation of CaS could proceed more completely than that of $\mathrm{CaSO}_{4}$. Therefore, the higher utility of sorbent $(\mathrm{CaO})$ in this novel reactor is possible.

Another advantage of this dual-screw feeder reactor is that it can be easily used for retrofit to various processes such as conventional coal combustors and coal gasifiers.

The objective of this project is (1) to provide basic design data by studying the chemical kinetics and the transport phenomena of coal pyrolysis and desulfurization processes in the proposed dual-screw feeder reactor and (2) to simulate the processes to find the optimum operating conditions.

To achieve above objective, the following research works have been performed:

(1) Experimental work investigating the coal pyrolysis, the sulfur reduction and the sulfur removal efficiency in this proposed reactor. Experimental investigation covers a range of variables including temperature, particle residence time and particle size.

(2) Experimental study of the combustion characteristics of the pyrolysis products.

(3) Studies of the rates of both coal pyrolysis and desulfurization processes to obtain the basic data, such as the reaction order, the rate constant and the activation energy. 
(4) Simulation of the overall process in the dual-screw feeder reactor based on the basic data. 


\section{BACKGROUND}

\subsection{Mild Pyrolysis of Coal}

The terminology of pyrolysis is used to refer to the processes in which coal is heated in the absence of oxygen and decomposes to produce gaseous, liquid and solid residuals. Coal pyrolysis is a very complicated process including a large number of chemical reactions occurring in conjunction with structure changes in the coal matrix. In pyrolysis processes, coal undergoes a series of chemical and physical changes and is converted into char, tar and light gases. Generally, the gaseous compounds include $\mathrm{CO}, \mathrm{CO}_{2}, \mathrm{H}_{2}$, hydrocarbon, $\mathrm{H}_{2} \mathrm{O}$, nitrogen compounds and sulfur containing species. The tar product is a mixture of the condensable hydrocarbuns. The observed rate of coal devolatilization is a complex function of the experimental conditions. Different pyrolysis conditions may result in different product distribution. The factors which affect the yield and composition of the volatile fraction are ${ }^{[7]}$ : coal rank, coal composition, particle size, temperature, heating rate, gas composition, pressure, sample size and type of reactor. Among them, temperature is the most important parameter affecting pyrolysis process. The decomposition extent and the product composition are different at different temperature. Table $2.1^{[8]}$ shows typical volatile products in different temperature regions.

There are many published studies of coal pyrolysis in the literature. Anthony and Howard ${ }^{[9]}$ have summarized most of these studies performed before middle 70 s. In the early 1980 s, 
Table 2.1 Temperature Regions in Coal Pyrolysis ${ }^{[8]}$

\begin{tabular}{||c|c|c|}
\hline Temperature $\left.^{\circ} \mathrm{C}\right)$ & Reactions & Products \\
\hline$<350$ & Mainly evaporation & Water and volatile organics \\
\hline $400-750$ & Primary degradation & Gas, tar and liquor \\
\hline $750-900$ & Secondary reactions & $\begin{array}{c}\text { Gas, tar liquor plus } \\
\text { additional hydrogen }\end{array}$ \\
\cline { 1 - 2 } $900-1100$ & & Acetylene carbon black \\
\hline$>16511$ & &
\end{tabular}

Elliott ${ }^{[10]}$ provided an excellent review of thie methods used in the study of coal pyrolysis. In 1985, Berkowitz ${ }^{[11]}$ presented a review examining the chemical processes of coal pyrolysis and their impact on the product properties. Jamaluddin et al ${ }^{[12]}$ conducted a literature survev on the modeling of coal devolatilization in 1987. More recently, Peter and $\mathrm{Jacob}^{[7]}$ reviewed the experimental techniques used to study the chemical and physical changes in coal pyrolysis, examined the influence of experimental conditions on the yield and composition of the volatile fraction, and presented some models describing the overall process of coal pyrolysis. A brief summary based on these reviews is given below.

The experimental spparatus used in the study of coal pyrolysis can be generally grouped into fluidized bed, fixed bed and batch reactors. Most of the experimental results and the correlations available for pyrolysis are applicable to coal particles below approximately $100 \mu \mathrm{m}$ in size, and for sample ranging from micrograms to maximum of a few grams. The result would be unreliable if the particle size and/or the sample size used in experiments are large. 
The complex decomposition phenomena of coal in pyrolysis process are not well understood. In the study of coal pyrolysis kinetics, the single-overall-reaction model is frequently used. This model is based on the following reaction:

$$
\text { Coal } \stackrel{k}{\longrightarrow} \text { Volatiles }+ \text { Residual char }
$$

Many authors approximated this reaction as a first or an $n^{\text {th }}$ order decomposition process occurring uniformly throughout the coal particle. However, these approaches failed to account for the dependency of the volatile yield on the final temperature. Consequently, a multiple-parallel-reaction (MPR) model ( or distributed-activation-energy model), originally proposed by Pitt ${ }^{[13]}$, was later adopted by other researchers ${ }^{[14,15,16,17]}$ to explain the experimental results or to develop more sophisticated models. This MPR model assumes that coal pyrolysis process includes a large number of independent parallel reactions, each of them having a certain activation energy:

$$
\text { Coal } \underset{k_{i}}{\longrightarrow} \sum_{i}\left(V_{i}+R_{i}\right)
$$

In this model, the activation energy distribution is assumed to follow some kind of function (for example, the Gaussian distribution function), and a common frequency factor is generally used. It permits correlation of coal decomposition data by using four parameters. One of the advantages of this approach is that the major shortcomings of the simple-overallreaction model are overcome without introducing a much larger set of adjustable parameters. 
Relatively fewer modeling works on the large coal particle pyrolysis have been reported. It is understood that a large temperature gradient could exist within a large coal particle if the external heat transfer coefficient is large. The shrinking core model was used by Phuoc and Mathur $^{[18]}$ in 1991 to describe the pyrolysis process and the temperature profile within the coal particle was obtained. Borghi et al. ${ }^{[19]}$ developed a model considering the chemical reactions and the external heat transfer as the rate controlling steps for coal pyrolysis. Bliek et al. ${ }^{[20]}$ proposed a Dusty-Gas model which considered the effects of intra-particle heat and mass transfer during the pyrolysis of non-caking coals. Their results indicate a kinetically controlled regime for small particles and a heat transfer controlled regime for large particles. It should be mentioned that most of the model developments were based on the experimental results of fluidized bed at higher temperature (generally $>1000 \mathrm{~K}$ ) with higher external heat transfer coefficients (the Biot number is about $1-20)^{[21]}$.

Recently, some molecular-level coal devolatilization models were developed ${ }^{[17,24,25]}$ to predict the volatile yield. In these models, the coal structure is approximated by a linear molecular chain or some network structure. In coal pyrolysis process, some of the chemical bonds are broken and the molecular structure of coal changes. These models describe how the bonds are broken and how the coal structure changes.

Mild pyrolysis of coal has been attracting increasing interest because it is more easily performed under relatively less severe conditions at lower temperature $\left(<550^{\circ} \mathrm{C}\right)$ and lower pressure (about 1 atm.) and with lower heating rate. Mild pyrolysis is more desirable for 
production of desulfurized solid fuel since it does not devolatilize much of the volatile coal component and therefore, causes much less destruction to the coal matrix structure. It is known that the physical properties of coal change relatively little until pyrolysis temperatures reach $550-600^{\circ} \mathrm{C}^{[11]}$. The total heating value of coal does not significantly decrease in the mild pyrolysis process while some sulfur containing bonds are broken. When pyrolysis temperature is higher than $600^{\circ} \mathrm{C}$, the pore structure of coal collapses since much of the volatile releases from the coal matrix. This change in coal matrix structure prevents further release of sulfur.

\subsection{Coal Desulfurization by Pyrolysis}

It is well known that there are two basic forms of sulfur in coal: inorganic sulfur (principally in the form of pyritic sulfur) and organic sulfur (a term used to define the sulfur chemically bonded to the coal molecules or matrix). The distribution of various sulfur forms in coal and the mechanism of their decomposition during pyrolysis have been studied for several decades. Some of the early research work was summarized by Eliot ${ }^{[24]}$ in his compilation. The decomposition rate of sulfur compounds during coal pyrolysis is affected by the nature of sulfur compound, the chemical and physical properties of coal and the pyrolysis conditions. It is generally recognized that the temperature plays an important role in coal desulfurization during pyrolysis. However, only a little experimental study has been reported in the literature regarding to this subject. 
It is known that under mild pyrolysis condition, the pyritic sulfur in coal is released mainly in the form of $\mathrm{H}_{2} \mathrm{~S}^{[25,26,27]}$ :

$$
\mathrm{FeS}_{2}+\mathrm{H}_{2}-\cdots>\mathrm{FeS}+\mathrm{H}_{2} \mathrm{~S}
$$

The moisture in coal reacts with ferrous sulfide:

$$
\begin{aligned}
& \mathrm{FeS}+\mathrm{H}_{2} \mathrm{O} \ldots>\mathrm{FeO}+\mathrm{H}_{2} \mathrm{~S} \\
& \mathrm{FeS}+4 \mathrm{H}_{2} \mathrm{O} \ldots>\mathrm{FeSO}_{4}+4 \mathrm{H}_{2} \\
& \mathrm{FeSO}_{4} \ldots>\mathrm{FeO}+\mathrm{SO}_{3}
\end{aligned}
$$

The release mechanism of organic sulfur from coal in pyrolysis process is not well investigated. However, it is generally known that the organic sulfur is released as $\mathrm{H}_{2} \mathrm{~S}$ and COS below $600^{\circ} \mathrm{C}$. Since the C-S bond is significantly weaker than the C-C bond (the typical values are 66 and $83 \mathrm{kcal} / \mathrm{mol}$, respectively $\left.{ }^{[28]}\right)$, the C-S bond might be more easily broken. Garcia and Moinelo ${ }^{[29]}$ reported that nearly all the organic sulfur in Cayirhan lignite was removed by pyrolysis at $500^{\circ} \mathrm{C}$. Alvin et al. ${ }^{[30]}$ studied the desulfurization on Wyoming subbituminous and Illinois \#6 coal and proposed an organic sulfur release-temperature profile as shown in table 2.2 .

Table 2.2 Proposed Organic Sulfur Release Mechanism at Different Temperature ${ }^{[30]}$

\begin{tabular}{lll}
\hline Temperature $^{\circ}$ C) & Decomposition \\
\hline $160-180$ & Aliphatic Thiols & R-C-S-H \\
$200-220$ & Disulfides & R-S-S-R \\
$220-250$ & Aromatic Thiols & - S-H \\
$240-280$ & Aliphatic Sulfides & R-S-R \\
$290-330$ & Alicyclic Sulfides & \\
$450-470$ & Aryl Sulfides & \\
$500-550$ & Thiophenic sulfur \\
$>500$ & Other sulfur form
\end{tabular}


Above $600^{\circ} \mathrm{C}$, the pore structure of coal collapses preventing further release of sulfur from coal. To sum up, both inorganic and organic sulfurs can be released from coal in the form of $\mathrm{H}_{2} \mathrm{~S}$ by mild pyrolysis. The formation of $\mathrm{H}_{2} \mathrm{~S}$ during coal pyrolysis is the key point to the enhancement of sorbent utilization in this proposed reactor.

The extent of the sulfur reduction depends upon the coal properties and the pyrolysis conditions. It has been dernonstrated that the pyrolysis of Illinois No.6 coal reduces up to $87 \%$ of total sulfur between 500 and $600^{\circ} \mathrm{C}^{[30]}$. Ibarra et $\mathrm{al}^{[31]}$ reported that, according to their studies on mild pyrolysis of a Spanish subbituminous coal, the reduction of total sulfur content was maximum at $550^{\circ} \mathrm{C}$ (Figure 1). These above researches show that the mild pyrolysis condition is desirable for coal desulfurization.

The pyritic sulfur in coal can also be transferred into other forms of sulfur during mild pyrolysis. Peter et $a^{[32]}$ studied the decomposition of pyrite in Prince coal and showed that the transformation from pyrite to pyrrhotite occurs mainly in the temperature range 500$550^{\circ} \mathrm{C}$. Taghiei et al. ${ }^{[33]}$ reported, after their studies on several coals, that pyrite began to convert to pyrrhotite at a temperature above $400^{\circ} \mathrm{C}$ during coal pyrolysis. Also, some researchers ${ }^{[31,32,34]}$ showed that in coal pyrolysis process, a certain amount of inorganic sulfur transferred to organic sulfur. This transformation might be due to the interaction of sulfur forms produced during coal pyrolysis with the organic matrix of coal, such as formation of new carbon-sulfur bonds by reaction of $\mathrm{H}_{2} \mathrm{~S}$ with olefine and alcohols, or sulfur trapping in the porous structure of char. 


\subsection{Sorbent Utilization}

Currently, lime is one of the most commonly used sorbents for the removal of sulfur from coal conversion processes. Consider two different reactions below:

$$
\begin{aligned}
& \mathrm{CaO}+\mathrm{H}_{2} \mathrm{~S} \ldots>\mathrm{CaS}+\mathrm{H}_{2} \mathrm{O} \\
& \mathrm{CaO}+\mathrm{SO}_{2}+1 / 2 \mathrm{O}_{2} \ldots->\mathrm{CaSO}_{4}
\end{aligned}
$$

Reaction (2) is involved in the dry injection FGD process. It is well understood that during the calcination of $\mathrm{CaCO}_{3}$, the decomposition to $\mathrm{CaO}$ will not generally result in a change in the overall particle dimensions. Theoretically, the conventional FGD in an oxidizing environment would limit the utilization of lime to $62 \%$ considering the molar volume changes before and after the reaction ${ }^{[27,35]}$ (The molar volumes of $\mathrm{CaSO}_{4}, \mathrm{CaCO}_{3}, \mathrm{CaO}, \mathrm{CaS}$ are $52.2,36.9,16.9$ and $28.86 \mathrm{~cm}^{3} /$ mole, respectively). Actual utilization of lime in FGD processes is of course far lower than this limit because other factors (such as internal surface area and porosity) may affect the reaction rate ${ }^{[36]}$. However, the molar volume of $\mathrm{CaS}$ is such that complete conversion of $\mathrm{CaO}$ to $\mathrm{CaS}$ by reaction (1) will reduce the particle porosity from 0.55 to 0.25 , and thus the fully expanded grains will not fill the intergrain void space within the particle ${ }^{[32]}$. It indicates that reaction (1) has an ability to achieve a $100 \%$ conversion since the reaction product, $\mathrm{CaS}$, does not impose restrictions on the maximum conversion attainable.

The reaction of $\mathrm{CaO}$ with $\mathrm{H}_{2} \mathrm{~S}$ has been studied by many investigators ${ }^{[27,37,38,39,40]}$. The reported values of the activation energy range from 3.6 to $37 \mathrm{kcal} / \mathrm{mol}$. These studies 
indicate a rapid rate of reaction (1) when it is carried out at moderate temperatures of about $600^{\circ} \mathrm{C}$ which is the upper range of temperatures of interest in this work. The rate of this reaction is a strong function of specific surface area. It has been shown that $t^{[37]}$ at $700^{\circ} \mathrm{C}$ with $5,000 \mathrm{ppm} \mathrm{H}_{2} \mathrm{~S}$ and $\mathrm{CaO}$ having a $\mathrm{BET}$ surface area of $40 \mathrm{~m}^{2} / \mathrm{g}$, about $90 \%$ conversion can be reached in 70 seconds. Since this reaction is known to follow the first-order kinetics with respect to the $\mathrm{H}_{2} \mathrm{~S}$ concentration, the reaction rate will be faster with increased concentration of $\mathrm{H}_{2} \mathrm{~S}$.

A number of models have been used to describe this type of gas-solid reaction. In 1980, Simons and Rawlins ${ }^{[41]}$, to study the kinetics of both reactions (1) and (2), used a "transport theory" to fit the high temperature experimental data. In their model, the pores of the $\mathrm{CaO}$ particle were assumed to be cylindrical tubes. Each pore that reaches the exterior surface of the calcine sample is depicted as the trunk of a tree. The radius of the trunk follows a distribution function. The $\mathrm{H}_{2} \mathrm{~S}$ or $\mathrm{SO}_{2}$ gas diffuses into the pore tree trunk of the particle and the heterogeneous reaction takes place at the walls of the trunk. Their result indicates both the rate constants and the activation energies for $\mathrm{H}_{2} \mathrm{~S}$ and $\mathrm{SO}_{2}$ reactions with $\mathrm{CaO}$ are roughly the same. However, this model is valid only at an early stage of the reaction because the sulfur deposition process is not considered. The sulfur deposit prevents the reactant gas from reaching the $\mathrm{CaO}$ sites, thereby reducing the reactivity. For both reactions (1) and (2), the particle porosity is a function of the reaction extent. Since the CaS particle has a porosity larger than that of $\mathrm{CaSO}_{4}$ particle, the reactant gas is easier to diffuse into $\mathrm{CaS}$ particle than into $\mathrm{CaSO}_{4}$ particle. As a result, the overall reaction rate of (1) would be faster 
than that of (2). In 1992, Efthimiadis and Sotirchos ${ }^{[42]}$ studied the reaction (1) in a thermogravimetric analysis system and other types of reactors, using fully calcined limestones or reagent grade $\mathrm{CaO}$ as the solid reactant. Their result showed the overall rate of sulfidation was influenced strongly by the particle size but rather weakly by the temperature. The generalized random pore model was used to fit their data. The comparison of the model with the experimental data showed that most differences in the behavior of limestone-derived sorbents during sulfidation originated from differences in the connectivity of their pores. 


\section{EXPERIMENTAL SYSTEM}

\subsection{Design and Construction of the Dual-Screw Feeder Reactor}

The screw feeder reactor, as shown in Figure 2, consists mainly of two concentric augers which are driven by two motors separately. The inner screw is used to drive coal particles through the inner tube where pyrolysis takes place, and the outer screw is used to drive the calcined limestone pellets or other renewable sorbent pellets through the outer tube where the sorbent pellets react with the $\mathrm{H}_{2} \mathrm{~S}$ component produced from the pyrolysis process. By adjusting the speed of the motor, the particle residence time can be easily controlled. The inside diameter (ID) of the inner tube is 1 inch and the outer tube 2 inches. Two quenching tanks are used to collect the char product and the reacted sorbent pellets. This reaction system is well sealed to prevent air from entering it. In considering the high corrosiveness of $\mathrm{H}_{2} \mathrm{~S}$ and other evolved gases, all parts of this reactor are made of stainless steel.

Three groups of band-type electrical heaters were installed on the surface of outer tube to provide a uniform temperature distribution along the feeder tube. These heaters are controlled by three temperature controllers separately. Several thermocouples are employed to sense the surface temperature. The length of the insulated heated zone is 20.5 inches.

In the original design, the inner screw was driven by a motor at one end only. When coal particles are heated to a certain temperature(for Ohio $\$ 8$ coal, it is about $450^{\circ} \mathrm{C}$ ), they swell 
and become plastic and sticky. The sticky coal particles tend to stick on the surface of both inner screw and inner tube. As more coal particles deposit on the screw and tube surface, it becomes more difficult for the coal particles to go through the feeder, and a large stress torque is produced. Due to increased friction between the inner screw and tube wall for a long operating time at an elevated temperature above $500^{\circ} \mathrm{C}$, the inner screw shaft was broken at the end of one experimental run. Aiter careful consideration, it was decided to change the drive mechanism of the inner screw. After reconstruction, the inner screw shaft is driven at the both ends to evenly distribute the load and thus to reduce the rotational torque. The experimental results showed that the reconstruction of the reactor was successful. The reaction temperature now can be raised to $500^{\circ} \mathrm{C}$. This improvement is important for deeper desulfurization in the coal pyrolysis process for an extended period of operation.

\subsection{Experimental Procedures}

The experimental flow diagram is show in Figure 3. In the experiment, the lime particles are fed into the outer tube until the outer tube is full of lime. At the beginning, nitrogen is entrained into the reactor to obtain the inert environment. Then, the system is preheated for 2-3 hours to reach an isothermal condition. After that, the coal particles are driven by the inner screw through the inner tube where they are heated and pyrolysis process, as well as desulfurization process, takes place. Undergoing both pyrolysis and desulfurization, the coal is converted into char and gaseous products. The char product drops into one of the 
quenching tanks, and the hot gaseous product enters the outer tube where the $\mathrm{H}_{2} \mathrm{~S}$ component reacts with $\mathrm{CaO}$ pellets. The cleaned volatiles then flow through three condensers. The condensable substances ("tar", it is actually a mixture of tar and water) are condensed there and the cooled gas enters a gas sampling bag which is used to collect the gaseous product. A sealed box which has negative pressure inside itself is used to contain this gas sampling bag. The pressure drop between the reactor system and the gas sampling bag allows the volatile product to flow through the line. The reacted lime particles are collected in another quenching tank.

At the end of each experiment, the weight and the volume of the collected noncondensable gas in the sampling bag are measured. The volume of the gas is measured by emerging the sampling bag into a water tank and noting the displaced volume of water. The amounts of char and tar are determined gravimetrically.

The relationship between particle residence time and screw rotation speed was determined by measuring the travel speed of metal balls through the tubes.

A Perkin Elmer Gas Chromatography (GC) is used to analyze the $\mathrm{H}_{2} \mathrm{~S}$ concentration in gaseous product. Two GC columns were installed in this unit. One is for $\mathrm{H}_{2} \mathrm{~S}$, and the other for hydrocarbon, carbon oxides, hydrogen and nitrogen. The operating temperature of GC was experimentally selected (oven $70^{\circ} \mathrm{C}$, injector $75^{\circ} \mathrm{C}$ and thermal detector $75^{\circ} \mathrm{C}$ ). Helium is used as the carrier gas. The flow rates of the carrier gas was set at $230 \mathrm{cc} / \mathrm{min}$ for A 
column and $250 \mathrm{cc} / \mathrm{min}$ for B column. The standard curve was obtained prior to experiments (Figure 3). During the experiments, the gaseous samples before and after reacting with lime in the outer tube are analyzed. The total sulfur content in char, coal and lime samples is analyzed by using a LECO sulfur analyzer. The ASTM standard method is used to analyze the organic sulfur content in coal samples.

The Ohio \#8 coal supplied by R \& F coal Co., Columbus, Ohio and the Quick lime supplied by Dravo Lime Co., Black River Branch, Ohio, are used in the experiments. The proximate analysis and elemental analysis of the Ohio \#8 coal are listed in Table 3.1 and table 3.2 .

Table 3.1 The Proximate Analysis of Ohio \#8 Coal

\begin{tabular}{|c|c|c|}
\hline Item & As Received(wt\%) & d.a.f.(wt\%) \\
\hline Fixed Carbon & 51.55 & 57.86 \\
\hline Volatile & 37.55 & 42.14 \\
\hline Moisture & 1.99 & --- \\
\hline Ash & 8.91 & -- \\
\hline Sulfur & 3.15 & 3.54 \\
\hline $\begin{array}{c}\text { Heating } \\
\text { Value(Btu/lb) }\end{array}$ & 12007 & 13476 \\
\hline
\end{tabular}

Table 3.2 The Elemental Analysis of Ohio \#8 Coal (d.a.f.base)

\begin{tabular}{|c|c|c|c|c|c|}
\hline Element & $\mathrm{C}$ & $\mathrm{H}$ & $\mathrm{N}$ & $\mathrm{S}$ & $\mathrm{O}^{\circ}$ \\
\hline wt \% (d.a.f.) & 80.15 & 5.71 & 2.10 & 3.54 & 8.5 \\
\hline
\end{tabular}

* obtained by difference 
In the experiment, the effect of coal particle size, residence time and temperature on the pyrolysis and desulfurization is investigated. The experimental conditions are:

Coal particle size(mesh): 4-8, 8-16, 16-35

Coal residence time(min.): $2,3,4,5,6$

Feeder temperature $\left({ }^{\circ} \mathrm{C}\right): 400,425,450,475$

Lime residence time(min.): 70-100

Lime particle size(mesh): 4-8, 8-16

To determine the relationship between the temperature and the maximum pyrolysis conversion, a thermal-gravimetric-analyzer (Thermal A. nalyst 2000, DuPont Instruments) is used. Nitrogen is used as the purge gas. The flow rate of nitrogen is 0.8 SCFH. The TGA run is extended for a long time until the rate of weight loss becomes undetectable.

A tube oven (Lindberg) is utilized to study the dependence of the maximum coal desulfurization on the temperature. In this experiment, the oven temperature is preselected. A ceramic boat with about 5 grams of coal sample $(30-60$ mesh) is put into the tube. Nitrogen is selected as the purge gas. The experiments show that, after one hour, the desulfurization reaches the maximum at a given temperature between $200-500^{\circ} \mathrm{C}$.

An Elemental Analyzer (LECO CHNS-932) is used to measure the carbon, hydrogen and nitrogen contents of the solid samples. 
The combustion characteristics of the pyrolysis products is studied in the seconc phase of the experiment. A Rijke type pulsating combustor was constructed for this purpose. The basic structure of the combustor is shown in Figure 4. It is 10 feet in height and the stack has an inside diameter of 5.5 inches. A rotating disk which is driven by a motor is installed to achieve a uniform temperature distribution along the cross section of the stack. Both the stack and the rotating disk are made of stainless steel. During the combustion operation, the entire stack pipe is sonically tuned and generates a harmonic sonic wave which promotes a fluidization-like effect on coal particles (the particles are suspended). The stack is well insulated by 2 high temperature insulation material to maintain the combustion temperature. To obtain the different fuel/air ratio, a flow meter is used to control the air flow rate. Five thermocouples were installed inside along the center of the stack to measure the combustion temperatur:. Originally, the combustor stack was made of cast iron. Due to the high corrosiveness of $\mathrm{SO}_{2}$ which results from coal combustion process, the cast iron stack was deeply rusted. Several holes appeared on the stack wall after an experimental period of about three months. To overcome this problem, a new stack was reconstructed using stainless steel.

In the experiment, the char and the volatiles which are produced from the pyrolysis process occurring in the feeder reactor are continuously fed into the combustor. The char is driven into the combustor by a separate screw tube which connects the combustor and the quenching tank of the feeder system. This screw has a higher rotation speed than the inner screw of the coal feeder to prevent an accumulatir of char in the quenching tank. During 
the combustion process, a small amount of emission gas is introduced into the condensers. The noncondensable gas then flows through a filter and goes into a $\mathrm{SO}_{2}$ analyzer. $\mathrm{A}$ computer was connected to the system to collect the data continuously. In this part of experiment, the combustion temperature and the $\mathrm{SO}_{2}$ concentration from the stack are considered as the important parameters. 


\section{RESULTS AND DISCUSSION}

\subsection{Coal Pyrolysis Kinetics}

A knowledge of the rates of coal decomposition in the pyrolysis process is essential in predicting the yield and product distribution. This part of study aims at providing basic data for the simulation work. As mentioned before, the coal pyrolysis is a very complicated process since a lot of chemical reactions and transport phenomena are involved. Different experimental conditions will result in totally different results. It is known, for example, the product distribution from a high heating rate process (for example, flash pyrolysis) is different from that of a low heating rate process although the final temperatures are the same, both of them resulting in different rate equations. The reason for this might be that the final char matrix structures in these two processes are different because of the "secondary reactions" taking place in the flash pyrolysis process. When coal is pyrolyzed under mild conditions, no evidence shows such differences among differing operating conditions as long as the conditions are "mild".

The measured data of pyrolysis product distribution resulted from the dual-screw feeder reactor are summarized in Table 4.1. As expected, it is observed that the volatilization yield increases as the reaction temperature rises and the particle residence time increases. These volatilization yield data are plotted in Figure 6. 
TABLE 4.1 Pyrolysis Product Distribution of OHIO \#8 Coal (8-16 mesh) in The Dual-Screw Feeder Reactor

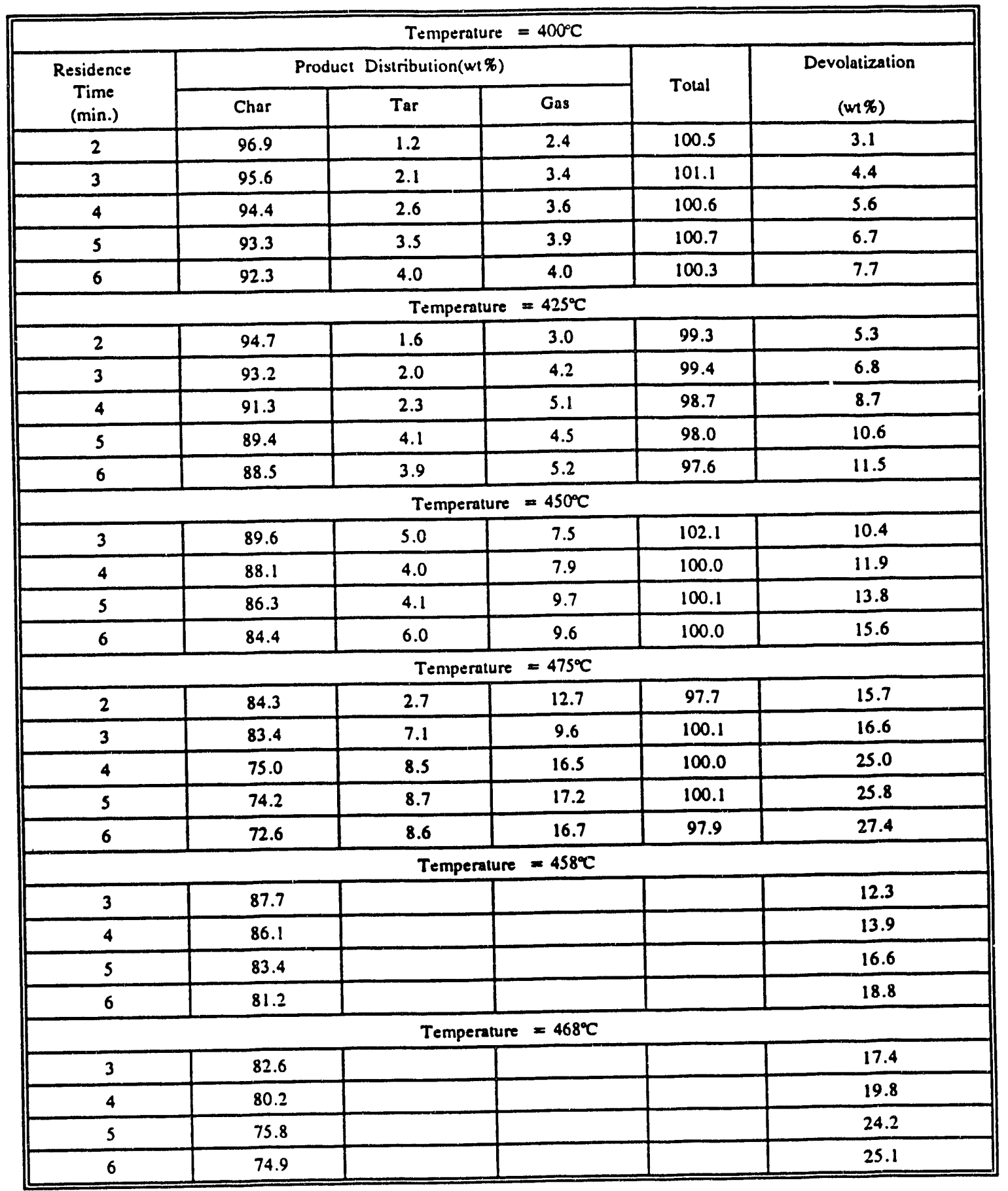


In the study of the coal devolatilization kinetics, the simple-overall-reaction model is employed to correlate the experimental data since this model is simple and effective in fitting the low temperature pyrolysis data. In this model, the dependence of the volatile yield on final temperature is considered. It is known that the atoms in final volatile mater molecules are originally bonded to the coal matrix with different bond energies. To break any one of these bonds, a certain amount of energy is required. At a given temperature, the thermal energy of an atom is at a corresponding level. Only those bonds whose bond energies are less than the thermal energy corresponding to the given temperature can be broken. Therefore, at a given temperature, the final volatile yield can be determined by extending the reaction time long enough. In this study, a thermal gravimetric analyzer (TGA) is used to determine the maximum volatilization yield at different temperatures. The experimental result is shown in Figure 7 . It can be seen that, when temperature is below $300^{\circ} \mathrm{C}$, the final volatilization yield is very small $(<5 \%)$. Between $300-500^{\circ} \mathrm{C}$, the volatilization yield increases sharply reaching its maximum at about $600^{\circ} \mathrm{C}$.

The apparent rate constant and the activation energy for coal decomposition reaction in the coal feeder reaction are estimated by assuming the first-order reaction mechanism:

$$
-\frac{d(W-W\rfloor}{d t}=k(W-W)
$$

where

$$
\begin{aligned}
& \mathrm{W}=\text { the weight of coal at residence time } \mathrm{t} \\
& \mathrm{W}_{\infty}=\text { the weight of coal when } \mathrm{t} \text { is infinite } \\
& \mathrm{k}=\text { rate constant }
\end{aligned}
$$


With the assumption that the particle temperature is the same as the feeder temperature, iniegrating Equation (4-1) gives

$$
\frac{x_{\infty}-x}{x_{\infty}}=\exp (-k t)
$$

where $\quad x=\left(W_{0}-W\right) / W_{0}$, the conversion

$$
\begin{aligned}
& \mathrm{W}_{0}=\text { the weight of coal when } \mathrm{t} \text { is } 0 \\
& \mathrm{x}_{\infty}=\left(\mathrm{W}_{0}-\mathrm{W}_{\infty}\right) / \mathrm{W}_{0}
\end{aligned}
$$

From Equation (4-2), a linear equation can be obtained:

$$
\ln \left(\frac{x_{-}}{x_{-}-x}\right)=k t
$$

There are two parameters in Equation (4-3) ( $k$ and $x_{\infty}$ ). The limiting conversion, $x_{\infty}$, represents the active (or effective) volatile weight fraction in the original coal which depends on temperature and is different from the volatile matter(VM) determined by proximate analysis. The $x_{\infty}$ could be experimentally determined by using infinite residence time at a given temperature. In practice, however, $x_{\infty}$ cannot be obtained from dual-screw feeder experiment because the motor rotation speed cannot be adjusted to a level that is slow enough to get a very long particle residence time, and because the outer tube surface temperature is different from the particle's temperature inside the inner tube (in the current experiment, it is impractical to measure the actual temperature of the coal particles). These are the reasons why the TGA is used to obtain the temperature dependence of $x_{\infty}$. The rate constant, $k$, in Equation (4-3) can be obtained by linear regression: 


$$
k=\frac{\sum, t_{i} \ln \left(\frac{x_{-}}{x_{m}-x_{i}}\right)}{\sum t_{i}^{2}}
$$

where, $\quad t_{i}=$ particle residence time,

$$
\mathrm{x}_{\mathrm{i}}=\text { conversion at } \mathrm{t}_{\mathrm{i}} \text {. }
$$

A comparison of the experimental data with Equation (4-3) illustrated in Figure 8 indicates a reasonable agreement between the first-order reaction assumption and the experimental result. The kinetic parameters of the coal pyrolysis process at different operating temperature are shown in Table 4.2.

Table 4.2 Kinetic Parameters for Coal Devolatilization

\begin{tabular}{||c|c|c|c|c|c|c|}
\hline $\mathrm{T}\left({ }^{\circ} \mathrm{C}\right)$ & 400 & 425 & 450 & 458 & 468 & 475 \\
\hline $\mathrm{x}_{\infty}$ & 0.1789 & 0.2445 & 0.2998 & 0.3105 & 0.3220 & 0.3289 \\
\hline $\mathrm{k}(1 / \mathrm{min})$. & 0.094 & 0.110 & 0.126 & 0.155 & 0.258 & 0.306 \\
\hline
\end{tabular}

The effect of temperature on the reaction rate can generally be defined by an Arrehnius type of relationship. Figure 9 demonstrates the Arrhenius plot of the experimental data. It is interesting to see that there are two temperature regions with different activation energies. When temperature is below $450^{\circ} \mathrm{C}$, the activation energy is $23,711 \mathrm{~J} / \mathrm{mol}$ which is much smaller than $170,021 \mathrm{~J} / \mathrm{mol}$, the activation energy at a temperature higher than $450^{\circ} \mathrm{C}$. Generally speaking, the activation energy of chemical reaction is much higher than that of heat transfer. When temperature is low, the volatilization yield is small, and the main process is limited by the heat transfer to raise the coal particle temperature. However, as 
the temperature rises, more volatile produces. As a result, the chemical decomposition process becomes the rate control step. The experimental results indicate that as the temperature rises, the controlling step could change from heat transfer to chemical decomposition.

The result of pyrolysis product distribution with different coal particle sizes is listed in Table 4.3. It is clearly seen that between 4 and 35 mesh, the coal particle size has no effect on the pyrolysis kinetics. From the TGA experiment result shown in Figure 7, it is known that most of the volatile releases at the temperature range higher than about $450^{\circ} \mathrm{C}$ which is also the coal swelling point. This means that the coal pyrolysis reaction is very slow before the coal particle swells. This observation explains the result that the coal particle size has no effect on pyrolysis. At a temperature below $450^{\circ} \mathrm{C}$, because the reaction is very slow, little difference in product distribution can be seen when different coal particle sizes are used.

TABLE 4.3 Effect of Coal Particle Size on Pyrolysis

\begin{tabular}{||c|c|c|c|c|c|c|c|c|c|c||}
\hline \multicolumn{2}{|c|}{ Particle Size } & \multicolumn{3}{|c|}{$4-8$ mesh } & \multicolumn{3}{c|}{$8-16$ mesh } & \multicolumn{3}{c||}{$16-35$ mesh } \\
\hline \multirow{2}{*}{$\mathrm{T}\left({ }^{\circ} \mathrm{C}\right)$} & \multirow{2}{*}{ Rt } & \multicolumn{8}{|c|}{ Product Distribution (wt\%) } \\
\cline { 2 - 14 } & (min) & Char & Tar & Gas & Char & Tar & Gas & Char & Tar & Gas \\
\hline 400 & 3 & 95.1 & 2.3 & 3.5 & 95.6 & 2.1 & 3.4 & 95.4 & 2.0 & 3.4 \\
\hline 400 & 6 & 92.5 & 4.1 & 4.0 & 92.3 & 4.0 & 4.0 & 92.0 & 4.3 & 4.3 \\
\hline 475 & 3 & 83.0 & 7.5 & 9.3 & 83.4 & 7.1 & 9.6 & 83.0 & 7.0 & 9.5 \\
\hline 475 & 6 & 73.0 & 9.0 & 17.0 & 72.6 & 8.6 & 16.7 & 72.9 & 8.5 & 17.0 \\
\hline
\end{tabular}


On the other hand, when reaction takes place at a temperature above $450^{\circ} \mathrm{C}$, where coal particles swells and stick together, the characteristics of individual particles disappeare.

\subsection{Coal Desulfurization by Pyrolysis}

During coal pyrolysis, the sulfur releases from coal mainly as $\mathrm{H}_{2} \mathrm{~S}$. The data in Tables 4.4 and 4.5 show the sulfur concentration in char and gas products after coal pyrolysis. Define desulfurization yield by:

$$
D S Y=\frac{W_{s o}-W_{s}}{W_{s o}}
$$

where $\quad \mathrm{W}_{\text {so }}$ is the sulfur content in coal,

$\mathrm{W}$, is the sulfur content in char product.

Table 4.6gives the desulfurization yields at different reaction conditions. These data are also plotted in Figure 10. It can be seen that when reaction temperature and coal particle residence time increase, the desulfurization yield rises quickly. At $475^{\circ} \mathrm{C}, 33.2 \%$ of total sulfur is removed in a residence time of 6 minutes.

By assuming the first order reaction of desulfurization as developed in the study of pyrolysis, we have: 


$$
\operatorname{Ln}\left(\frac{x_{s \infty}}{x_{s \infty}-x_{s}}\right)=k_{s} t
$$

where $\quad x_{s}=\left(W_{s o}-W_{s}\right) / W_{s o}$, conversion at time $t$

$x_{s \infty}=\left(W_{s o}-W_{s o 0}\right) / W_{s o}$, limiting conversion

$\mathrm{W}_{\mathbf{s}}=$ The weight of sulfur in char product

$W_{s o}=$ The weight of sulfur in coal when at $t$ is 0

$\mathrm{W}_{\mathrm{s} \infty}=$ The weight of sulfur in char when $\mathrm{t}$ is infinite

The limiting desulfurization conversion $x_{300}$ is a function of operating temperature. In the complex structure of coal, sulfur atoms exist in different bonds with other atoms. To break these bonds which have different bond energies, different levels of energy is necessary. $\mathbf{x}_{\mathbf{3}}$ could be regarded as the fraction of total sulfur atoms whose bonds could be broken at a given temperature. In this research, a tube oven is used to obtain the dependence of limiting desulfurization on the pyrolysis temperature. The results are shown in Table 4.7 and plotted in Figure 11. It is seen, from Figure 11 , when temperature is below $250^{\circ} \mathrm{C}$, little sulfur releases from the coal during pyrolysis. This observation is in agreement with the TGA result (Figure 7).

Figure 12 shows a reasonable fit between the experimental data and the first order reaction model. The Arrhenius plot for desulfurization data (Figure13) gives the activation energy of $78,783 \mathrm{~J} / \mathrm{mol}$ for the desulfurization reaction. This value is much smaller than the devolatilization activation energy indicating that the desulfurization rate is higher than devolatilization rate under mild pyrolysis conditions. 
TABLE 4.4 Sulfur Content in Char

\begin{tabular}{|c|c|c|c|c||}
\hline \multirow{2}{*}{$\begin{array}{c}\text { Residence } \\
\text { Time } \\
\text { (min.) }\end{array}$} & \multicolumn{4}{|c|}{ Sulfur Content in Char (wt.\%) } \\
\cline { 2 - 5 } & $400^{\circ} \mathrm{C}$ & $425^{\circ} \mathrm{C}$ & $450^{\circ} \mathrm{C}$ & $475^{\circ} \mathrm{C}$ \\
\hline 2 & 3.11 & 3.22 & & 3.01 \\
\hline 3 & 3.03 & 3.06 & 3.14 & 2.98 \\
\hline 4 & 3.06 & 3.04 & 3.03 & 3.07 \\
\hline 5 & 3.05 & 3.08 & 2.82 & 2.89 \\
\hline 6 & 3.02 & 3.01 & 2.86 & 2.90 \\
\hline
\end{tabular}

TABLE 4.5 $\mathrm{H}_{2} \mathrm{~S}$ Concentration in Pyrolysed Gas

\begin{tabular}{||c|c|c|c|c||}
\hline \multirow{2}{*}{$\begin{array}{c}\text { Residence } \\
\text { Time } \\
\text { (min.) }\end{array}$} & \multicolumn{4}{|c|}{$\mathrm{H}_{2} \mathrm{~S}$ in gas (volume \%) } \\
\cline { 2 - 5 } & $400^{\circ} \mathrm{C}$ & $425^{\circ} \mathrm{C}$ & $450^{\circ} \mathrm{C}$ & $475^{\circ} \mathrm{C}$ \\
\hline 2 & 1.13 & 2.91 & & 4.08 \\
\hline 3 & 1.08 & 3.03 & 3.91 & 4.06 \\
\hline 4 & 1.16 & 2.97 & 3.90 & 4.06 \\
\hline 5 & 1.10 & 3.07 & 3.76 & 4.00 \\
\hline 6 & 1.17 & 3.04 & 3.81 & 4.04 \\
\hline Average & 1.13 & 3.00 & 3.85 & 4.05 \\
\hline
\end{tabular}


TABLE 4.6 Sulfur Distribution in Pyrolysis Products of OHIO \#8 Coal (8-16 mesh)

\begin{tabular}{|c|c|c|c|c|}
\hline \multicolumn{5}{|c|}{ Temperature $=400^{\circ} \mathrm{C}$} \\
\hline \multirow{2}{*}{$\begin{array}{c}\text { Residence } \\
\text { Time } \\
\text { (min.) } \\
\end{array}$} & \multicolumn{3}{|c|}{ Sulfur Distribution(wt\%) } & \multirow{2}{*}{$\begin{array}{c}\text { Desulfurization } \\
(w t \%) \\
\end{array}$} \\
\hline & In Char & In $\mathrm{Tar}^{\circ}$ & In Gas & \\
\hline 2 & 95.3 & 3.83 & 0.87 & 4.7 \\
\hline 3 & 91.9 & 6.90 & 1.20 & 8.1 \\
\hline 4 & 91.8 & 7.27 & 1.43 & 8.2 \\
\hline 5 & 90.3 & 8.29 & 1.41 & 9.7 \\
\hline 6 & 89.4 & 8.56 & 1.64 & 10.6 \\
\hline \multicolumn{5}{|c|}{ Temperature $=425^{\circ} \mathrm{C}$} \\
\hline 2 & 96.9 & 0.26 & 2.84 & 7.1 \\
\hline 3 & 90.5 & 5.30 & 4.20 & 9.5 \\
\hline 4 & 88.1 & 6.76 & 5.14 & 11.9 \\
\hline 5 & 87.5 & 7.71 & 4.79 & 12.5 \\
\hline 6 & 84.6 & 9.84 & 5.56 & 15.4 \\
\hline \multicolumn{5}{|c|}{ Temperature $=450^{\circ} \mathrm{C}$} \\
\hline 3 & 89.2 & 0.98 & 9.82 & 10.8 \\
\hline 4 & 84.8 & 5.41 & 9.79 & 15.2 \\
\hline 5 & 77.3 & 4.38 & 18.32 & 22.7 \\
\hline 6 & 76.6 & 5.08 & 18.37 & 23.4 \\
\hline \multicolumn{5}{|c|}{ Temperature $=475^{\circ} \mathrm{C}$} \\
\hline 2 & 80.5 & 2.42 & 17.08 & 19.5 \\
\hline 3 & 78.4 & 8.00 & 13.60 & 21.6 \\
\hline 4 & 73.17 & 2.99 & 23.81 & 26.8 \\
\hline 5 & 68.1 & 7.38 & 24.52 & 32.0 \\
\hline 6 & 66.8 & 6.44 & 26.73 & 33.2 \\
\hline
\end{tabular}

* Obtained by difference 
TABLE 4.7 Limiting Desulfurization Conversion of Ohio $\# 8$ Coal in Tube Oven

\begin{tabular}{|c|c|c|c|c|c|c|}
\hline $\mathrm{T}\left({ }^{\circ} \mathrm{C}\right)$ & 250 & 300 & 350 & 400 & 450 & 500 \\
\hline $\mathrm{x}_{\text {so }}$ & 0.2541 & 0.2960 & 0.3301 & 0.3760 & 0.4227 & 0.4443 \\
\hline
\end{tabular}

TABLE 4.8 Kinetic Parameter for Ohio \#8 Coal Desulfurization

\begin{tabular}{|c|c|c|c|c|}
\hline $\mathrm{T}\left({ }^{\circ} \mathrm{C}\right)$ & 400 & 425 & 450 & 475 \\
\hline $\mathrm{x}_{300}$ & 0.3760 & 0.3994 & 0.4227 & 0.4325 \\
\hline $\mathrm{k}_{\mathrm{s}}$ & 0.061 & 0.082 & 0.132 & 0.251 \\
\hline
\end{tabular}

From Table 4.5 , it is observed that the sulfur concentration in gas remains almost the same level at a given reaction temperature while the residence time changes. Figure 14 shows the effect of the reaction temperature on the sulfur concentration in the gas product. As expected, it is observed that the hydrogen sulfide concentration in gas product increases with the reaction temperature. However, as the temperature rises, it tends to reach an upper limit about $4.2 \%$ (volume).

The result of sulfur distribution with different coal particle size is shown in Table 4.9.

The result shows that the coal particle size has no effect on the desulfurizaton under the experimental conditions. The observation that the coal particle size has no effect on both the pyrolysis and the desulfurization processes tells us that neither mass transfer nor heat 
transfer inside the coal particle could be the controlling step.

The experimental results also show that the $\mathrm{CaO}$ sorbent has a significant sulfur removal efficiency in this dual-screw feeder reactor at conditions where the sorbent particle size is 4-16 mesh. It is seen that, from the data listed in Table 4.10, the sulfur concentration in the gas product which results from the pyrolysis process in the inner tube and flows through the outer tube where it reacts with $\mathrm{CaO}$ pellets becomes undetectable. This indicates that the sulfur-containing gas could be thoroughly cleaned with $\mathrm{CaO}$ pellets under experimental conditions.

TABLE 4.9 Effect of Coal Particle Size on Desulfurization

\begin{tabular}{|c|c|c|c|c|c|c|c|c|c|c|}
\hline \multicolumn{2}{|c|}{ Particle Size } & \multicolumn{3}{|c|}{$4-8$ mesh } & \multicolumn{3}{|c|}{$8-16$ mesh } & \multicolumn{3}{|c|}{$16-35$ mesh } \\
\hline \multirow{2}{*}{$\mathrm{T}^{\circ} \mathrm{C}$} & \multirow{2}{*}{$\begin{array}{r}\mathrm{Rt} \\
(\mathrm{min})\end{array}$} & \multicolumn{9}{|c|}{ Sulfur Distribution (wt\%) } \\
\hline & & Char & Tar & Gas & Char & Tar & Gas & Char & Tar & Gas \\
\hline 400 & 3 & 91.1 & 7.63 & 1.27 & 91.9 & 6.90 & 1.20 & 91.7 & 7.00 & 1.30 \\
\hline 400 & 6 & 90.0 & 8.40 & 1.60 & 89.4 & 8.56 & 1.64 & 89.8 & 8.56 & 1.64 \\
\hline 475 & 3 & 78.1 & 8.70 & 13.2 & 78.4 & 8.00 & 13.6 & 78.0 & 8.60 & 13.4 \\
\hline 475 & 6 & 67.0 & 6.10 & 26.9 & 66.8 & 6.44 & 26.7 & 67.1 & 5.90 & 27.0 \\
\hline
\end{tabular}


TABLE 4.10 The Sulfur Removal Efficiency of CaO pelletin Dual-Screw Feeder

\begin{tabular}{|c|c|c|c|c|}
\hline \multirow{2}{*}{$\begin{array}{c}\mathrm{H}_{2} \text { S concentration } \\
\text { of Pyrolysis gas } \\
\text { (Volume \%) }\end{array}$} & \multicolumn{4}{|c|}{ Temperature $\left({ }^{\circ} \mathrm{C}\right)$} \\
\cline { 2 - 5 } & 400 & 425 & 450 & 475 \\
\hline Before Reacted With $\mathrm{CaO}$ & 1.17 & 3.04 & 3.81 & 4.04 \\
\hline After Reacted With $\mathrm{CaO}$ & 0.00 & 5.00 & 0.00 & 0.00 \\
\hline
\end{tabular}

* Residence Time: Coal particles (8-16 mesh) 6 min. $\mathrm{CaO}$ Pellets (4-16 mesh) $80 \mathrm{~min}$.

Table 4.11 shows the sulfur balance on the coal feeder reactor. After pyrolysis, the coal is converted into char, tar and noncondensable gas, and the sulfur in original coal distributes in char, tar, lime sorbent and emission gas. By measuring the sulfur contents in all of the products, we can make the sulfur balance.

$$
S_{c o a l}=S_{c h a r}+S_{\text {car }}+S_{c a O}+S_{g a s}
$$

The sulfur concentration in noncondensable gas is measured in vclume $\%(\mathrm{~V}, / \mathrm{V})$. It is converted into weight $\%\left(\mathrm{~W}_{\mathrm{g}} / \mathrm{W}\right)$ before making sulfur balance. At an ambient pressure, the ideal gas law can be used:

$$
\begin{array}{cc}
P V=n R T & P V=\frac{W}{M} R T \\
P V_{s}=n_{s} R T & P V_{s}=\frac{W_{s}}{M_{s}} R T
\end{array}
$$

where

$$
\begin{aligned}
& P=\text { pressure; } \\
& V \text { = volume of the gas; }
\end{aligned}
$$


$\mathrm{V},=$ volume of $\mathrm{H}_{2} \mathrm{~S}$ in gas;

$\mathrm{W}, \mathrm{W}_{\mathrm{s}}=$ weights of gas and sulfur in gas;

$M, M_{3}$ - molecular weights of gas and sulfur.

From Equation (4-8) and (4-9), we have

$$
\frac{W_{s}}{W}=\frac{M_{s} P V}{W R T}\left(\frac{V_{s}}{V}\right)
$$

Equation (4-10) is used to calculate the weight \% of sulfur in gas.

Table 4.11. Sulfur Balance on Reactor

\begin{tabular}{|c|c|c|c|c|c|c|c|}
\hline \multirow{3}{*}{$\begin{aligned} \mathrm{T} & =475^{\circ} \mathrm{C} \\
\mathrm{t} & =6 \mathrm{~min}\end{aligned}$} & \multicolumn{2}{|c|}{ Input(g) } & \multicolumn{5}{|c|}{ Product(g) } \\
\hline & Coal & $\mathrm{CaO}$ & Char & Gas & $\operatorname{Tar}$ & $\mathrm{CaO}$ & Total \\
\hline & 300 & 300 & 216.0 & 50.1 & 25.1 & 305.1 & 596.3 \\
\hline$S \%$ & 3.15 & 0 & 2.89 & 0 & 2.25 & 0.74 & \\
\hline$S(g)$ & 9.45 & 0 & 6.24 & 0 & 0.65 & 2.26 & 9.10 \\
\hline \multirow{3}{*}{$\begin{aligned} \mathrm{T} & =400^{\circ} \mathrm{C} \\
\mathrm{t} & =5 \mathrm{~min}\end{aligned}$} & \multicolumn{2}{|c|}{ Input(g) } & \multicolumn{5}{|c|}{ Product(g) } \\
\hline & Coal & $\mathrm{CaO}$ & Char & Gas & Tar & $\mathrm{CaO}$ & Total \\
\hline & 600 & 400 & 555.5 & 13.9 & 21.6 & 405.2 & 996.2 \\
\hline $5 \%$ & 3.15 & 0 & 3.01 & 0 & 7.22 & 0.175 & \\
\hline$S(g)$ & 18.90 & 0 & 16.72 & 0 & 1.56 & 0.727 & 19.01 \\
\hline
\end{tabular}

Under a mild pyrolysis condition, the released sulfur from coal is mostly from organic sulfur. The organic sulfur in Ohio $\# 8$ coal was determined as $1.72 \%$ (45.4\% of total sulfur). Table 4.12 shows the analysis results of the organic sulfur content in chars which came from the pyrolysis process in the dual-screw feeder under different operating conditions. 
It is seen, from Table 4.13 and Figure 15 , that as the feeder temperature and the coal particle residence time increase, the organic sulfur removal efficiency rises. The organic sulfur removal efficiency is calculated as follows:

$$
E f f=\frac{S_{\text {orgo }}-S_{\text {orgc }}}{S_{\text {orgo }}}
$$

where $\quad S_{\text {org } 0}$ is the organic sulfur content in the original coal

$S_{\text {orge }}$ is the organic sulfur content in the char product.

From Equation (4-11), it is calculated that at a temperature of $475^{\circ} \mathrm{C}$ and a residence time of 6 minutes, $33.2 \%$ of total sulfur or $73.1 \%$ of organic sulfur is released from coal. It is shown, from the result in Table 4.13 , that at the same condition, $73.4 \%$ of organic sulfur was also removed, indicating a strong evidence that under the experimental conditions, mostly organic sulfur is released.

Also, it is seen, from Figure 15, that as the reaction temperature and residence time increase, the organic sulfur removal efficiency rises quickly. It is expected that when the temperature is further raised and/or the residence time is increased, more than $95 \%$ of organic sulfur would be removed. 
Table 4.12. The Organic Sulfur Content(wt\%) In Char Produced Under Different Pyrolysis Conditions

\begin{tabular}{|c|c|c|c|c||}
\hline \multirow{2}{*}{$\begin{array}{c}\text { Residence } \\
\text { Time (min) }\end{array}$} & \multicolumn{5}{|c|}{ Temperature $\left({ }^{\circ} \mathrm{C}\right)$} \\
\cline { 2 - 5 } & 400 & 425 & 450 & 475 \\
\hline 2 & & 1.601 & & 1.289 \\
\hline 3 & 1.770 & 1.510 & 1.534 & 1.261 \\
\hline 4 & 1.628 & 1.303 & & 1.370 \\
\hline 5 & 1.056 & & 0.941 & 1.062 \\
\hline 6 & & 1.080 & 0.860 & 0.630 \\
\hline
\end{tabular}

Table 4.13 The Organic Sulfur Removal efficiency(wt\%)

\begin{tabular}{||c|c|c|c|c||}
\hline \multirow{2}{*}{$\begin{array}{c}\text { Residence } \\
\text { Time(min) }\end{array}$} & \multicolumn{5}{|c|}{ Temperature $\left({ }^{\circ} \mathrm{C}\right)$} \\
\cline { 2 - 5 } & 400 & 425 & 450 & 475 \\
\hline 2 & & 11.85 & & 36.8 \\
\hline 3 & 1.62 & 18.2 & 20.1 & 38.9 \\
\hline 4 & 10.6 & 30.3 & & 40.3 \\
\hline 5 & 42.7 & & 52.8 & 54.2 \\
\hline 6 & & 44.4 & 57.8 & 73.4 \\
\hline
\end{tabular}




\subsection{The Combustion Characteristics of The Pyrolyzed Products}

When the pyrolysis conditions in the dual-screw feeder are changed, the degree of the desulfurization of coal is also changed and the $\mathrm{SO}_{2}$ concentration in the emission gas from the combustor stack is changed accordingly. The heating value of the coal char is somewhat changed depending upon the degree of pyrolysis. A combustor (Figure 5) was set up to study the combustion characteristics of the pyrolyzed products. The experimental results showed that the combustion temperature inside the stack can go up to above $1600^{\circ} \mathrm{F}$. At this very high temperature, almost all sulfur element can be converted into $\mathrm{SO}_{2}$ in a short time. The combustion temperature can be adjusted by change of the coal feed rate and the coal/air ratio. In the experiments, the pyrolyzed gas product is scrubbed by calcined lime pellets in the outer tube of the screw feeder and is introduced into the combustor.

Table 4.14 shows the experimental results. It is seen that the combustion temperature becomes higher as the pyrolysis temperature rises, indicating that after pyrolysis and desulfurization, the total heating value of the products does not decrease much (Theoretically, only the heating value of removed sulfur is lost). As expected, the $\mathrm{SO}_{2}$ emission level is lowered as the feeder temperature is raised (Figure 16). When the feeder temperature rises, sulfur is reduced from the coal in the form of $\mathrm{H}_{2} \mathrm{~S}$ and goes through the outer tube of the dual-screw feeder where it reacts with the lime pellets. As a result, the $\mathrm{SO}_{2}$ concentration in the emission gas becomes lower. 
Table 4.14 Combustion Characteristics of The Pyrolyzed Products

\begin{tabular}{|c|c|c|}
\hline $\begin{array}{c}\text { Feeder } \\
\text { Temperature }\left({ }^{\circ} \mathrm{C}\right)\end{array}$ & $\begin{array}{c}\text { Combustion } \\
\text { Temperature }\left({ }^{\circ} \mathrm{F}\right)\end{array}$ & $\begin{array}{c}\mathrm{SO}_{2} \text { Emission } \\
\text { From Stack (ppm) }\end{array}$ \\
\hline $25($ room $\mathrm{T})$ & 1790 & 840 \\
\hline 400 & 1790 & 810 \\
\hline 450 & 1810 & 750 \\
\hline 475 & 1840 & 660 \\
\hline
\end{tabular}

Experiment condition: coal feed rate $=49 \mathrm{~g} / \mathrm{min}$. air flow rate $=0.54 \mathrm{~m}^{3} / \mathrm{min}$. coal particle size $=4-16$ mesh

TABLE 4.15 Elemental Analysis of Char Product (wt\%, d.a.f)

\begin{tabular}{||l|lllll||}
\hline Conversion & $\mathrm{C}$ & $\mathrm{H}$ & $\mathrm{N}$ & $\mathrm{H} / \mathrm{C}$ & $\mathrm{S}$ \\
\hline 0.000 & 0.8016 & 0.0571 & 0.0210 & 0.0713 & 0.0354 \\
0.031 & 0.7974 & 0.5517 & 0.0199 & 0.6919 & 0.0342 \\
0.067 & 0.8057 & 0.0544 & 0.0196 & 0.0675 & 0.0337 \\
0.068 & 0.8047 & 0.0484 & 0.0197 & 0.0602 & 0.0338 \\
0.087 & 0.8137 & 0.0492 & 0.0197 & 0.0605 & 0.0337 \\
0.104 & 0.8147 & 0.0521 & 0.0194 & 0.0639 & 0.0349 \\
0.106 & 0.8085 & 0.0496 & 0.0193 & 0.0614 & 0.0342 \\
0.119 & 0.8196 & 0.0500 & 0.0190 & 0.0609 & 0.0337 \\
0.138 & 0.8309 & 0.0501 & 0.0188 & 0.0603 & 0.0315 \\
0.157 & 0.8470 & 0.0498 & 0.0192 & 0.0587 & 0.0337 \\
0.166 & 0.8337 & 0.0393 & 0.0190 & 0.0471 & 0.0334 \\
0.258 & 0.8619 & 0.8619 & 0.0190 & 0.0599 & 0.0328 \\
\hline
\end{tabular}


The results of elemental analyses of the coal and char products are listed in Table 4.15. It was found that the elemental contents of carbon, hydrogen, nitrogen and sulfur change with the volatilization yield. These data are plotted in Figures 17 to 20. It can be seen that as the pyrolysis conversion increases, the carbon content in the char product increases but the hydrogen content decreases. This observation indicates that the hydrogen atoms in the coal are easier to release than carbon atoms during pyrolysis. The carbon content is clirectly related to the heating value. The increase of carbon content indicates the overall heating value of char and volatile product does not decline during the pyrolysis of Ohio \#8 coal.

It is also can be seen that the nitrogen component reduces with pyrolysis conversion when conversion is low $(<0.15)$. When pyrolysis conversion is higher than 0.15 , the increase of volatilization does not cause further denitrification. As a result, lower devolatilization conversion is ideal for denitrification in the case that Ohio \#8 coal is used. However, the sulfur content in the coal linearly decreases with the pyrolysis conversion. 


\section{V.SIMULATION OF THE DÚAL-SCREW FEEDER REACTOR}

\subsection{Assumptions}

The processes taking place in the coal feeder reactor include chemical reactions, mass transfer and heat transfer. These processes are:

(1) Heat transfer from outer surface to inner surface of the outer tube.

(2) Heat transfer through the space within the outer tube, where the mixture of lime and gas is moving, to the outer surface of the inner tube.

(3) Reaction of $\mathrm{H}_{2} \mathrm{~S}$ with $\mathrm{CaO}$ in the outer tube.

(4) Heat transfer from outer surface to inner surface of the inner tube.

(5) Heat transfer from inner tube wall to coal particles.

(6) Coal decomposition reaction.

(7) Mass transfer of the volatiles in the particle.

(8) Mass transfer of the volatiles from particle surface to the surroundings.

The heat effect of process (3) can be ignored compared to process (6). The heats of the reaction, $\mathrm{CaO}(\mathrm{s})+\mathrm{H}_{2} \mathrm{~S}(\mathrm{~g})-.->\mathrm{CaS}(\mathrm{s})+\mathrm{H}_{2} \mathrm{O}(\mathrm{g})$, is about $-52 \mathrm{~kJ} / \mathrm{mol}$ or $-1530 \mathrm{~kJ} / \mathrm{kg}-\mathrm{H}_{2} \mathrm{~S}$ at $450^{\circ} \mathrm{C}$ (the standard enthalpy values for $\mathrm{CaO}, \mathrm{H}_{2} \mathrm{~S}, \mathrm{CaS}$ and $\mathrm{H}_{2} \mathrm{O}$ are $-635,-20,-483$ and $242 \mathrm{~kJ} / \mathrm{mol}$, respectively, and the specific heat values for them are $43,34,82$ and $34 \mathrm{~kJ} / \mathrm{mol}$ $\mathrm{K}$, respectively. The molecular weight of $\mathrm{H}_{2} \mathrm{~S}$ is 34.) which is about the same as the heat effect of coal devolatilization (about $10^{3}-10^{4} \mathrm{~kJ} / \mathrm{kg}^{[43]}$ ). The typical $\mathrm{H}_{2} \mathrm{~S}$ concentration in 
volatile product is $1-5$ mole $\%$. That means, for every one mole of volatile produced, less than 0.05 moles of $\mathrm{H}_{2} \mathrm{~S}$ react with $\mathrm{CaO}$. Therefore, the heat effect of process (3) is less than $5 \%$ of that resulting from process (6).

The main problem in the simulation work lies with the difficulty to correlate the heat transfer coefficient, an important factor for scale-up, since the geometric shape of the screw is complex and the flow pattern of the gas and the solid particles in the system is very complicated. For example, when coal particles move through the inner tube, their surface partially touches the inner wall of the tube, partially touches the rotating screw surface, and partially exposes to the product gas. A method to simulate this problem is considering the coal particle's surroundings as a lumped phase including the wall of tube, the surface of screw, and the gas. The average heat transfer coefficient could be estimated by using an optimization method in which the heat transfer coefficient is considered as one of the variables.

From the experimental data, it is seen that the devolatilization yield depends on feeder temperature and residence time only. The particle size has no effect on the process. Neither mass transfer nor heat transfer inside the coal particle is appeared to be the controlling step. In the present experiments, the outer tube was filled with lime pellets which have a long residence time (about $80 \mathrm{~min}$. ), so it is reasonable to assume that the lime pellets' temperature is the same as that of the outer tube surface. The inner screw has a surface area larger and is effectively used for heat conduction medium from the tube wall. The 
pyrolyzed gas fills the space between coal particles and moves along with the inner screw. Since the gas yield in unit time(sec.) is not large (slow pyrolysis) and gas is well mixed by the screw rotation and coal particle movement, we assume the gas temperature is the same as the outer tube surface temperature. When coal particles move along the inner tube, their surface partially touches to the inner tube wall or the screw surface and partially exposes to the pyrolyzed gas from which the coal particles get heat energy to raise their temperature.

Based on the above description, the following assumptions are made in the model:

(a) The mass transfer and the heat transfer processes inside the coal particle are so fast that they have no resistance to the reaction;

(b) There is no temperature or concentration gradient inside the coal particle;

(c) The pyrolysis reaction in the coal particle obeys a uniform-conversion-model, that is, the reaction takes place uniformly throughout the particle;

(d) The controlling step is the heat transfer from surroundings to coal particle. The surroundings includes the pyrolyzed gas and some metal part surfaces to which the particle touches;

(e) All metal parts in the feeder have the same temperature as the outer tube surface.

\subsection{Mathematical Model}

Let us consider a coal particle at any time, $t$, after it enters the feeder. The following energy 
balance equation can be obtained:

$$
W_{T} C_{V} \frac{d T}{d t}=h S\left(T_{S}-T\right)-\frac{d W_{T}}{d t}\left(\Delta H_{r}\right)
$$

where $\quad \mathrm{W}_{\mathrm{T}}$ - total weight of the particle at residence time $\mathrm{t}(\mathrm{kg} / \mathrm{per}$ particle),

$\mathrm{C}_{\mathrm{V}}$ - specific heat of the coal particle $(\mathrm{kJ} / \mathrm{kg}-\mathrm{K})$,

$\mathrm{T}$ - temperature of the coal particle $(\mathrm{K})$,

$\mathrm{t}$ - residence time (min.),

$S$ - surface area of the particle $\left(\mathrm{m}^{2}\right)$,

$\mathrm{h}$ - heat transfer coefficient $(\mathrm{kJ} / \mathrm{min}-\mathrm{m}-\mathrm{K})$,

$T_{S}$ - surroundings' temperature $(\mathrm{K})$,

$\Delta \mathrm{H}_{\mathrm{r}}$ - heats of pyrolysis $(\mathrm{kJ} / \mathrm{kg})$.

In Equation (5-1), the term on the left side represents the enthalpy increase of the particle in unit time. The first term on the right side describes the heat transfer from surroundings to the particle. The remaining term is about the heats of reaction produced in unit time.

The total weight of coal at time $t$ can be written as:

$$
W_{T}=W_{T 0}(1-x)
$$

where

$$
\begin{aligned}
& \mathrm{W}_{\mathrm{To}}=\text { The weight of coal when } \mathrm{t} \text { is } 0 \\
& \mathrm{x}=\text { conversion. }
\end{aligned}
$$

Assuming the coal pyrolysis follows the first-order-reaction model, we have 


$$
\frac{d x}{d t}=k_{0}\left(x_{\infty}-x\right) e^{-\frac{E}{R T}}
$$

where

$$
\begin{aligned}
& \mathrm{k}_{\mathrm{o}}-\text { = preexponential index, } \\
& \mathrm{E}-\text { = activation energy, } \\
& \mathrm{R}=\text { gas constant. }
\end{aligned}
$$

By substituting Equation (5-2) into Equation (5-1), we obtain the following differential equation:

$$
\frac{d T}{d t}=\left(\frac{h}{C_{V}}\right)\left(\frac{S}{W_{T 0}}\right)\left(\frac{T_{s}-T}{1-x}\right)-\left(\frac{\Delta H_{r}}{C_{V}}\right)\left(\frac{1}{1-x}\right) \frac{d x}{d t}
$$

The conversion $x$ and the particle temperature $T$ in Equations (5-3) and (5-4) are functions of heat transfer coefficient $h$. Since it is very difficult to estimate the heat transfer coefficient in this system, this value is used as a parameter to be obtained by using an optimization method. The objective function is the error between the experimental data and the predicted values:

$$
E r=\sum\left(x_{i}(h)-x_{i}\right)^{2}
$$

where, $x_{i}(h)$ is the predicted conversion at the given condition which is the function of $h$, and $\mathbf{x}_{\mathrm{i}}$ is the corresponding conversion resulted from experiments. 


\subsection{Estimation of the Parameters}

\section{(1) Specific Heat of Coal and Char}

Coal consists of moisture, ash, volatile material and fixed carbon. The total weight of coal can be written as:

$$
W_{T}=W_{a s h}+W_{\text {mois }}+W_{V F}
$$

where, $\quad \mathrm{W}_{\mathrm{ash}}=$ the weight of ash in coal,

$$
\begin{aligned}
& \mathrm{W}_{\text {mois }}=\text { the weight of moisture in coal, } \\
& \mathrm{W}_{\mathrm{VF}}=\text { the weight of volatile material and fixed carbon in coal }
\end{aligned}
$$

During coal pyrolysis, the moisture component releases first followed by the volatile component. However, the weight of ash component does not change.

The specific heat of the ash in a coal can be expressed $a s^{[44]}$ :

$$
C_{\text {ash }}=0.594+5.86 \times 10^{-4}(T+273) \quad(k J / k g-K)
$$

To date, no successful correlation has been reported to estimate the specific heat of the moisture in coal. Generally, it is approximated to the specific heat of water. Figure 21 shows the specific heat of water as a function of temperature within the experimental range. By using the nonlinear regression method, the specific heat data of water can be fitted by Equation (5-8): 


$$
\begin{array}{r}
C_{\text {mois }}=4.13253+3.7319 \times 10^{-3} \mathrm{~T}^{2}+9.9268 \times 10^{-7} \mathrm{~T}^{3} \\
-4.11809 \times 10^{-9} \mathrm{~T}^{4}+6.37778 \times 10^{-12} \mathrm{~T}^{5} \\
(\mathrm{~kJ} / \mathrm{kg}-\mathrm{K})
\end{array}
$$

The specific hea: of the volatile and fixed carbon component can be modeled by applying the Einstein form of the quantum theory for the description of solid specific heat ${ }^{[45]}$ :

$$
C_{V F}=3\left(\frac{R}{a}\right) g\left(\frac{1200}{T}\right) \quad(k J / k g-K)
$$

where

$$
\begin{aligned}
& \mathrm{R}=\text { gas constant }(8.314 \mathrm{~kJ} / \mathrm{kmoal}-\mathrm{K}) \\
& \mathrm{T}=\text { temperature }(\mathrm{K})
\end{aligned}
$$

$a$ is the mean atomic weight defined by

$$
\left.\frac{1}{a}=\frac{C}{12}+H+\frac{O}{16}+\frac{N}{14}+\frac{S}{32} \quad(k m o l) k g\right)
$$

where $\mathrm{C}, \mathrm{H}, \mathrm{O}, \mathrm{N}, \mathrm{S}$ are the mass fractions of the respective elements and $\mathrm{g}$ is a function defined by

$$
g(x)=\frac{x^{2} e^{x}}{\left(e^{x}-1\right)^{2}}
$$

By linear or nonlinear regression of the elemental analysis data shown in Figures $17-20$, we have following expressions:

$$
\begin{aligned}
& C=0.273172 x+0.790334 \\
& H=-0.0562016 x+0.0575
\end{aligned}
$$




$$
\begin{aligned}
& N=0.0208773-0.0250717 x+0.109175 x^{2}+0.156014 x^{3} \\
& S=-0.0120155 x+0.0354 \\
& O=1-C-H-N-S
\end{aligned}
$$

It should be noted that the above expressions are based on the so called "dryash free" base (d.a.f.). They are valid only for conversion $x>0.0199$ (the moisture content of the Ohio $\# 8$ coal is $1.99 \%)$. When $x<0.0199$, the elemental analysis results of the original coal are used:

$$
C=0.8016, \quad H=0.0571, \quad N=0.0210, \quad S=0.0354, \quad O=0.085
$$

The mass fractione of the ash, the moisture and the volatile and fixed carbon components are calculated by uning the following equations.

When $x<0.0199$,

$$
z_{a s h}=\frac{W_{a s h}}{W_{0}(1-x)}, \quad z_{V F}=\frac{W_{V F o}}{W_{0}(1-x)}, \quad z_{\text {mois }}=1-z_{a s h}-z_{V F}
$$

when $x>0.0199$,

$$
z_{\text {ash }}=\frac{W_{\text {ash }}}{W_{0}(1-x)}, \quad z_{\text {mois }}=0, \quad z_{V F}=1-z_{\text {asf }}
$$

The specific heat of the coal or char then is 


$$
C_{V}=z_{a s h} C_{a s h}+z_{m o i s} C_{m o i s}+z_{V F} C_{V F} \quad(k J / k g-K)
$$

\section{(2) Heats of Reaction}

During coal pyrolysis, the moisture component releases first. At this stage, the heats of reaction actually is nothing but the latent heat of the moisture to its vapor. This latent heat is assumed to be the phase transition heat of water to its vapor at the same temperature as the coal particle. Figure 21 demonstrates the vaporization heat of water can be expressed as:

$$
\Delta H=2442.67-0.804209 T-0.00878266 T^{2} \quad(k J / k g)
$$

After the end of moisture release, the volatile component in coal begins to decompose. This decomposition reaction requires some amount of energy exchange with the surroundings. In this coal feeder system, the heats of reaction, $\Delta \mathrm{H}_{r}$, is a function of the conversion and the temperature since the operating pressure is constant. To estimate the heats of reaction, let us consider $1 \mathrm{~kg}$ of coal with undergoing the thermodynamic loop showing on next page.

The total heats of reaction for $x(x<1) \mathrm{kg}$ of volatile mater and water releasing from the coal is 


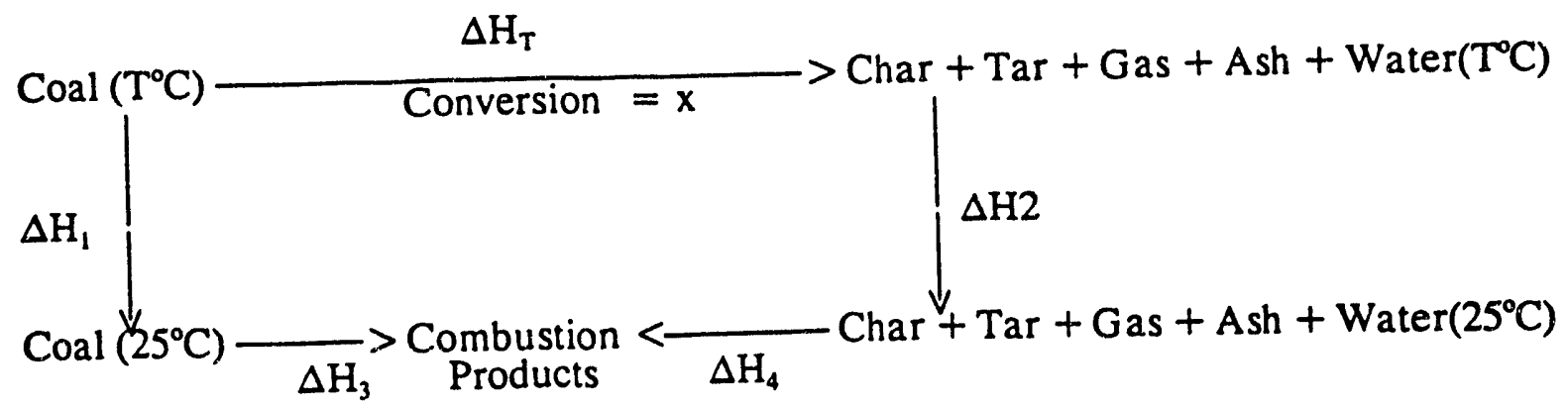

$$
\Delta H_{T}=\Delta H_{1}+\Delta H_{3}-\Delta H_{2}-\Delta H_{4} \quad(k J)
$$

The heats of reaction is defined as

$$
\Delta H_{r}=\frac{\partial\left(\Delta H_{\tau}\right)}{\partial x}
$$

When $x>0.0199$,we do not need to consider the heat of moisture vaporization. Ash content is considered inert and has nothing to do with the heats of reaction. In Equation $(5-16), \Delta \mathrm{H}_{3}$ is the calorific value of coal at $25^{\circ} \mathrm{C}$. Francis and Lloyd ${ }^{[46]}$ reported the following correlation for the calorific value of coal and char:

$$
\Delta H_{3}=1000 \times\left(1-x_{\text {mois }}-x_{\text {ash }}\right)(34.56 C+123.34 H-12.88 O+6.22 S) \quad(k J)
$$

where $x_{\text {mois }}$ and $x_{\text {ash }}$ are the moisture and ash mass fraction in the coal, and $C, H, O, S$ are the respective mass fractions. $\Delta H_{1}$ can be calculated by the following equation: 


$$
\Delta H_{1}=\left(1-x_{\text {mois }}-x_{a s h}\right) \int_{298}^{T(K)} C_{c o a l} d T \quad(k J)
$$

where $C_{\text {coal }}$ is the specific heat of coal, which can be calculated by Equation(5-9).

To estimate $\Delta \mathrm{H}_{2}$ and $\Delta \mathrm{H}_{4}$, the mass fractions of the char, tar and gas products must be known. It can be obviously seen

$$
x=x_{\text {tar }}+x_{\text {gas }}+x_{\text {mois }}
$$

where $x$ is the total conversion, $x_{\text {tar }}$ and $x_{g a s}$ are the tar yield and the gas yield respectively, and $x_{\text {mois }}$ is the mass fraction of moisture in original coal. Figure 23, which is plotted based on the experimental result, demonstrates the relationship between the gas yield and the total conversion. It shows the gas yield can be estimated by

$$
x_{\text {gas }}=0.6552 x-0.3002
$$

The mass fractions of tar and char products then can be determined as follows:

$$
\begin{gathered}
x_{\text {tar }}=x-x_{g a s}-x_{\text {mois }} \\
x_{\text {char }}=1-x-x_{\text {ash }}
\end{gathered}
$$

The specific heat of the char $\left(C_{\text {char }}\right)$ can be calculated by using Equation $(5-9)$ as described before. It has been shown that the specific heat of the tar is a function of temperature ${ }^{[44]}$ : 


$$
C_{\text {tar }}=4.22 \times 10^{-3}(T+273) \quad(\mathrm{kJ} / \mathrm{kg}-\mathrm{K})
$$

The specific heat of gas product is related to the composition of the gas. Table 5.1 lists the analysis results of the composition of gas produced from the pyrolysis process in the dualscrew coal feeder reactor. It is seen, from Table 5.1, the main components in the gas product are $\mathrm{CO}_{2}$ and $\mathrm{CH}_{4}$ which sum about $80 \%$ (volume) of the total gas product. The average composition of the gas is shown as follows:

$\begin{array}{llllll}\mathrm{H} 2 \mathrm{~S} & \mathrm{CO} 2 & \mathrm{CH} 4 & \mathrm{CO} & \mathrm{H} 2 & \text { Unknown } \\ 2.96 & 39.01 & 39.99 & 3.86 & 0.05 & 14.13\end{array}$

To simplify the problem, the gas could be considered as a mixture of $\mathrm{CO}_{2}$ and $\mathrm{CH}_{4}$ only. The normalized mole fractions of $\mathrm{CO}_{2}$ and $\mathrm{CH}_{4}$ are:

$$
\mathrm{y}_{\mathrm{CO} 2}=0.4713, \quad \mathrm{y}_{\mathrm{CH} 4}=0.5287
$$

Converting these values to mass fractions gives

$$
\mathrm{m}_{\mathrm{CO} 2}=0.6967, \quad \mathrm{~m}_{\mathrm{CH} 4}=0.3033
$$

The thermodynamic properties of $\mathrm{CO}_{2}$ and $\mathrm{CH}_{4}$ are listed in Table $5.2^{[45]}$. Finally, the specific heat of the gas then can be calculated by

$$
C_{\text {gas }}=m_{\mathrm{CO}_{2}} C_{\mathrm{CO}_{2}}+m_{\mathrm{CH}_{4}} C_{\mathrm{CH}_{4}}
$$


TABLE 5.1 Pyrolysis Gas Composition

\begin{tabular}{|c|c|c|c|c|c|c|}
\hline \multirow{2}{*}{$\begin{array}{l}\text { Residence } \\
\text { Time(min.) }\end{array}$} & \multicolumn{6}{|c|}{$\mathrm{T}=400^{\circ} \mathrm{C}$} \\
\hline & $\mathrm{H}_{2} \mathrm{~S}$ & $\mathrm{CO}_{2}$ & $\mathrm{CH}_{4}$ & $\mathrm{CO}$ & $\mathrm{H}_{2}$ & unknown \\
\hline 2 & 1.13 & 38.7 & 42.1 & 3.91 & 0 & 14.16 \\
\hline 3 & 1.08 & 36.2 & 39.3 & 5.21 & 0 & 18.21 \\
\hline 4 & 1.16 & 43.1 & 36.5 & 6.22 & 0.09 & 12.93 \\
\hline 5 & 1.1 & 33.9 & 44.1 & 2.13 & 0 & 18.77 \\
\hline \multirow[t]{2}{*}{6} & 1.17 & 37.8 & 41.6 & 4.01 & 0 & 15.42 \\
\hline & \multicolumn{6}{|c|}{$\mathrm{T}=425^{\circ} \mathrm{C}$} \\
\hline 2 & 2.91 & 39.5 & 40.2 & 6.11 & 0.12 & 11.16 \\
\hline 3 & 3.03 & 45.1 & 40.3 & 4.32 & 0 & 7.25 \\
\hline 4 & 2.97 & 36.3 & 45.1 & 5.03 & 0 & 10.6 \\
\hline 5 & 3.07 & 40.8 & 39.6 & 3.27 & 0 & 13.26 \\
\hline \multirow[t]{2}{*}{6} & 3.04 & 39.4 & 38.5 & 2.04 & 0.07 & 16.95 \\
\hline & \multicolumn{6}{|c|}{$\mathrm{T}=450^{\circ} \mathrm{C}$} \\
\hline 3 & 3.91 & 38.5 & 40.6 & 4.15 & 0.13 & 12.71 \\
\hline 4 & 3.9 & 35.8 & 39.6 & 5.35 & 0 & 15.35 \\
\hline 5 & 3.76 & 39.2 & 37.9 & 3.15 & 0.21 & 15.78 \\
\hline \multirow[t]{2}{*}{6} & 3.81 & 39.8 & 38.9 & 3.02 & 0.12 & 14.35 \\
\hline & \multicolumn{6}{|c|}{$\mathrm{T}=475^{\circ} \mathrm{C}$} \\
\hline 2 & 4.08 & 42.3 & 37.6 & 4.13 & 0 & 11.89 \\
\hline 3 & 4.06 & 37.8 & 39.7 & 2.09 & 0.18 & 16.17 \\
\hline 4 & 4.06 & 41.4 & 36.8 & 4.01 & 0.08 & 13.65 \\
\hline 5 & 4 & 38.7 & 39.8 & 2.15 & 0 & 15.35 \\
\hline 6 & 4.04 & 36.8 & 41.7 & 2.95 & 0 & 14.51 \\
\hline
\end{tabular}


TABLE 5.2 Thermodynamic Properties of $\mathrm{CO}_{2}$ and $\mathrm{CH}_{4}$

\begin{tabular}{||c|c|c|c|}
\hline \multirow{2}{*}{ Species } & \multirow{2}{*}{$\begin{array}{c}\text { Calorific } \\
\text { Value } \\
(\mathrm{kJ} / \mathrm{kg})\end{array}$} & \multicolumn{2}{|c|}{ Specific Heat, $\mathrm{C}=\mathrm{a}+\mathrm{b}(\mathrm{T}-273)(\mathrm{kJ} / \mathrm{kg}-\mathrm{K})$} \\
\cline { 3 - 4 } & & $\mathrm{a}$ & $\mathrm{b}$ \\
\hline $\mathrm{CH}_{4}$ & 55499 & 2.224 & 0.003078 \\
\hline $\mathrm{CO}_{2}$ & 0 & 1.959 & 0.002896 \\
\hline
\end{tabular}

The specific heat of the product including char, tar and gas is

$$
\begin{gathered}
C_{\text {product }}=x_{\text {gas }} C_{\text {gas }}+x_{\text {tar }} C_{\text {tar }}+x_{\text {char }} C_{\text {char }} \quad(k J / K) \\
\Delta H_{2}=\int_{\pi(K)}^{298} C_{\text {product }} d T \quad(k J)
\end{gathered}
$$

$\mathrm{AH}_{4}$ is the heat of combustion of the products at $25^{\circ} \mathrm{C}$ :

$$
\Delta H_{4}=x_{c h a r} \Delta H_{c h a r}+x_{\text {car }} \Delta H_{\text {war }}+x_{g a s} \Delta H_{g a s} \quad(k J)
$$

In Equation (5-27), $\Delta \mathrm{H}_{\mathrm{char}}$ can be estimated by Equation $(5-9), \Delta \mathrm{H}_{\mathrm{tar}}=38500 \mathrm{~kJ} / \mathrm{kg}^{[45]}$, and

$$
\Delta H_{\text {gas }}=m_{\mathrm{CH}_{4}} \Delta \mathrm{H}_{\mathrm{CH}_{4}}+m_{\mathrm{CO}_{2}} \Delta H_{\mathrm{CO}_{2}}
$$

where $\Delta \mathrm{H}_{\mathrm{CH} 4}$ and $\Delta \mathrm{H}_{\mathrm{CO} 2}$ are the calorific values of $\mathrm{CH}_{4}$ and $\mathrm{CO}_{2}$.

Figure 24 demonstrates the total energy required for conversion $x$. It is seen that at a given temperature, $\Delta \mathrm{H}_{\mathrm{T}}$ can be expressed by the following equation: 


$$
\Delta \mathrm{H}_{\mathrm{T}}=\mathrm{a}^{\prime}+\mathrm{bx}+\mathrm{cx}^{2}
$$

The values of $a, b$ and $c$ in above equation are functions of temperature. Table 5.3 lists the values of $a, b$ and $c$.

TABLE 5.3 Values of $a, b$ and $c$ at Different Temperatures

\begin{tabular}{|c|c|c|c|}
\hline Temperature $\left.^{\circ} \mathrm{C}\right)$ & $\mathrm{a}$ & $\mathrm{b}$ & $\mathrm{c}$ \\
\hline 100 & -32229.8 & -3757.30 & 4905.39 \\
\hline 200 & -31989.3 & -3939.14 & 4996.98 \\
\hline 300 & -31727.1 & -4117.98 & 5093.82 \\
\hline 400 & -31446.9 & -4288.43 & 5194.55 \\
\hline 500 & -31151.4 & -4446.76 & 5298.11 \\
\hline
\end{tabular}

From Equation (5-17), it is known the heats of reaction for pyrolysis of Ohio \#8 coal is

$$
\Delta \mathrm{Hr}=\mathrm{b}+2 \mathrm{cx}
$$

Figure 25 shows the relationship between $b, c$ and temperature. It is seen that $b$ and $c$ can be fitted by the following linear equations.

$$
\begin{aligned}
& b=-1.72821 \mathrm{~T}-3591.46 \\
& c=0.983009 \mathrm{~T}+4802.87
\end{aligned}
$$

To sum up, the following correlation can be used to calculate the heats of reaction:

$$
\Delta H_{r}=-1.72821 T-3591.46+2(0.983009 T+4802.87) x\left(k J / k g, T^{\circ} \mathrm{C}\right)
$$

It is interesting to see that the heats of pyrolysis of Ohio $\# 8$ coal (dry base) is negative under the experimental conditions. This result shows the pyrolysis of Ohio $\# 8$ coal (dry 
base) is an exothermic reaction. Merrick ${ }^{(45)}$ pointed out that the endothermic reaction below $650^{\circ} \mathrm{C}$ may not even exist. However, the overall heat requirement for pyrolysis of Ohio \#8 coal including the sensible heat and the heat of evaporation of water is endothermic and is estimated to be $10360 \mathrm{~kJ}$ for $1 \mathrm{~kg}$ of coal with conversion $\mathrm{x}=0.3$ at $500^{\circ} \mathrm{C}$.

\section{(3) Other Parameters}

The values of the kinetic parameters $\left(k_{0}, E\right.$, and $\left.x_{\infty}\right)$ in Equation (5-3) are important to the simulation work. In section 4.1 , the values of $k_{0}$ and $E$ were estimated:

$$
k_{o}=2.343 \times 10^{11}(1 / \mathrm{min} .), \quad E=170,02 \hat{i}(\mathrm{~kJ} / \mathrm{kmol})
$$

The limiting conversion $x_{\infty}$ is a function of temperature as illustrated in Figure 7. By nonlinear regression of the measured data, the value of $x_{\infty}$ can be correlated with temperature as follows:

$$
\begin{array}{ll}
25<\mathrm{T}<175^{\circ} \mathrm{C}, & \mathrm{x}_{\infty}=0.02968445-1.013613 / \mathrm{T}+235.006 / \mathrm{T}^{3}-1633.29 / \mathrm{T}^{4} \\
175<\mathrm{T} 430^{\circ} \mathrm{C}, & \mathrm{x}_{\infty}=-0.2358186+0.00343825 \mathrm{~T}+1.51705 \times 10^{-5} \mathrm{~T}^{2}+2.291687 \times 10^{-8} \mathrm{~T}^{3} \\
430<\mathrm{T}<700^{\circ} \mathrm{C}, & \mathrm{x}_{\infty}=0.3556763+15804.64 / \mathrm{T}^{2}-1.112338 \times 10^{15} / \mathrm{T}^{6}
\end{array}
$$

In the experiments, the average diameter of the coal particles is $0.00259 \mathrm{~m}(2.59 \mathrm{~mm})$. Assuming the coal particle is a sphere, we can get the surface area of the particle, that is $S=1.818 \times 10^{-5} \mathrm{~m}^{2}$. The density of the coal was experimentally measured, $\rho=1305 \mathrm{~kg} / \mathrm{m}^{3}$, so the weight of the original coal particle with a diameter of $2.59 \mathrm{~mm}$ can be calculated. The result is $W_{\text {TO }}=2.373 \times 10^{5} \mathrm{~kg}$. 


\subsection{Simulation Results}

With a given value of the heat transfer coefficient $h$, Equations (5-3) and (5-4) can be solved simultaneously. For each $h$ value, Equation (5-5) gives a corresponding error value (Er). Figure 26 illustrates the simulation result. It can be seen that the optimal value of the heat transfer coefficient, $\mathrm{h}$, is about $20.5 \mathrm{~kJ} / \mathrm{min}-\mathrm{m}-\mathrm{K}(341.7 \mathrm{~W} / \mathrm{m}-\mathrm{K})$. With this value of heat transfer coefficient, solving Equations (5-3) and (5-4) gives the agreement between simulation results and experimental results. Figure 27 shows the relationship between the simulation and the measured data.

Figure 28 shows the particle temperature change with the residence time. It can be seen that the particle temperature increases very quickly at the beginning stage. In about one half a minute after entering the inner tube, it reaches a temperature slightly lower than that of the feeder. After that, the particle temperature changes very slowly. This result indicates that the particle gets the most heat during a short period right after it is fed into the inner tube. 


\section{CONCLUSIONS}

The experimental results of devolatilization and desulfurization of an Ohio \#8 coal in the dual-screw feeder reactor reported here demonstrate that an increasing the temperature in mild coal pyrolysis leads to the increase of both the devolatilization yield and the desulfurization yield. Under the experimental conditions, mainly the organic sulfur releases in the form of $\mathrm{H}_{2} \mathrm{~S}$. Both the devolatilization and the desulfurization processes can be described by using the first-order-reaction model which gives the activation energy values for pyrolysis and desulfurization of $170,021 \mathrm{~kJ} / \mathrm{mol}$ and $78,783 \mathrm{~kJ} / \mathrm{mol}$, indicating the sulfur is easier to release than volatiles. The significant hydrogen sulfide removal efficiency of $\mathrm{CaO}$ pellets in this dual-screw feeder reactor shows that the reaction rate of $\mathrm{H}_{2} \mathrm{~S}+\mathrm{CaO}--->>$ $\mathrm{H}_{2} \mathrm{O}+\mathrm{CaS}$ is fast enough under the experimental conditions to assume a complete conversion. At a temperature of $475^{\circ} \mathrm{C}$ and a residence time of 6 minutes, $73.1 \%$ of the organic sulfur was removed in the screw feeder reactor. The investigation of the combustion characteristics of the pyrolysis products shows that the mild pyrolysis process taking place in the dual-screw feeder reactor does not cause a measurable decrease of the total heating value of the char and the volatiles.

The simulation results shows that the mild pyrolysis of Ohio \#8 coal (dry base) is possibly an exothermic process when the heats of evaporation of water and the sensible heat are not considered. However, the overall heats requirement for pyrolysis of Ohio $\# 8$ coal is still endothermic and is estimated to be $10360 \mathrm{~kJ}$ for $1 \mathrm{~kg}$ of coal with a conversion of 0.3 at 
$500^{\circ} \mathrm{C}$. The heat transfer coefficient is about $341.7 \mathrm{~W} / \mathrm{m}-\mathrm{K}$. This value indicates a good heat transfer performance of the dual-screw feeder reactor.

The results of this research suggest that a temperature between 500 and $600^{\circ} \mathrm{C}$ is favored for releasing more organic sulfur from coal during pyrolysis. 


\section{FIGURES}

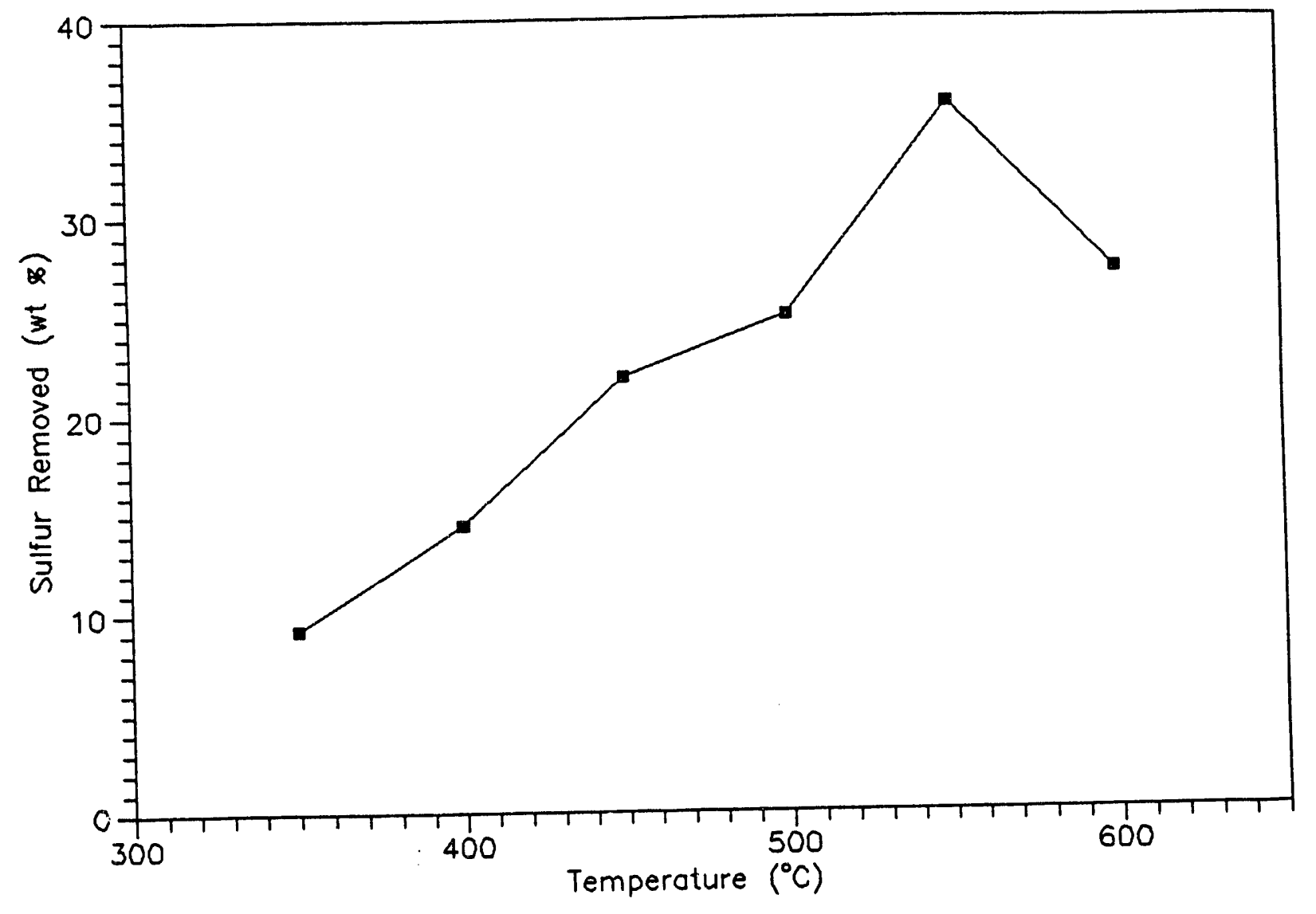

Figure 1. Effect of Temperature on Sulfur Removal in Pyrolysis of Utrillas Coal ${ }^{[30]}$ 


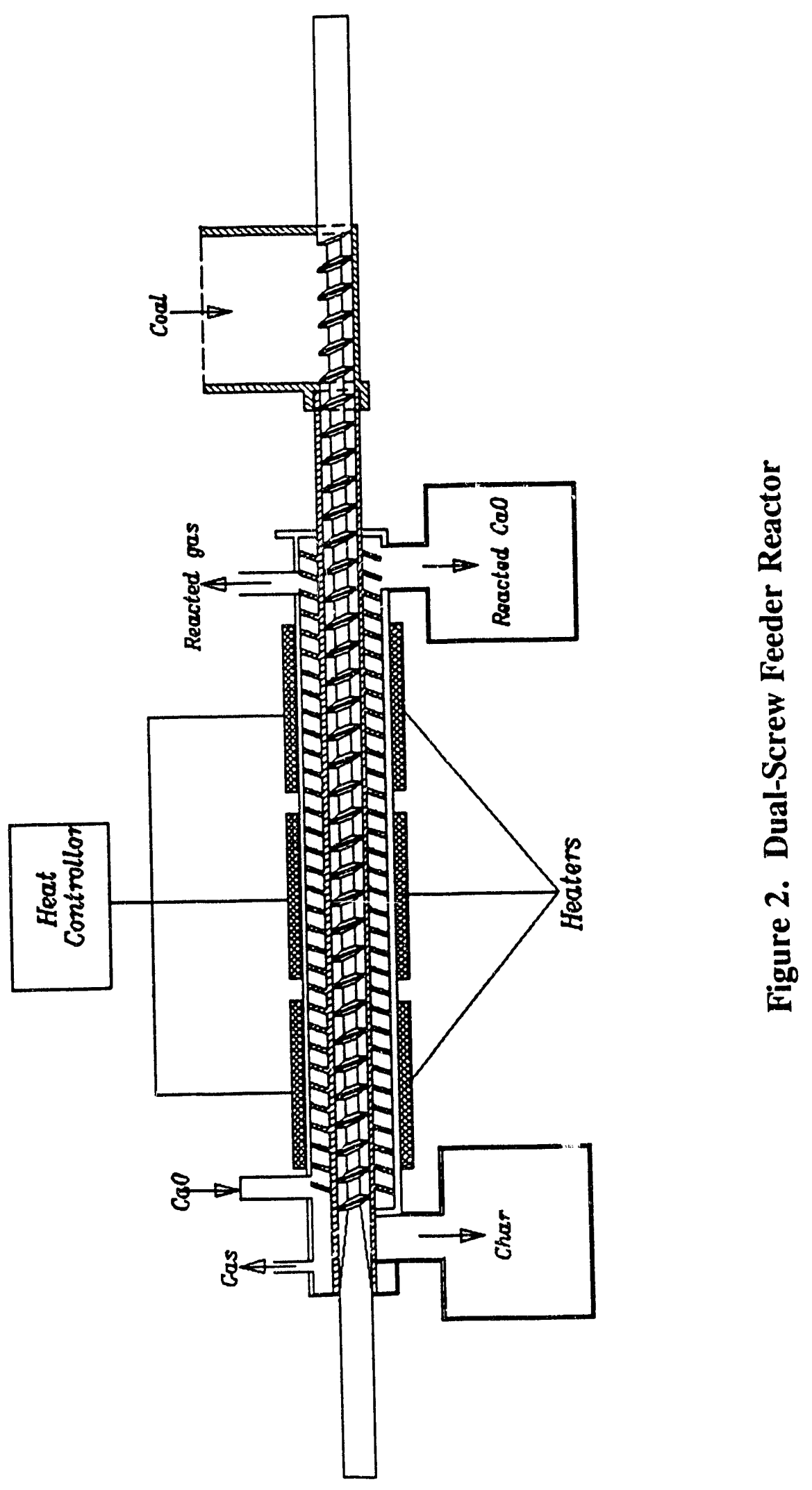




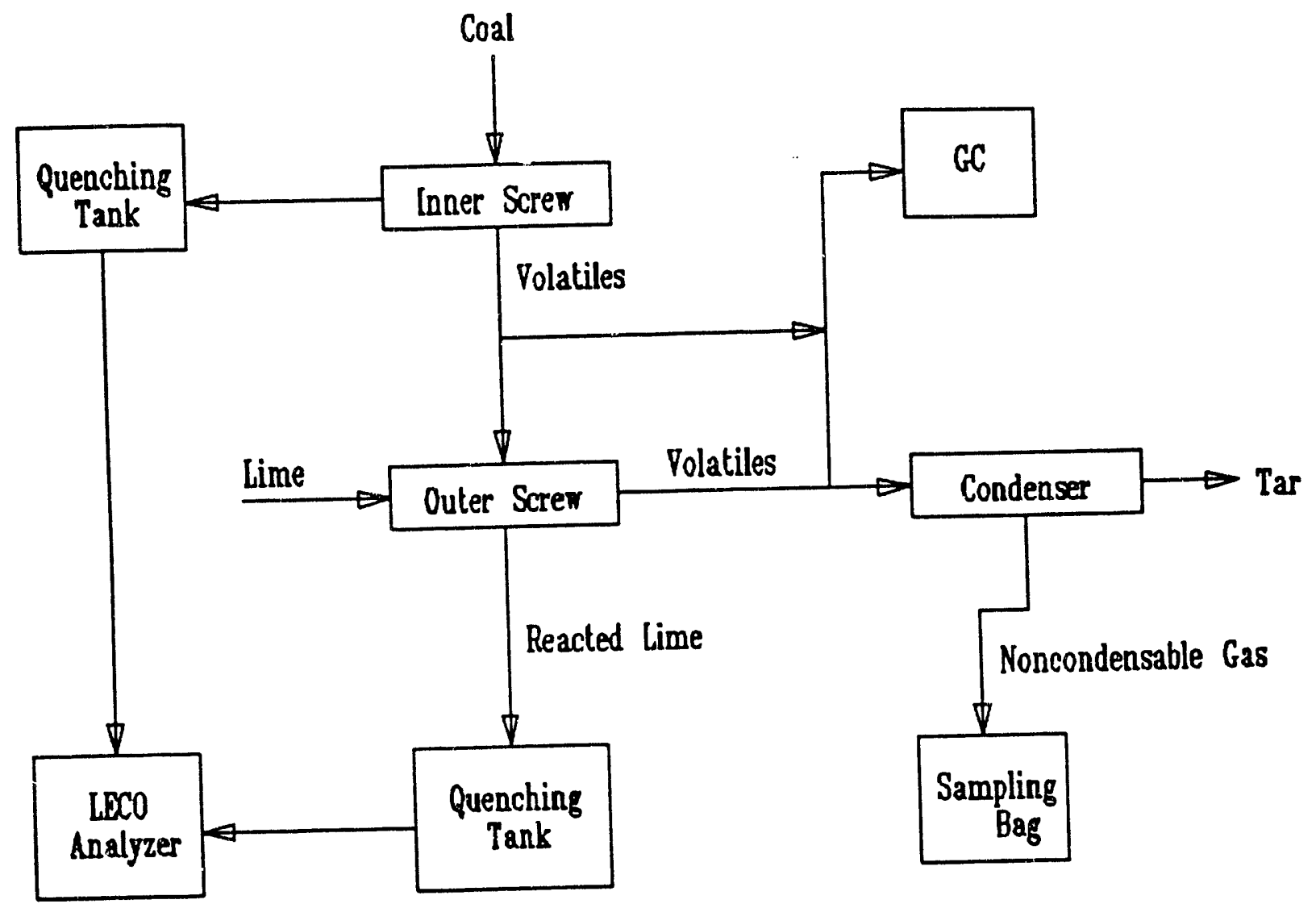

Figure 3. Flow Diagram 


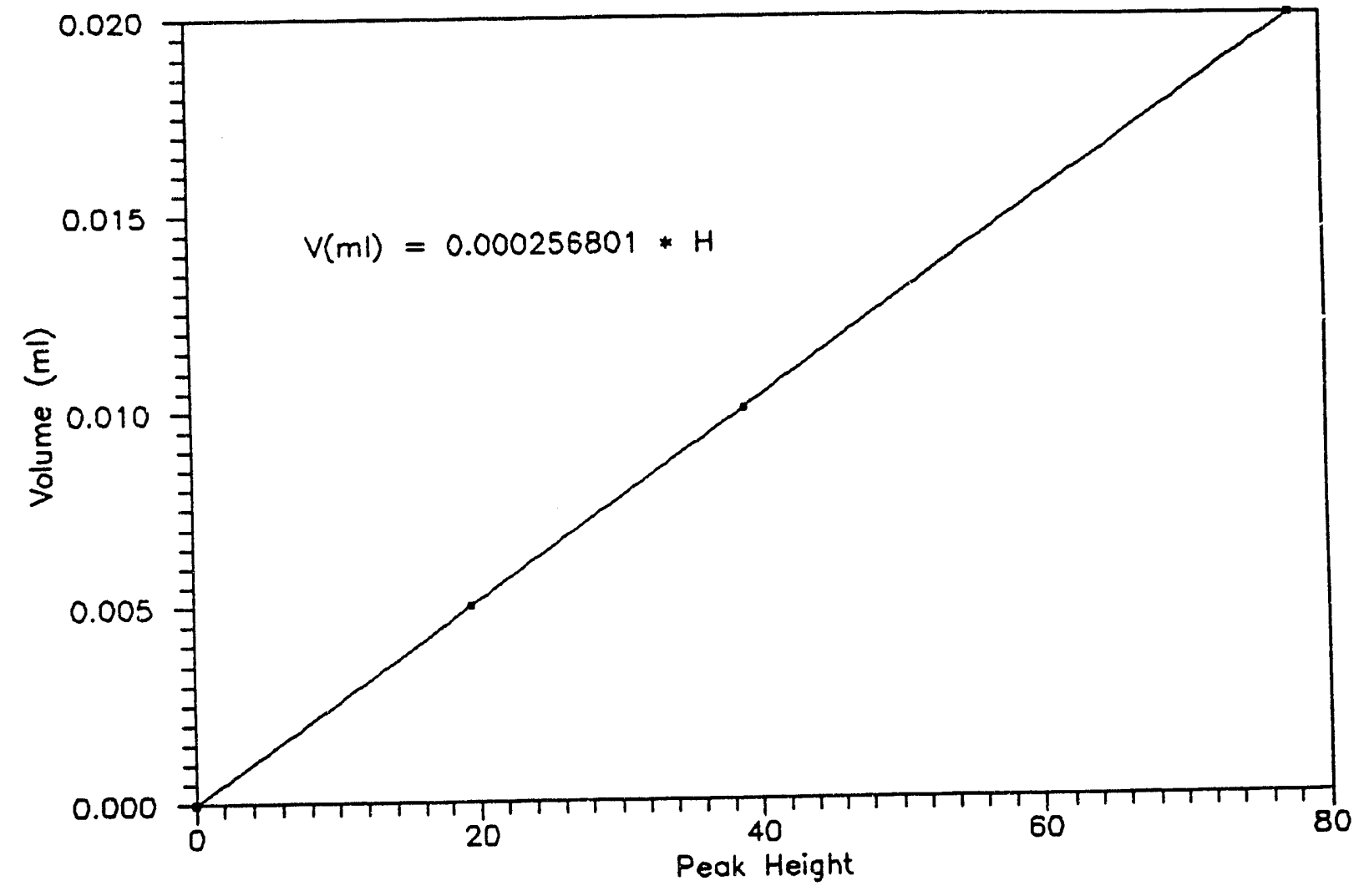

Figure 4. GC Standard Curve, $\mathrm{H}_{2} \mathrm{~S}, \mathrm{Rt}=3.4 \mathrm{~min}$. 


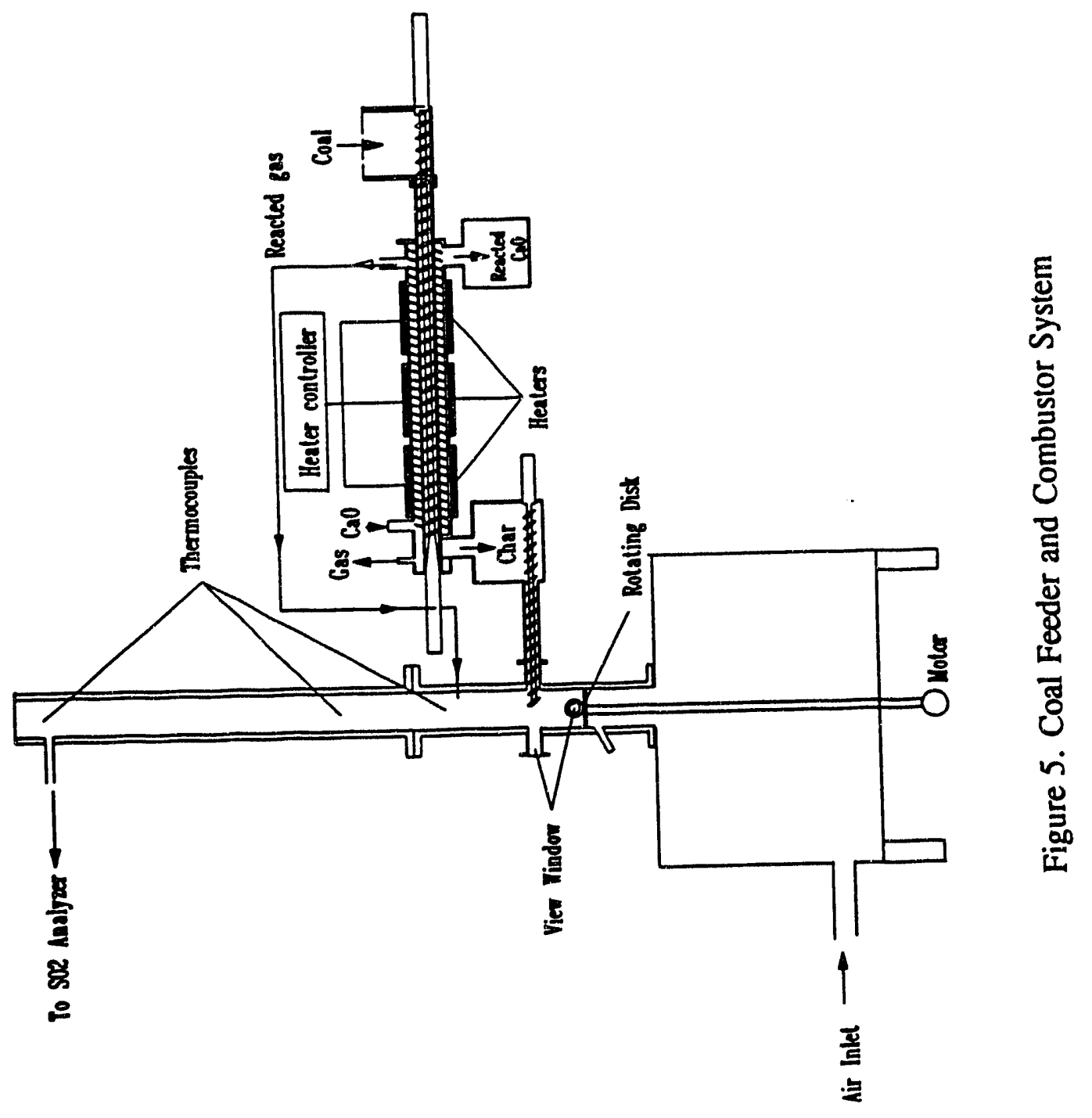

5 


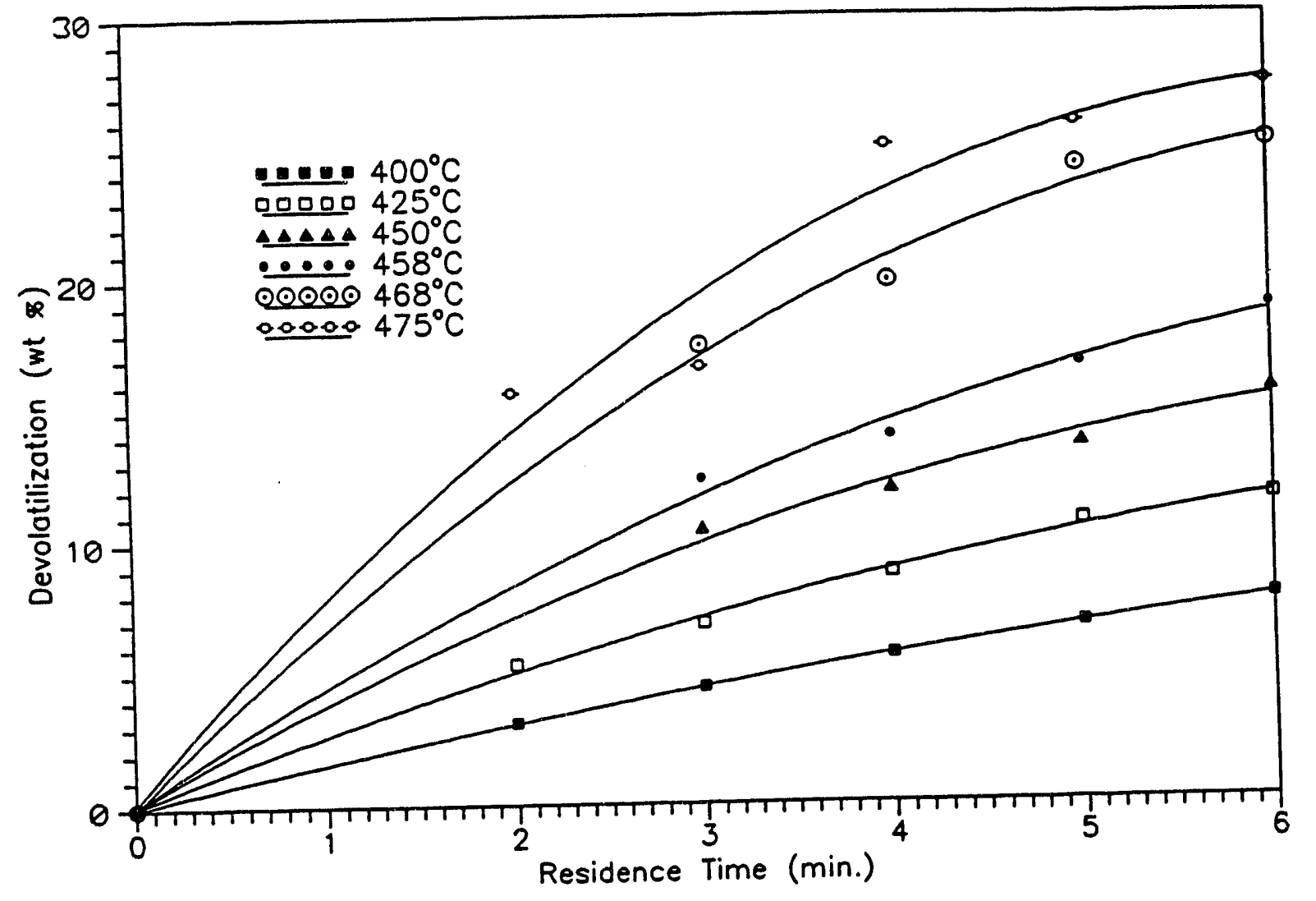

Figure 6. Pyrolysis of Ohio \#8 Coal(4-35 mesh) in Dual-Screw Feeder 


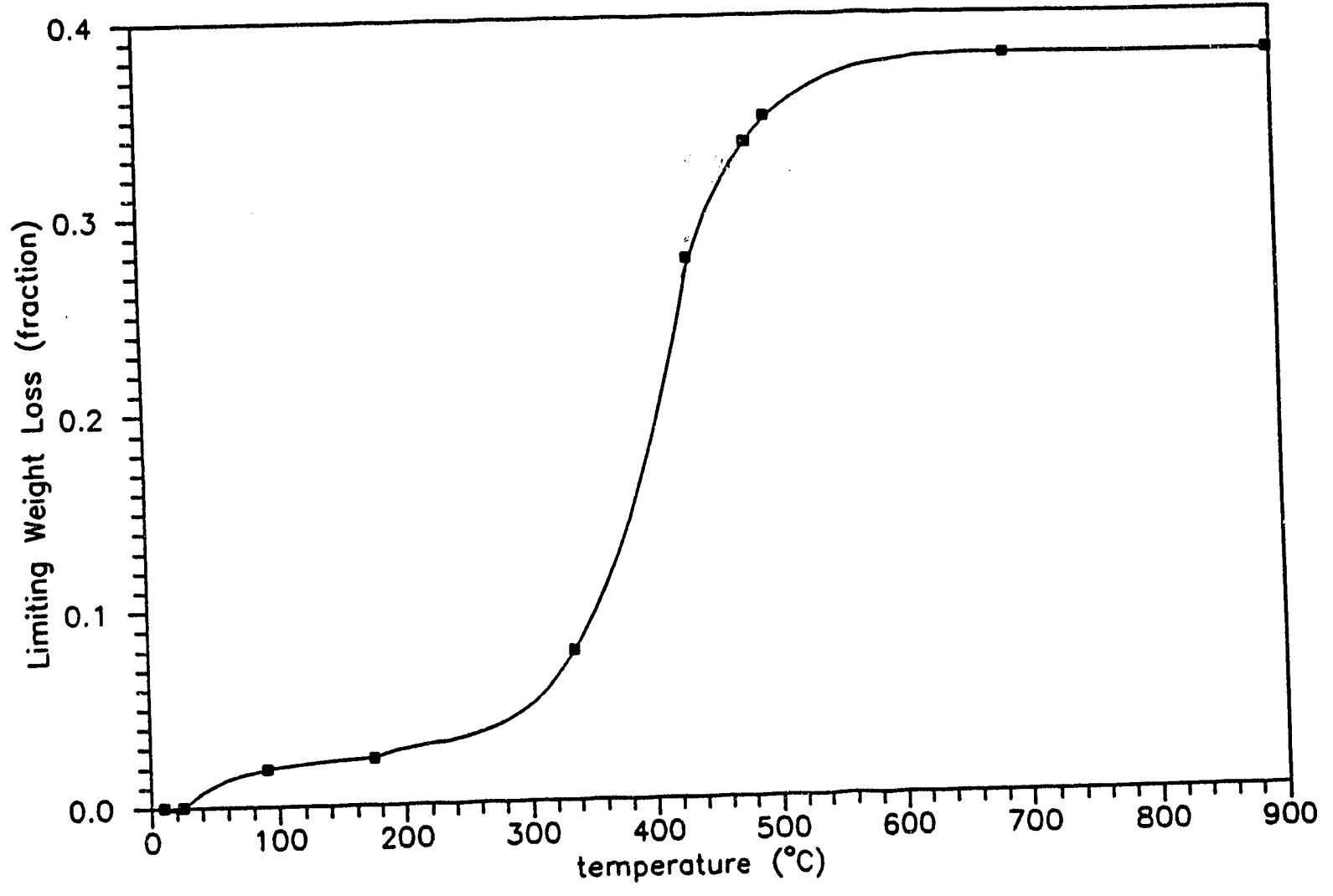

Figure 7. Temperature vs. Maximum Weight Loss

(TGA Data) 


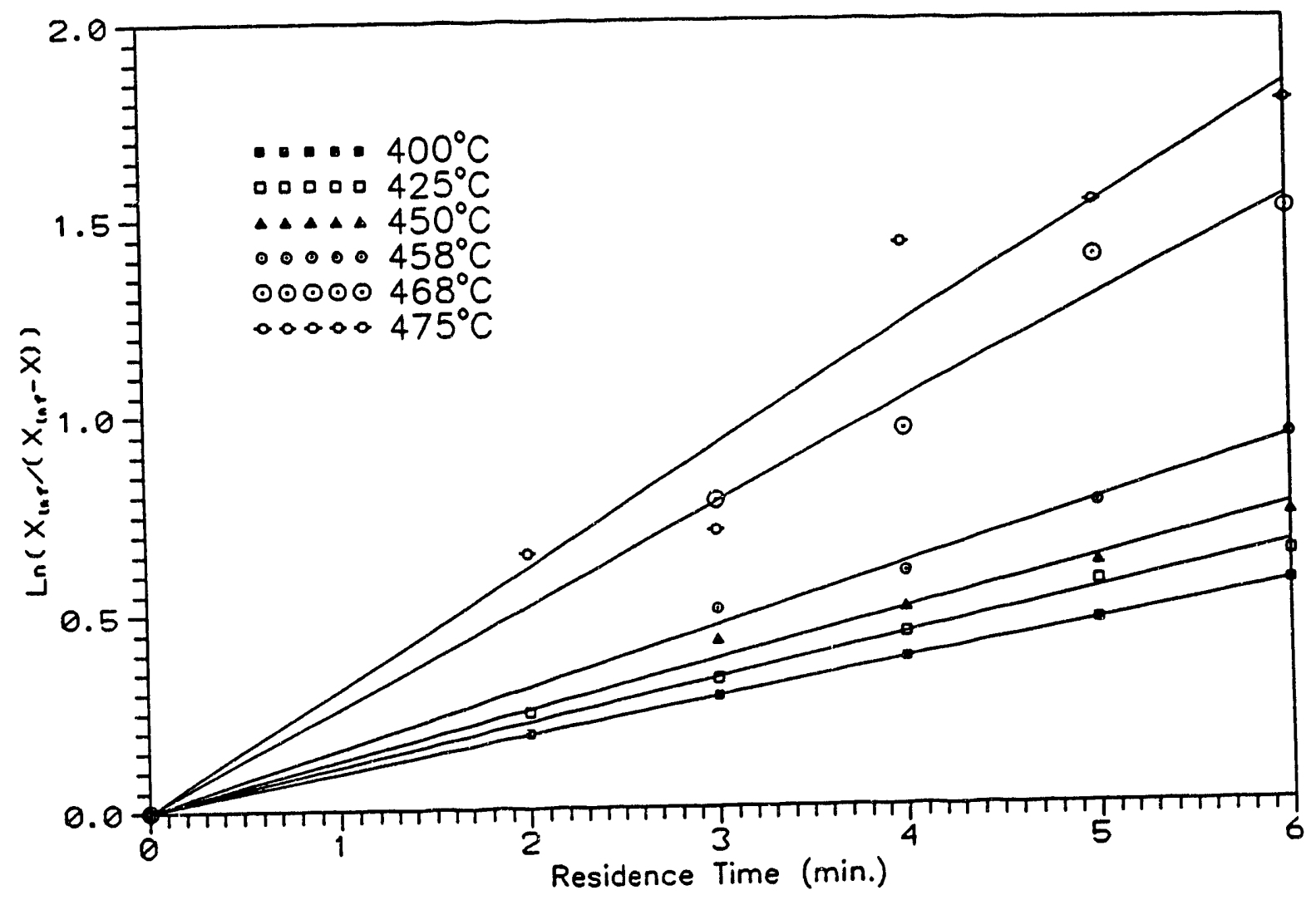

Figure 8. Comparison of Measured Pyrolysis Data with First Order Reaction Assumption 


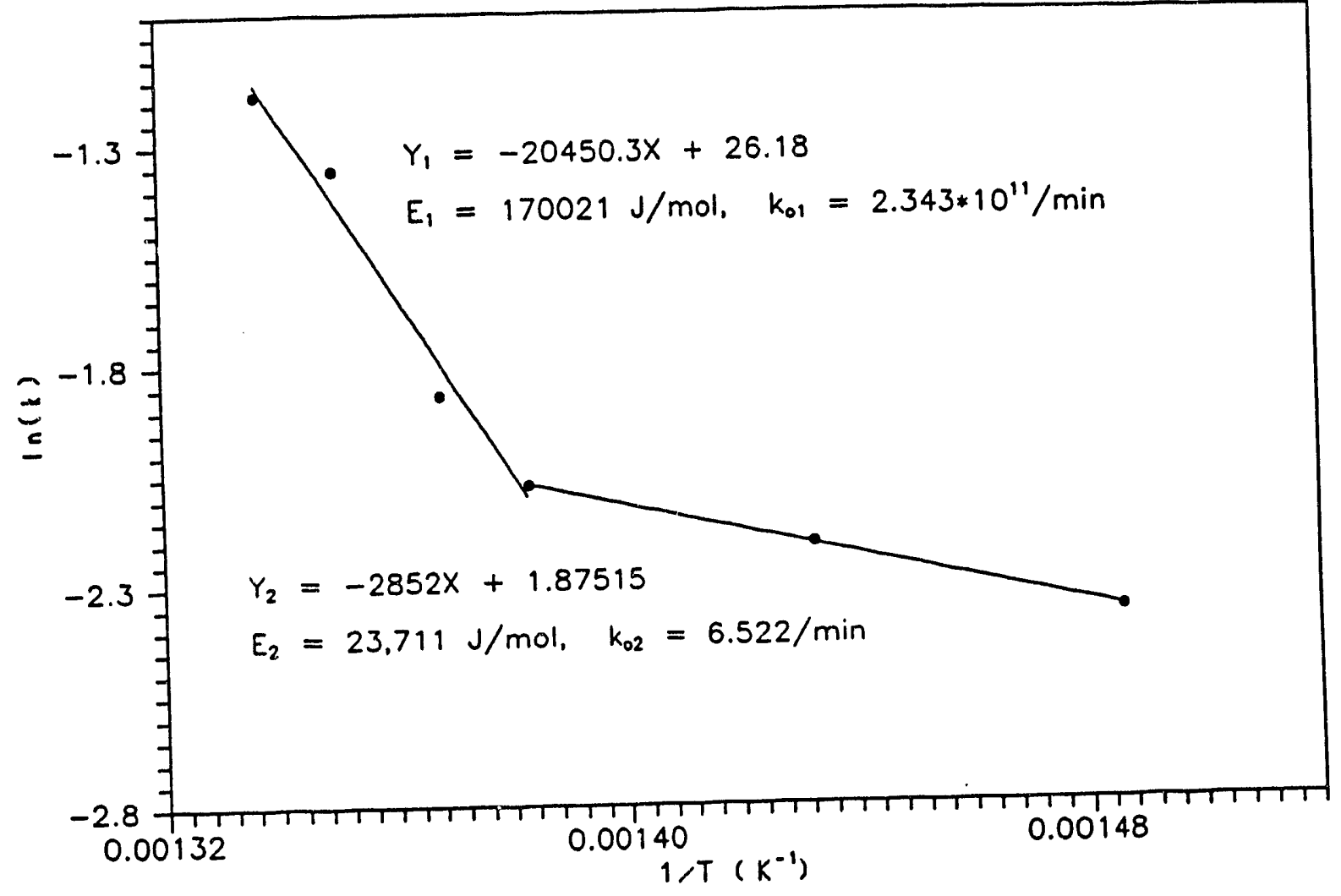

Figure 9. Arrhenius Plot for Pyrolysis Data 


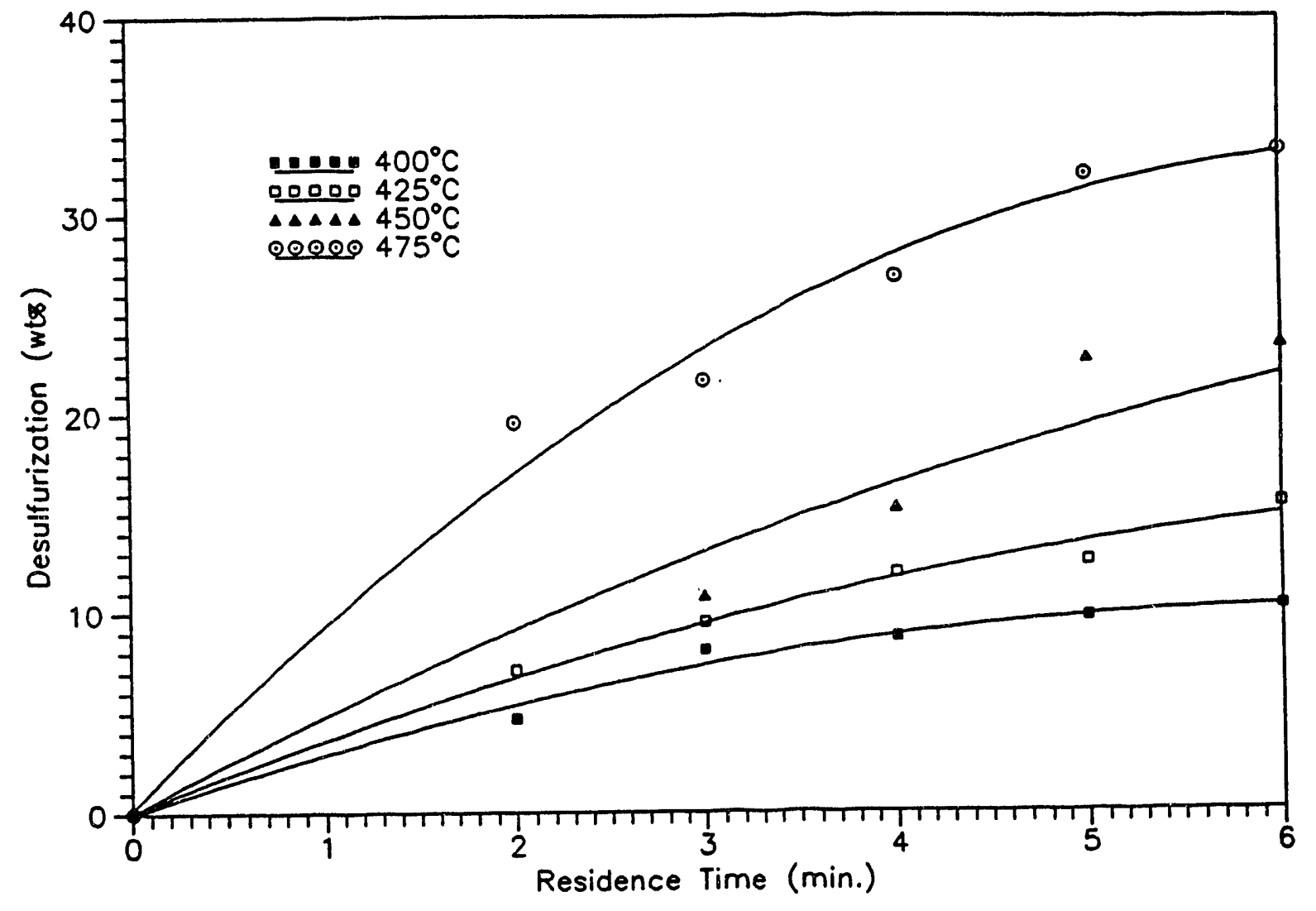

Figure 10. Desulfurization of Ohio \#8 Coal (4-35 mesh) by Pyrolysis in Dual-Screw Feeder 


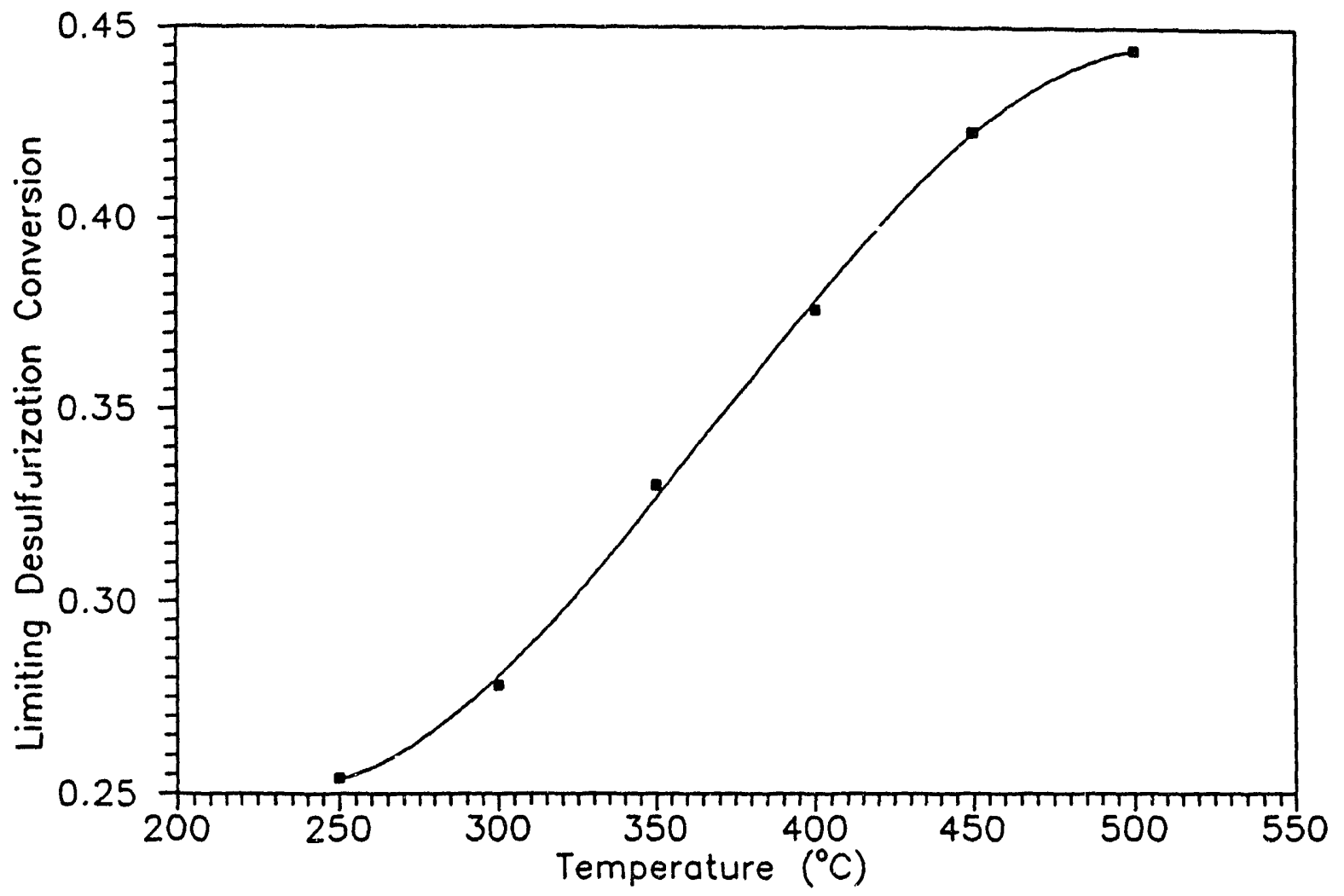

Figure 11. Temperature vs. Maximum Desulfurization (Oven Heating Data)

73 


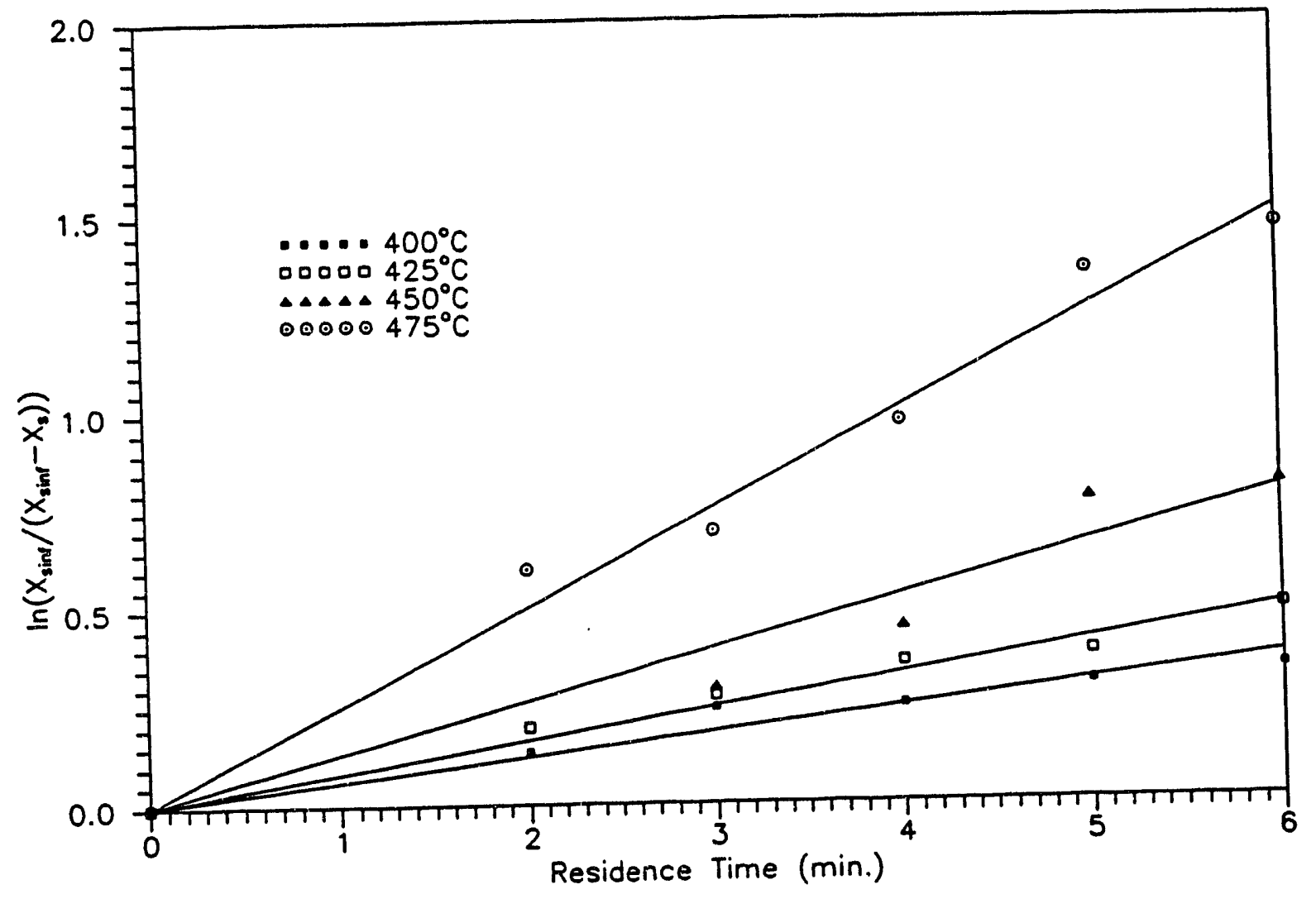

Figure 12. Comparison of Measured Desulfurization data with First Order Reaction Assumption 


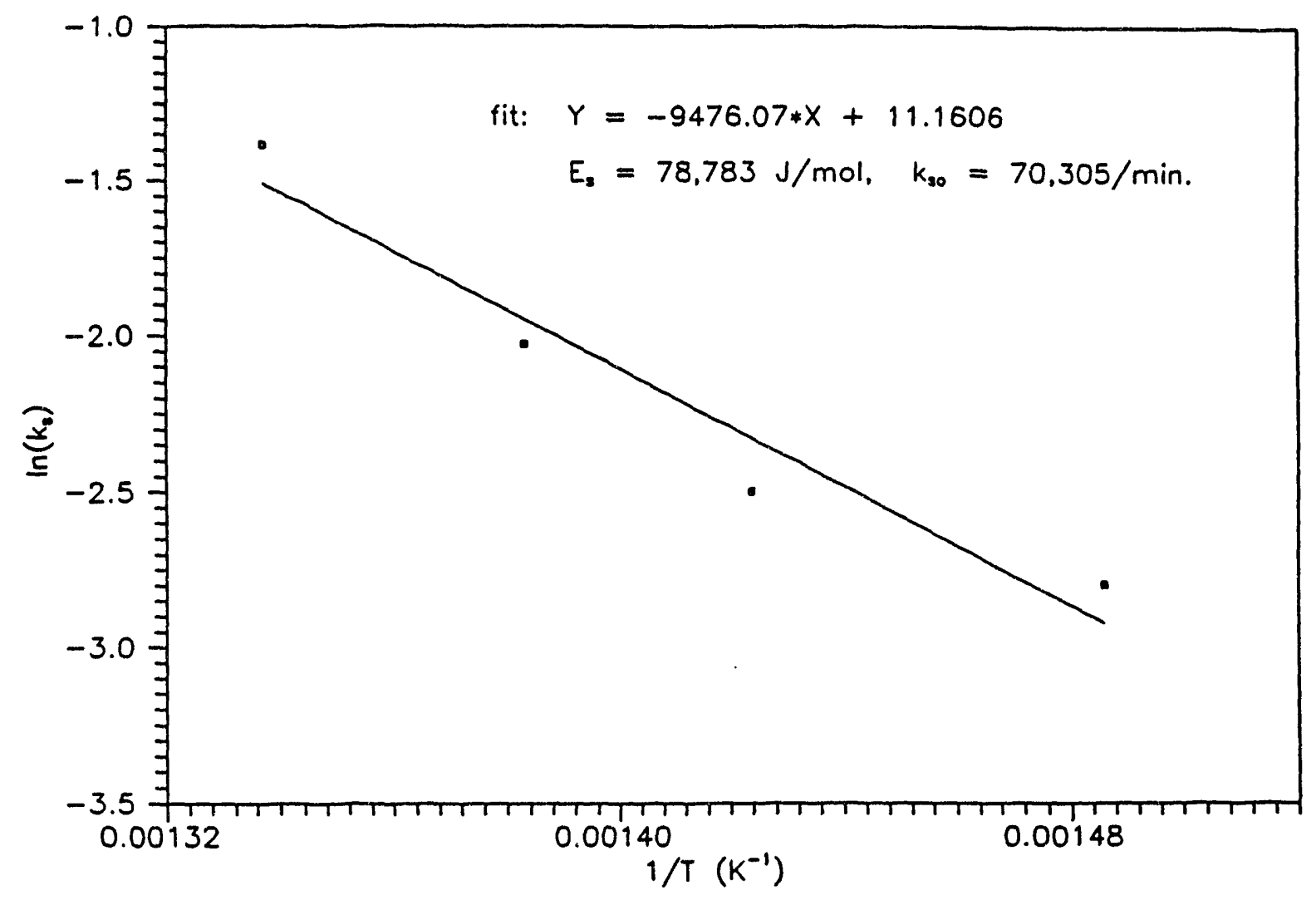

Figure 13. Arrhenius Plot for Desulfurization Data 


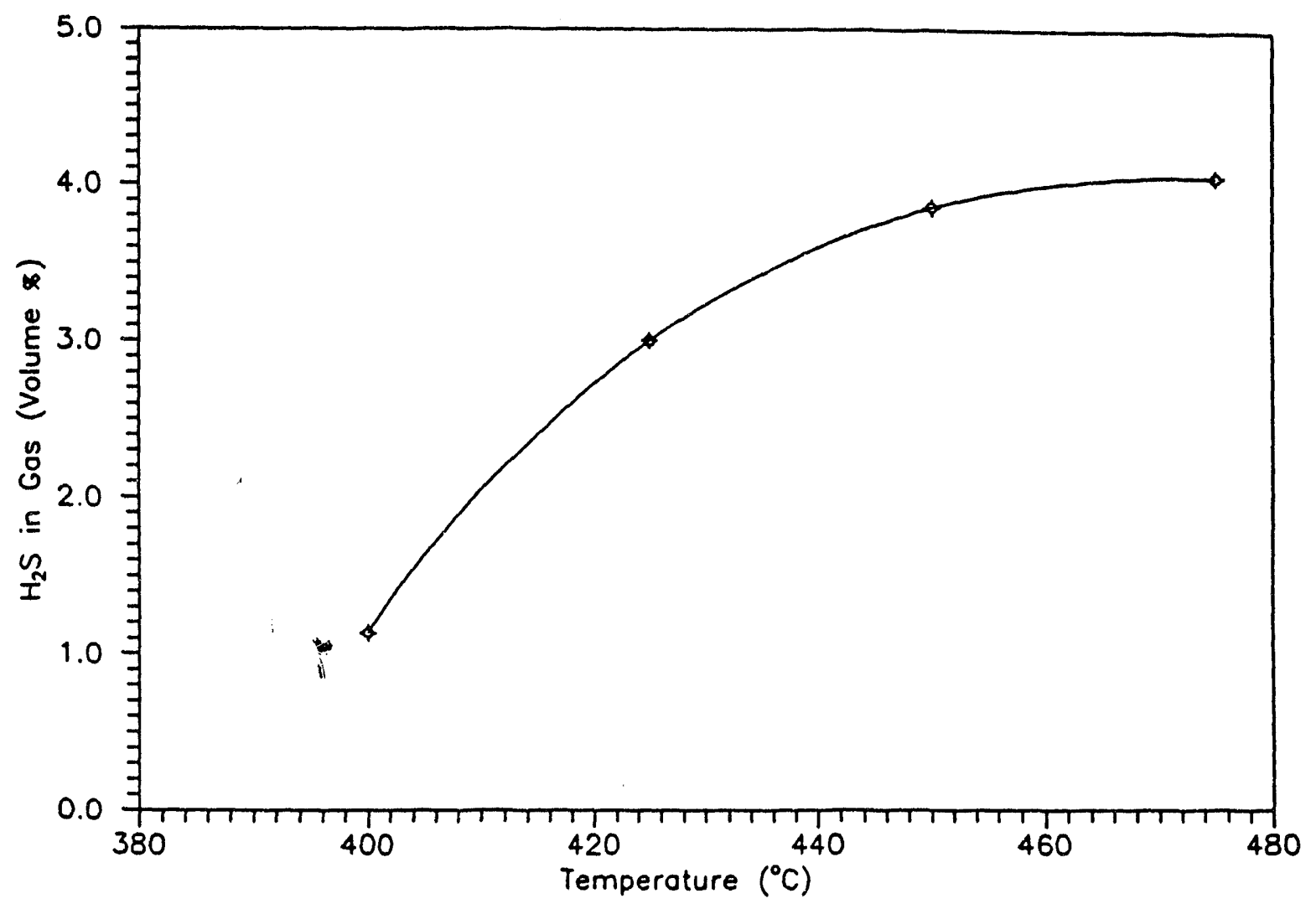

Figure 14. Effect of Temperature on $\mathrm{H}_{2} \mathrm{~S}$ Concentration in Gas 


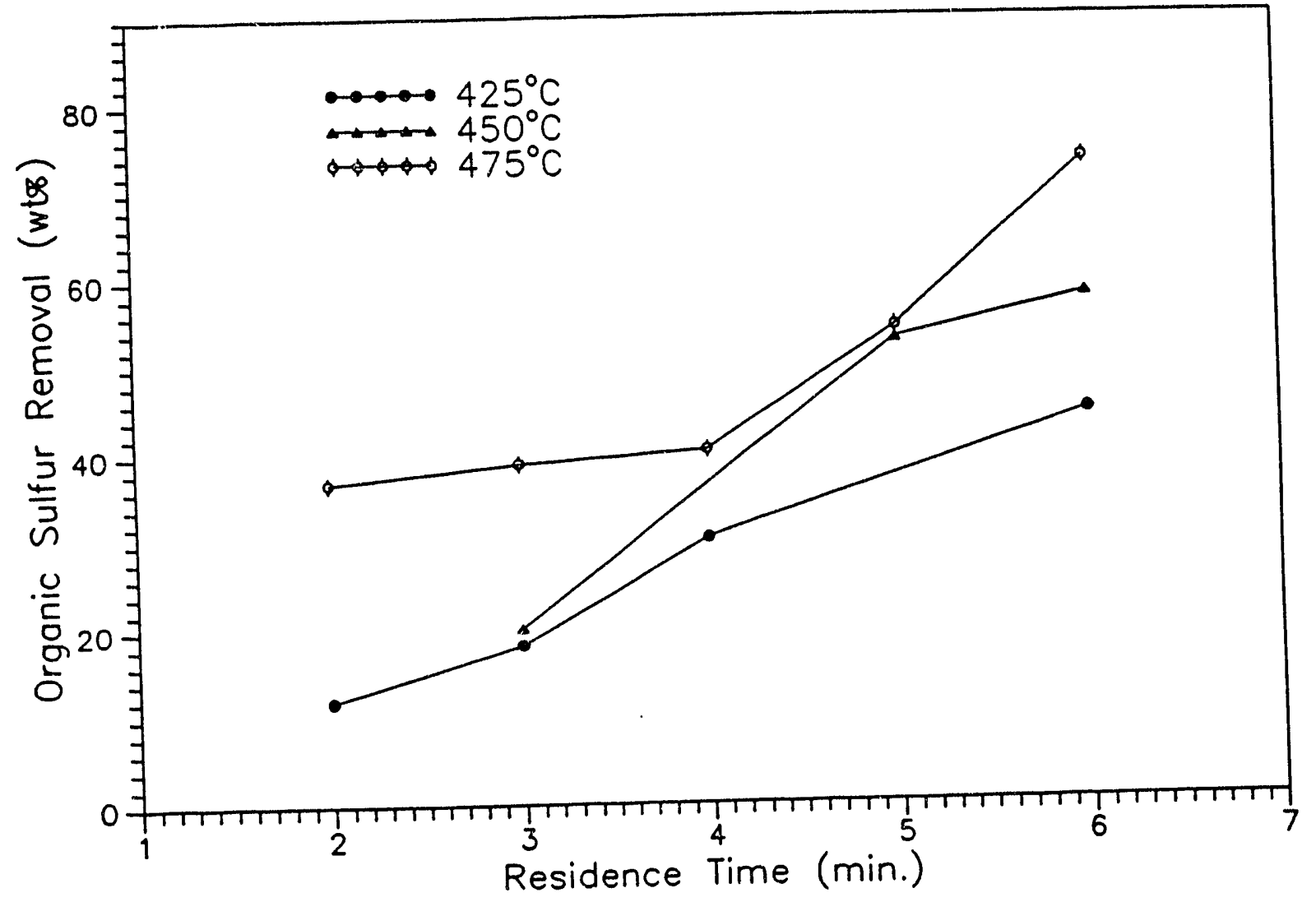

Figure 15. Organic Sulfur Removal Efficiency in Dual-Screw Feeder 


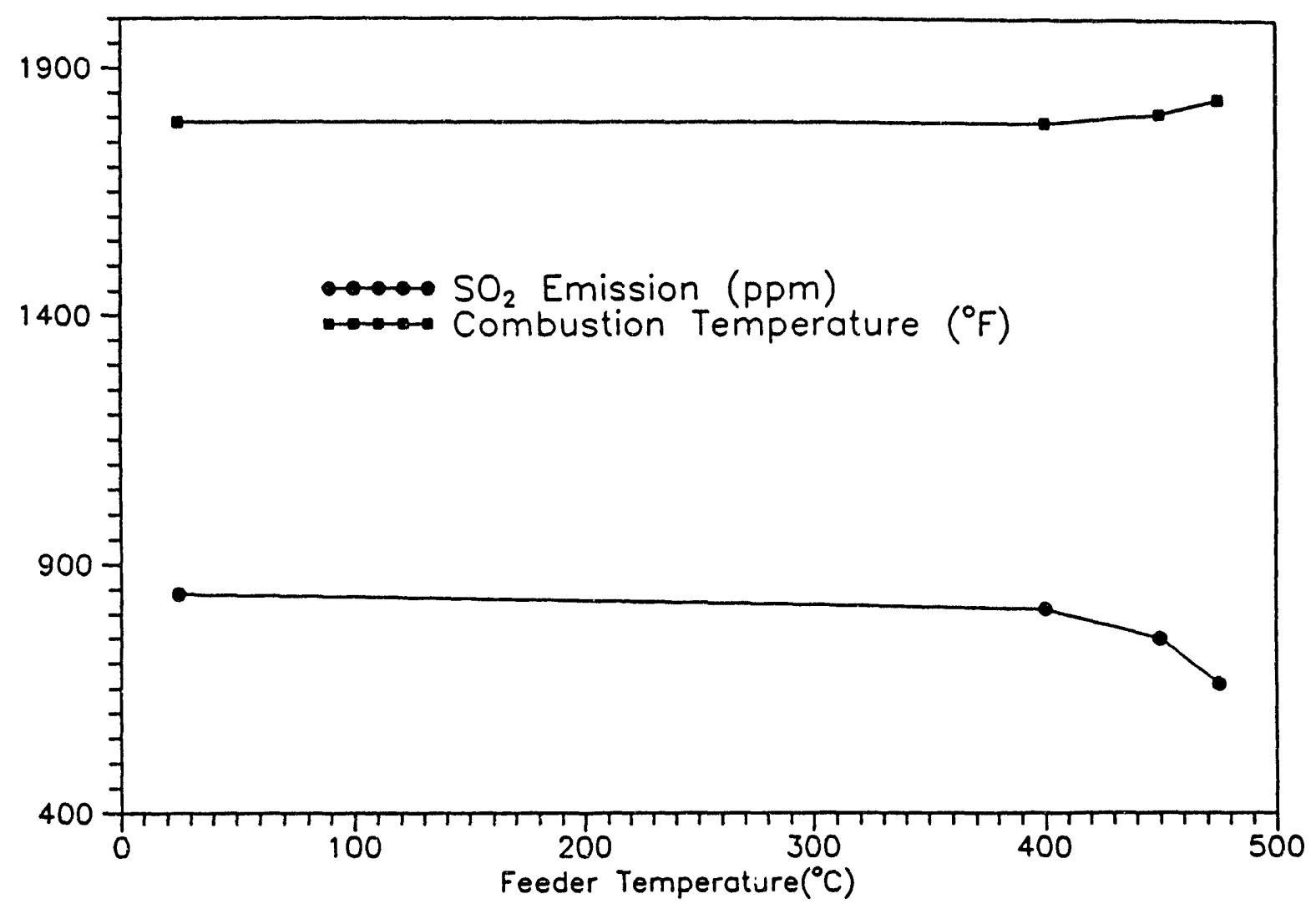

Figure 16. Combustion Characteristics of The Pyrolysis Products 


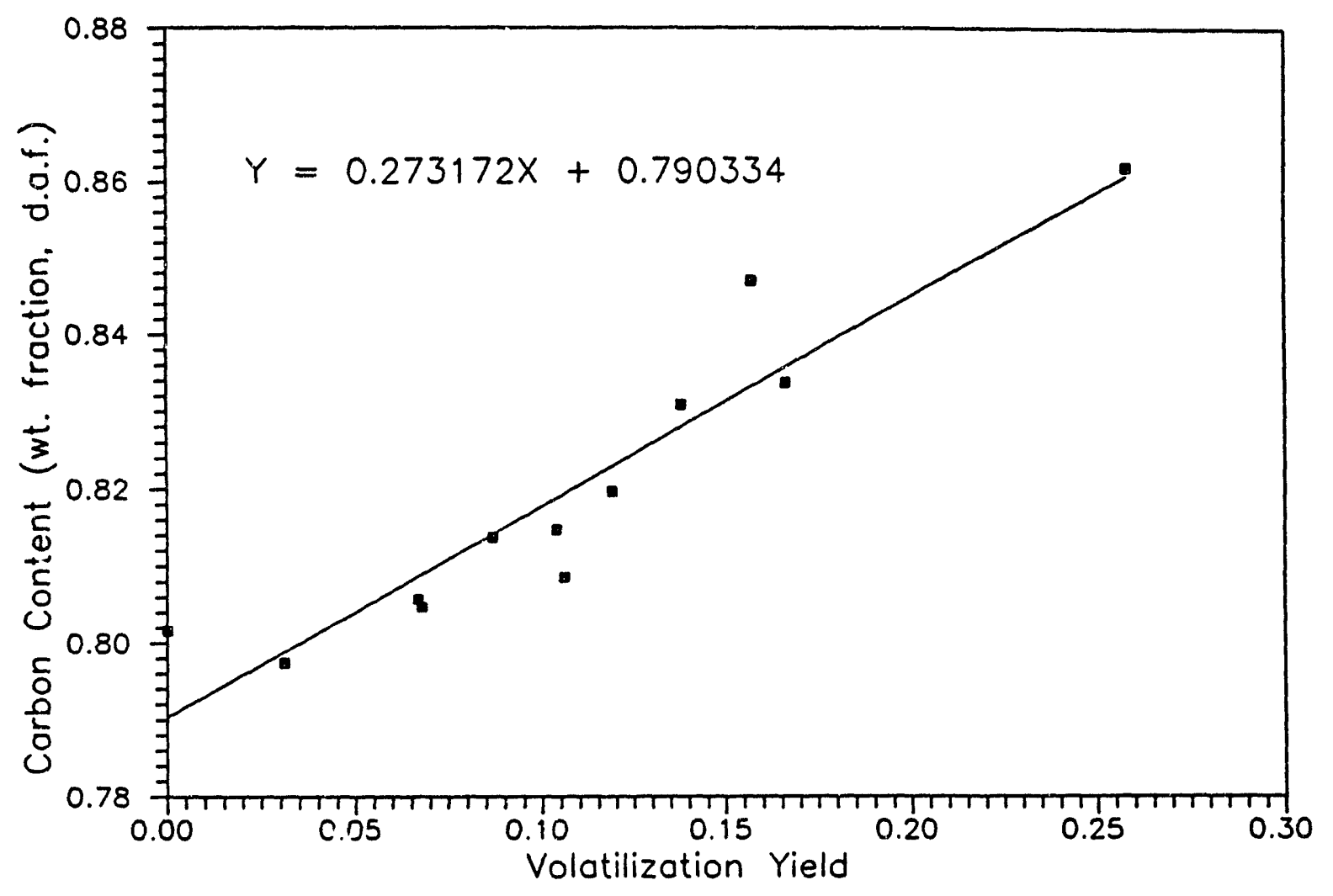

Figure 17. Carbon Content in Char Products 


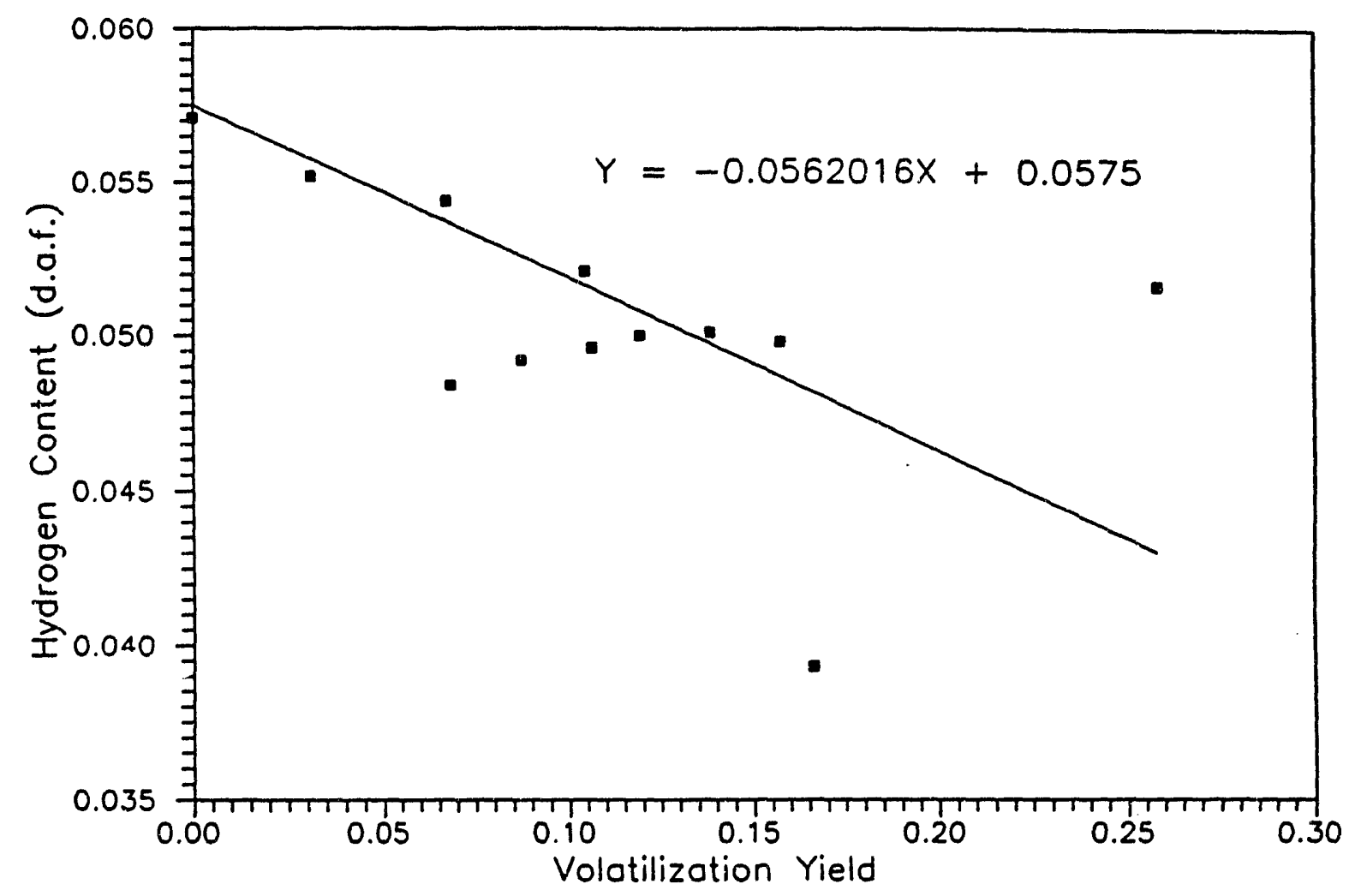

Figure 18. Hydrogen Content in Char Products 


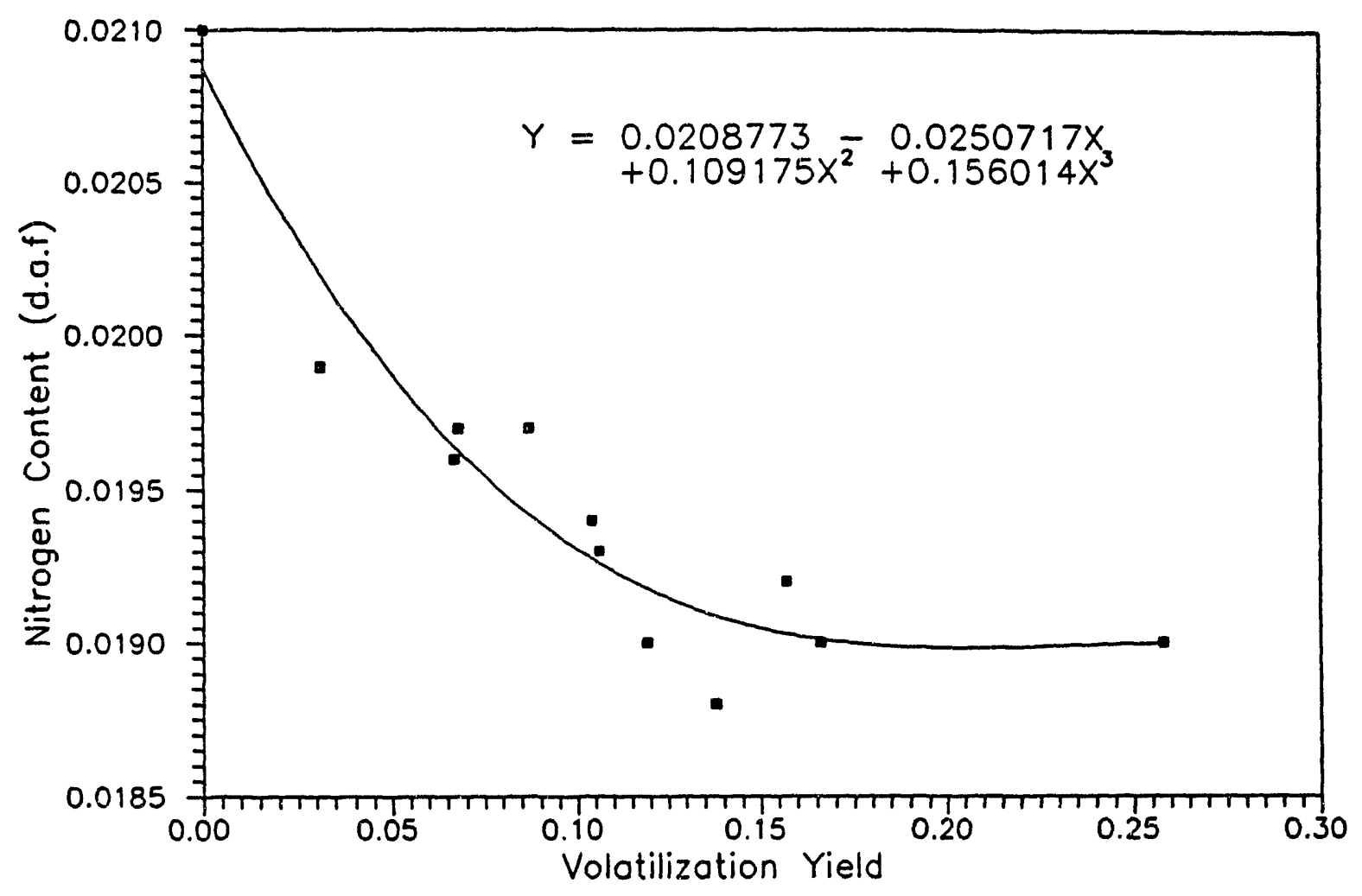

Figure 19. Nitrogen Content in Char Products 


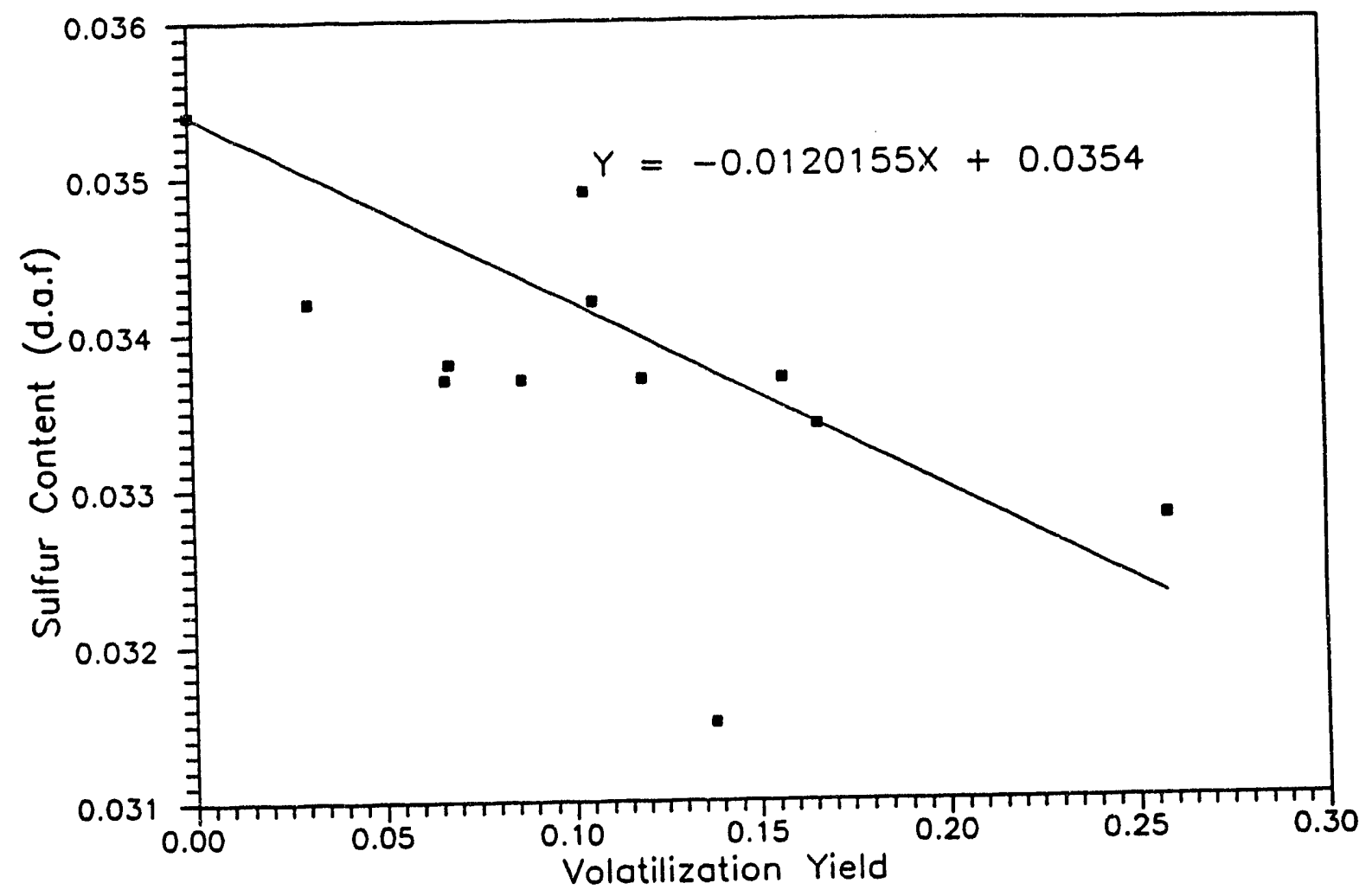

Figure 20. Sulfur Content in Char Products 


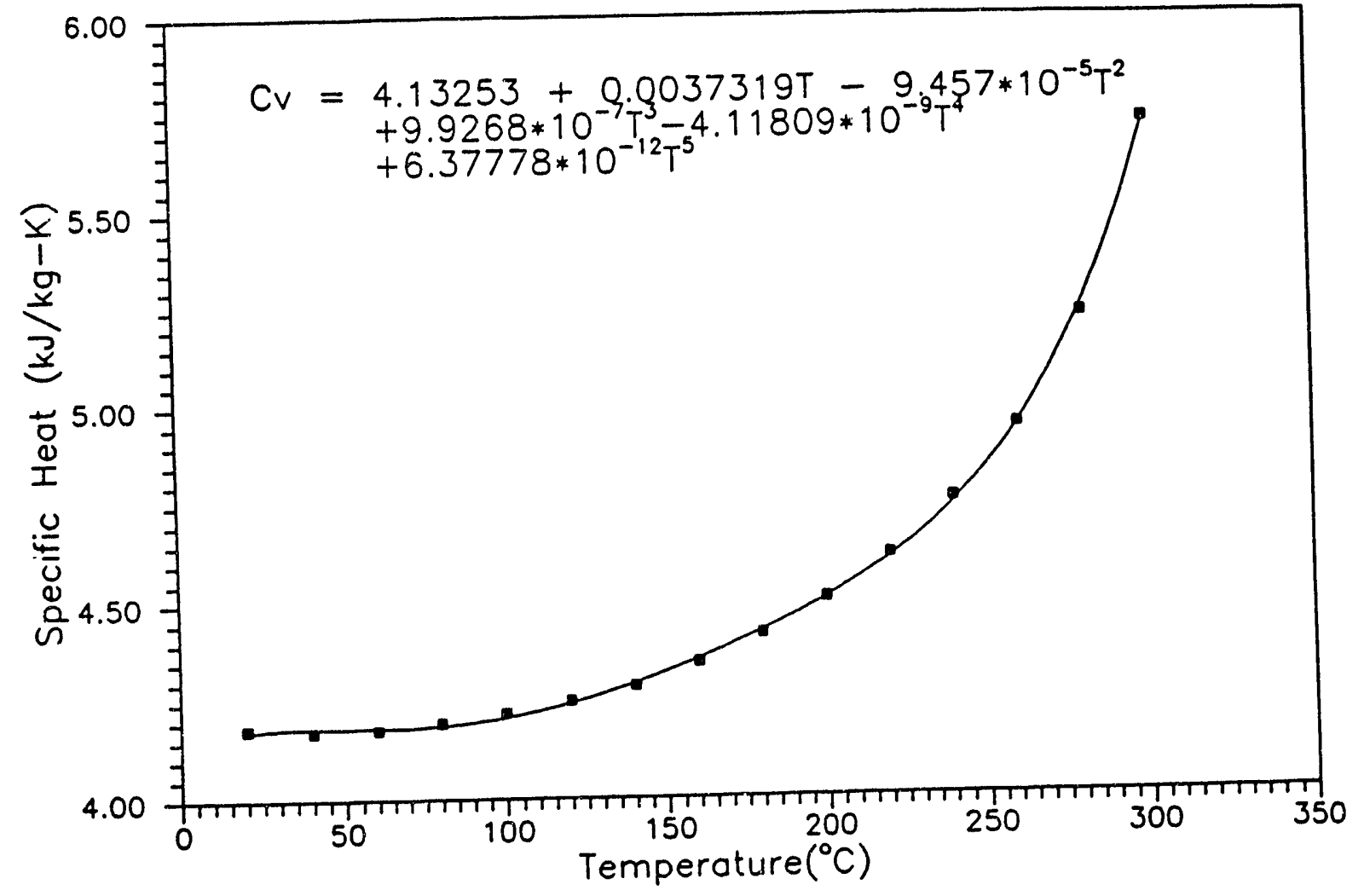

Figure 21. Specific Heat of Water at Different Temperature 


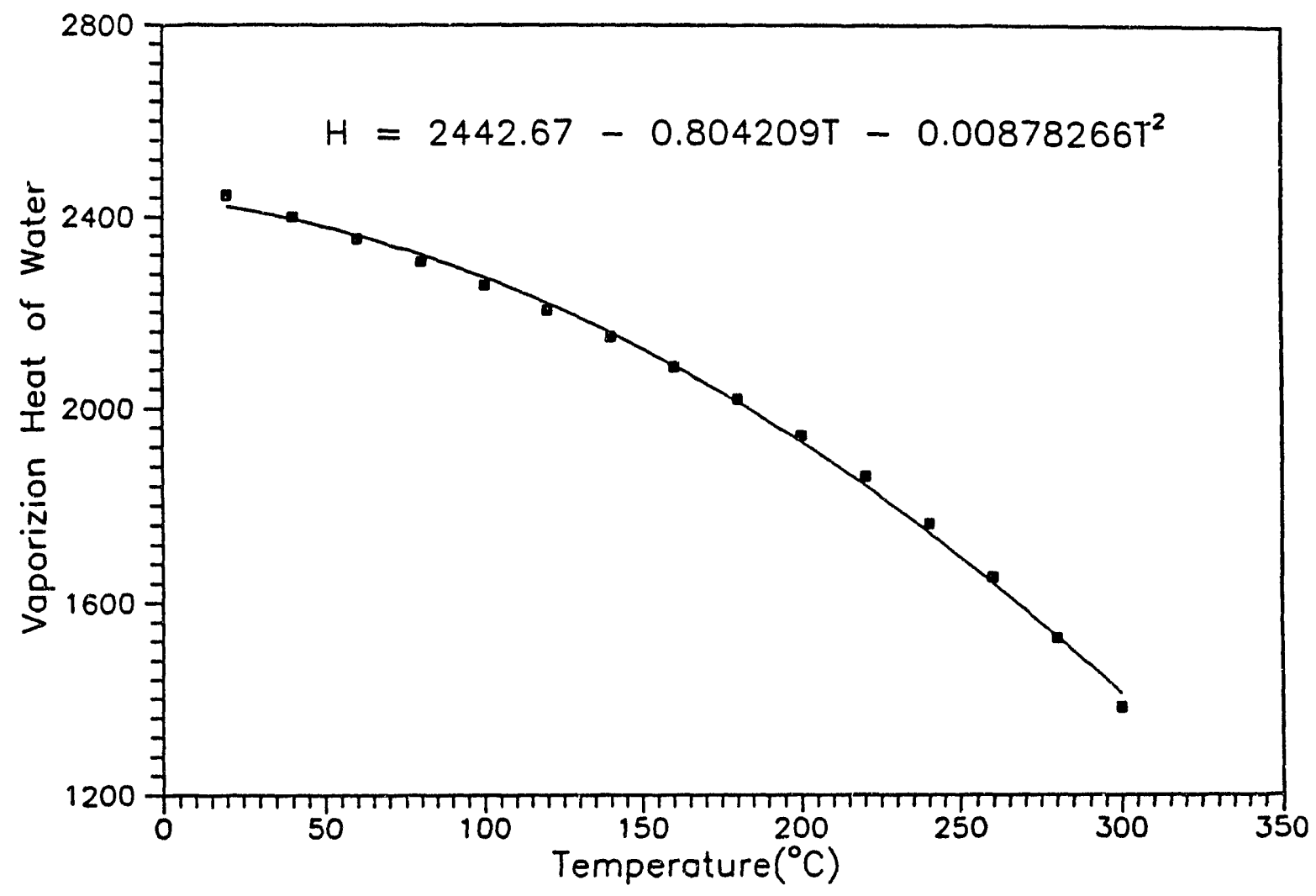

Figure 22. Vaporization Heat of Water 


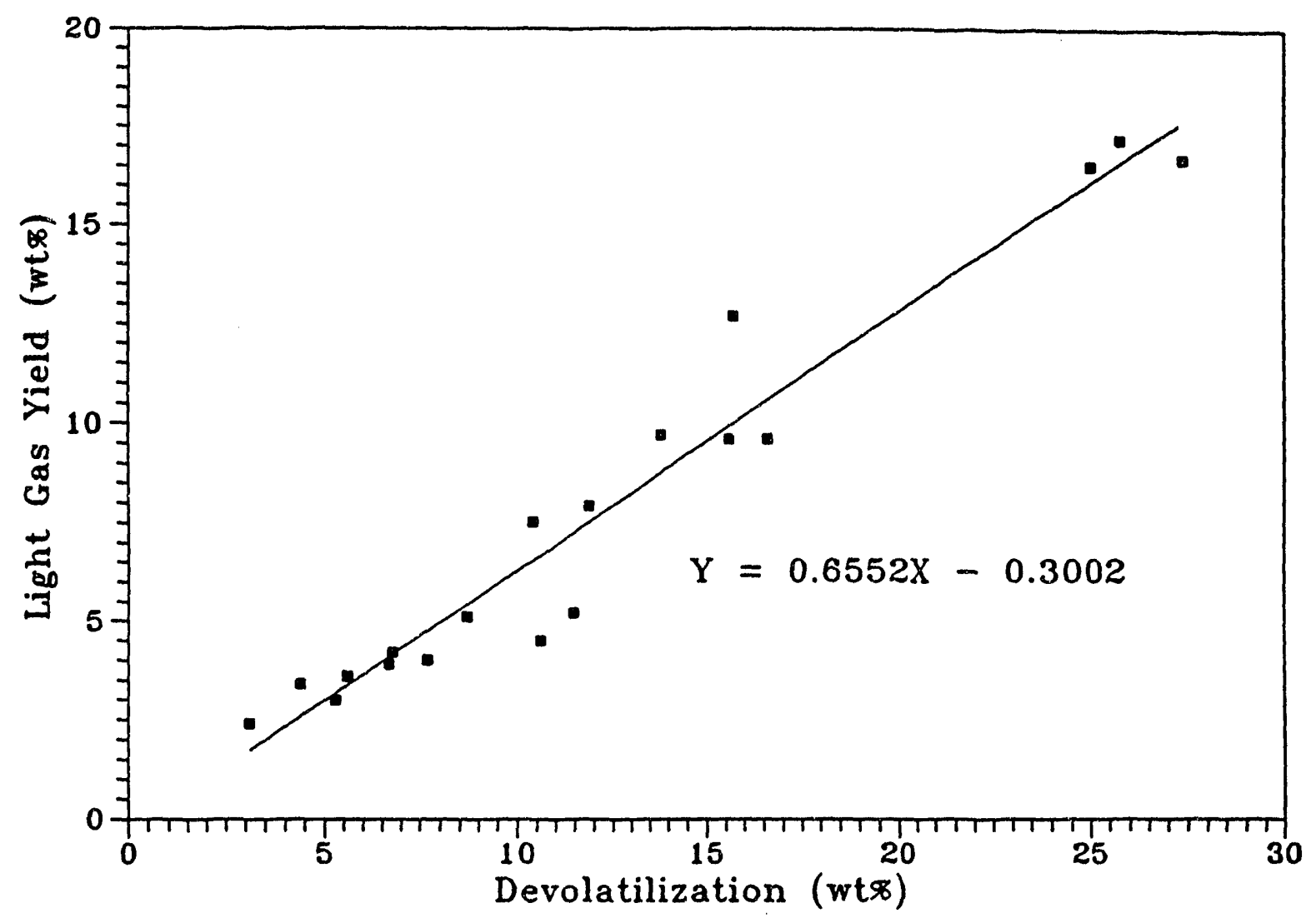

Figure 23. Light Gas Yield vs. Total Pyrolysis Conversion 


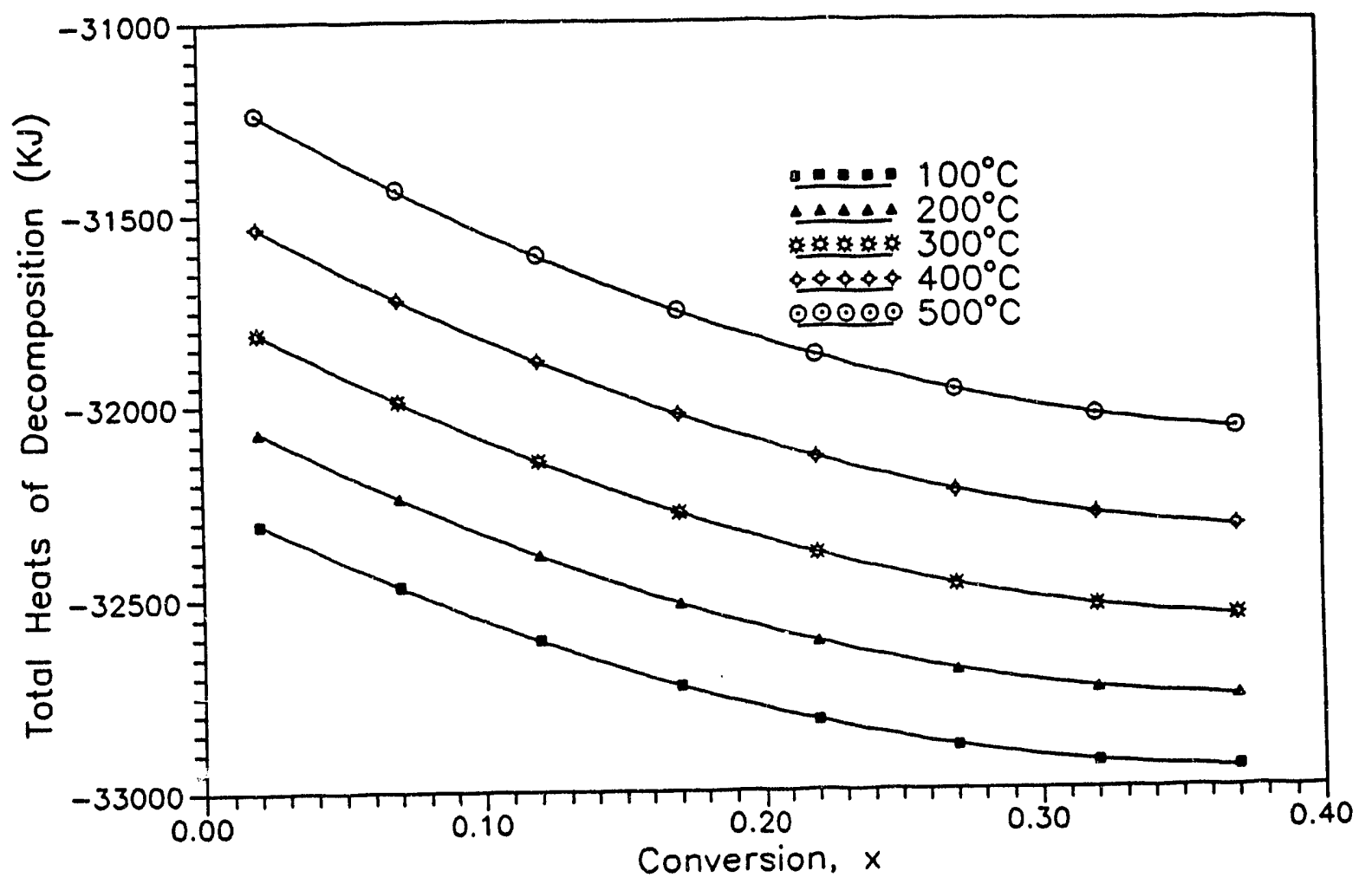

Figure 24. Energy Requirement of Coal Decomposition for Conversion $x$ 

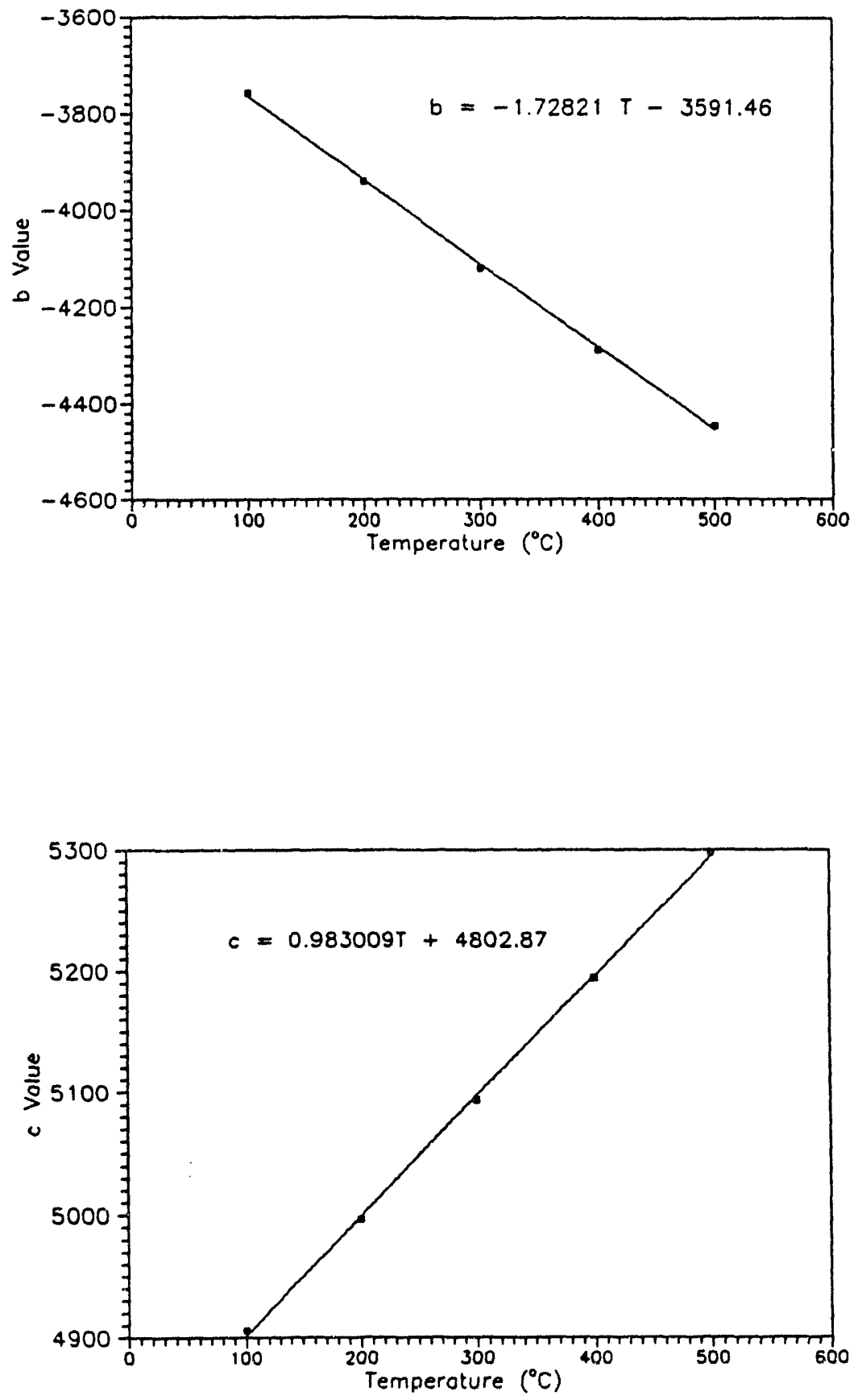

Figure 25. Correlations of $\mathrm{b}$ And $\mathrm{c}$ with Temperature 


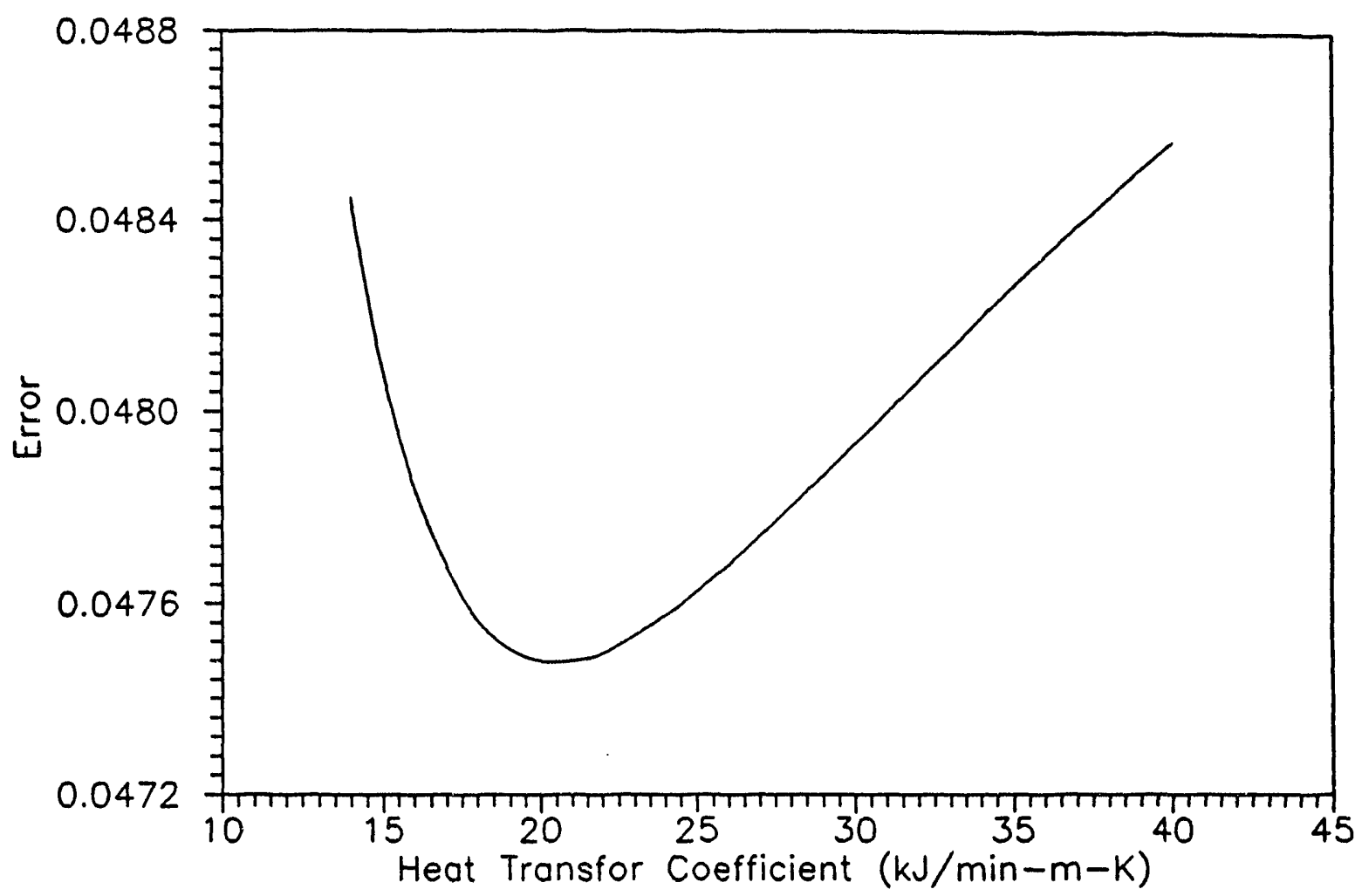

Figure 26. Relationship Between Error and Heat Transfor Coefficient 


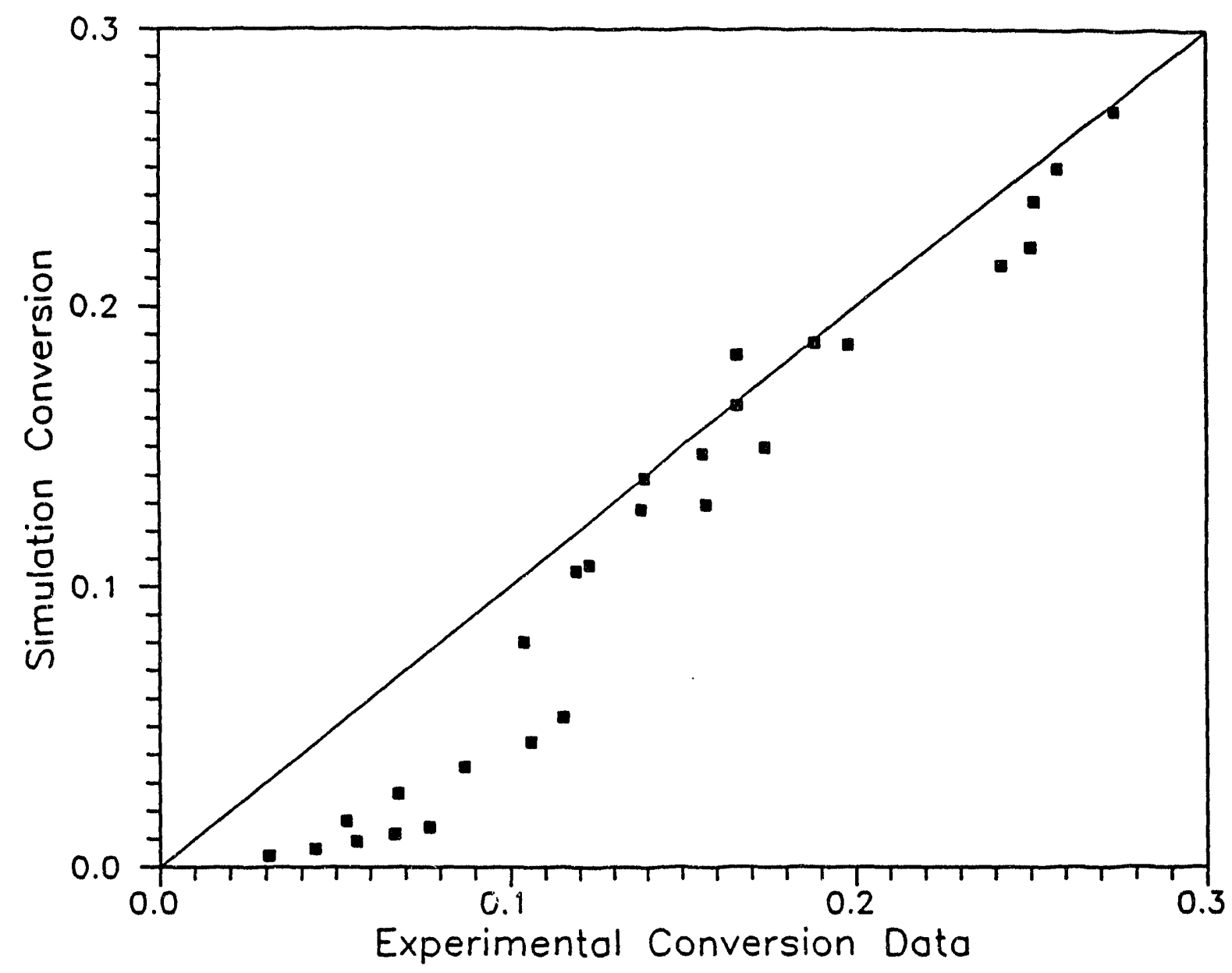

Figure 27. Comparison of Predicted Value with Experimental Result 


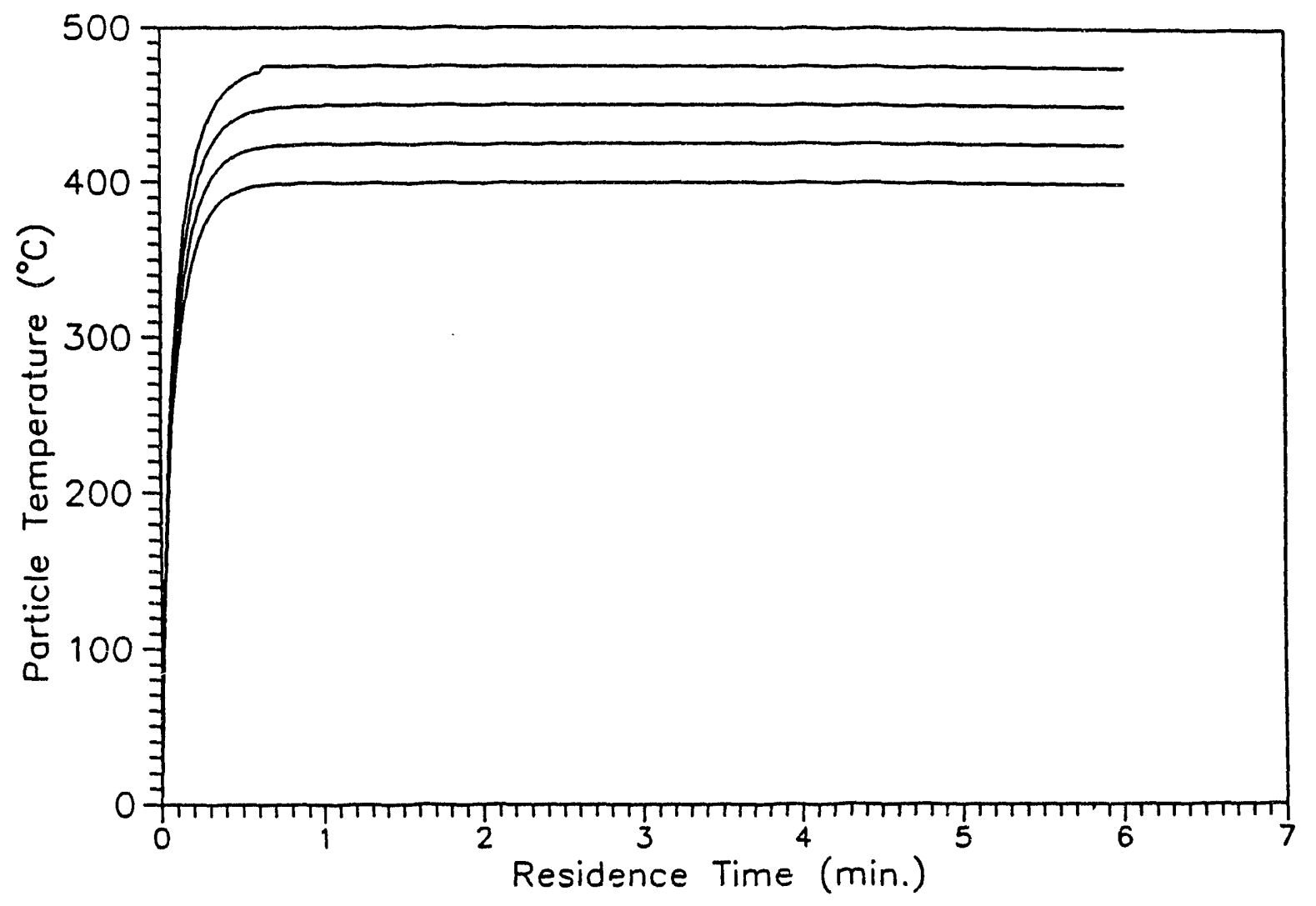

Figure 28. Particle Temperature vs. Residence Time 


\section{REFERENCES}

1. Hessley, R. K., Reasoner, J. W. and Riley, J. T., "Coal Science", John Wiley \& Sons, Inc.(1986)

2. National Coal Association, "U.S.Coal Production, Consumption to Rise in 1992", Coal, 97(3), pp9-10 (1992)

3. OCDO Newsletter, VIII, issue 9, Ohio Coal Development Office, Columbus, Ohio, June/July (1989)

4. Feibus, H., "The Challenge for Advanced Coal Processing and Utilization Research and Development in The 1990s",in Markuszewski, R. and Wheelock, T.D. (ed):"Processing and Utilization of Kigh-Sulfur Coals, II", pp3-8, Elsevier (1990)

5. Keener, T. C., and Keener, S., "Current Status of Flue Gas Desulfurization in the United States", in Environmental Engineering: Proceeding of the 1986 Specialty Conference

6. Offten, G. R. et al., "Assessment of dry Sorbent Emission Control Technologies - Part 2, Applications", JAPCA., 37(8), pp968-980 (1987)

7. Peter, J. J. T. and Jacob, M., "Slow and Rapid Pyrolysis of Coal"; in Yuda Yürüm (ed): "New Trends in Coal Science", pp305-338, Kluwer Academic Publishers (1988)

8. Ladner, W. R., "The Products of Coal Pyrolysis: Properties, Conversion and Reactivity", Fuel Processing Technology, 20, pp207-222 (1988)

9. Anthony, D. B. and Howard, J. B., "Coal Devolatilization and Hydrogasification", AlChE J., 22(4), pp625-656 (1976)

10. Elliott, M. A., et al., "Chemistry of Coal Utilization", 2nd Supplementary Vol., V/ileyInterscience Publication (1981) 
11. Berkowitz, N. "The Chemistry of Coal",pp213-274, Elsevier (1985)

12. Jamaluddin, A. S., Wall, T. F. and Truelove J. S., "Modeling of Devolatilization and Combustion of Pulverized Coal under Rapid Heating Conditions", in Volborth, A.(ed): "Coal Science and Chemistry",pp61-109, Elsevier (1987)

13. Pitt, G. J., "The Kinetics of the Evolution of Volatile Products from Coal", Fuel, 41, pp41 (1962)

14. Anthony, D. B. et al., "Rapid Devolatilization of Pulverized Coal", 15th Symposium (International) on Combustion, pp1303, The Combustion Institute, Pittsburgh, PA (1975)

15. Anthony, D. B. et al., "Rapid Devolatilization and Hydrogasification of Bituminous Coal", Fuel, 55, pp121-128 (1976)

16. Vargas, J. M. and Perlmutter, D. D., "Interpretation of Coal Pyrolysis Kinetics", Ind. Eng. Chem. Process Des. Dev., 25, pp49-54 (1986)

17. Niksa, S., "FLASHCHAIN theory of Rapid Coal Devolatilization Kinetics", Energy \& Fuels, 5(5), pp647-683 (1991)

18. Phauoc, T. X. and Mathur, M. P., "Transient Heating of Coal Particles Undergoing Pyrolysis",Comb. Flame, 85, pp380-388 (1991)

19. Borghi, G. et al., "A Model of Coal Devolatilization and Combustion in Fluidized Beds", Comb. Flame, 61, pp1-16 (1985)

20. Bliek, A. K. et al., AIChE J., 31, pp1666 (1985)

21. Agarwal, P. K. and La Nauze, R. D., "Transfer Processes Loca' to The Coal Particle: A Review", Chem. Eng. Res. Des., 67, pp457-480 (1989)

22. Fletcher, T. H. et al., "Chemical Procolation Model for Devolatilization. 3. Direct Use 


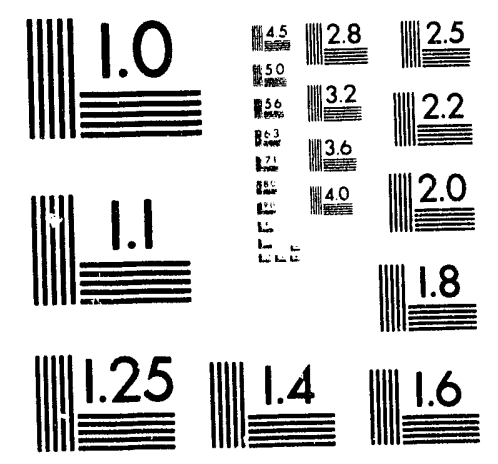



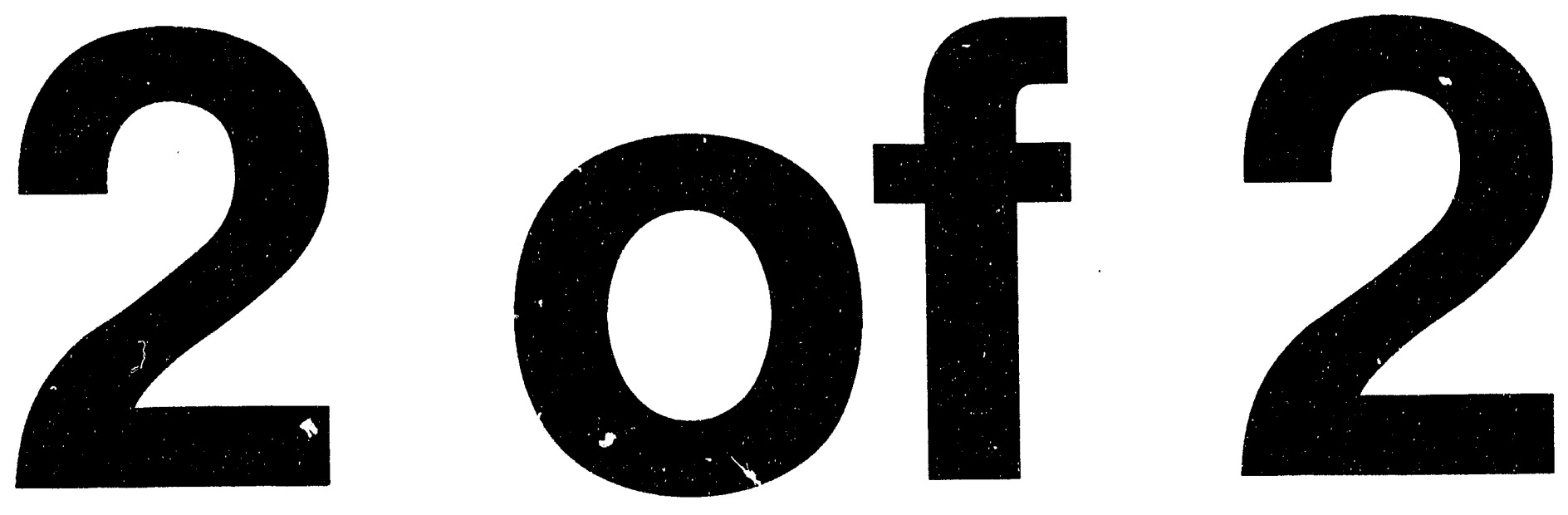
of ${ }^{13} \mathrm{C}$ NMR Data to Predict Effects of Coal", Energy \& Fuels, 6, pp414-431 (1992)

23 Solomon, P. R. et al., "An Empirical Model for Coal Fluidity Based on a Macromolecular Network Pyrolysis Model", Energy \& Fuels, 6, pp143-154 (1992)

24. Eliot, R. C., "Coal Desulfurization Prior to Combustion", Noyes Data Corp., Park Ridge, New Jersey, pp33-5113 (1978)

25. Attar, A., Desai, P. and Messenger, L. R., "Transformations of Organic sulfur Functional Groups During Coal Pyrolysis",Paper 68d, The 73rd Annual AIChE Meeting, Chicago, Illinois, November 17-20 (1983)

26. Attar, A. and Messenger, L. R., "The Desulfurization of Organic Sulfur and the Transformation of Organic Sulfur Functional Groups in Coal Pyrolysis", Chem. Eng. Commun., 20, pp53-62 (1983)

27. Attar, A. and Dupuis, F., "The Rate and The Fundamental Mechanisms of the Reaction of Hydrogen Sulfide with the Basic Minerals in Coal", Ind.Chem.Pro.Des.and Dev.,18, pp607-618 (1979)

28. March, J., "Advanced Organic Chemistry",pp23, John Wiley, N.Y.(1985)

29. Carcia, R. and Moinelo, S. R., "Pyrolytic Desulfurization of Some High-Sulfur Coals", Energy \& Fuels, 5 pp582-586 (1991)

30. Alvin, M. A., Archer, D. H. and Ahmed, M. M., "Pyrolysis of Coal for Production of Low-Sulfur Fuel", EPRI Report, Report Number EPRI AP-5005, January (1987)

31. Ibarra, J. V., Miranda, J. L. and Perez, A. J., "Product Distribution and Sulfur Forms in The Low Temperature Pyrolysis of A Spanish Subbituminous Coal", Fuel Processing Technology, 15, pp31-34 (1987) 
32. Peter, J. C. et al., "Decomposition of Pyrite and Trapping of Sulfur in a Coal Matrix During Pyrolysis of Coal", Fuel, 63, pp1579-1582 (1984)

33. Taghiei, M. M. et al., "In Site X-ray Absorption Fine Structure Spectroscopy Investigation of Sulfur Functional Groups in Coal during Pyrolysis and Oxidation", Energy \& Fuels, 6, pp293-300 (1992)

34. Gryglewicz, G. and Jasinko, S., "The Behavior of pyritic Sulfur During Pyrolysis of Metaanthracitte ", in Markuszewski, R and Wheelock, T. D.(ed): "Processing and Utilization of High-Sulfur Coals", Elsevier (1990)

35. Attar, A., "Kinetic Studies Related to the LIMB Burner", EPA Technical Report, Report No. EPA-600/7-84-070, June (1984)

36. Zarkanitis, S. and Sotirchos, S. V., "Factors limiting The Capacity of Calcined Limestones for $\mathrm{SO}_{2}$ Removal: Model Predictions vs. Experimental Evidence", in Markuszewski, R and Wheelock, T. D.(ed): "Processing and Utilization of High-Sulfur Coals", Elsevier (1990)

37. Borgwardt, R. H., "Surface Area of Calcium Oxide and Kinetics of Calcium Sulfide Formation", Environmental Progress, 3(2), pp129-135 (1984)

38. Pell, M., "Reaction of Hydrogen Sulfide with Fully calcined Dolomite", PhD Thesis, City University of N.Y. (1971)

39. Kamath, V. S. and Petrie, T. W., "Rate of Reaction of Hydrogen Sulfide-Carbonyl Sulfide Mixture with Fully Calcined Dolomite", Environ. Sci. Technol., 15, pF966-968, (1981)

40. Keairns, D. L., Archer, D. H. and Newby, R. A., "Evaluation of the Fluidized-Bed 
Combustion Process, Vol. IV, Fluidized-Bed Oil gasification/Desulfurization", EPA650/2-73-048d,(NTIS PB 233-101) (1973)

41. Simons, G. A. and Rawlins, W. T., "Reaction of Sulfur Dioxide and Hydrogen Sulfide with Porous Calcined Limestone", Ind. Eng. Chem. Process Des. Dev., 19(4) pp565$572(1980)$

42. Efthimiadis, E. A. and Sotirchos, S. V., "Sulfidation of Limestone-Derived Calcines", Ind. Eng. Chem. Res., 31, pp2311-2321 (1992)

43. Tromp, P. J. J., Kapteijn, F. and Moulijn, J. A., "Characterization of Coal pyrolysis by Means of Differential Scanning Calorimetry. 1. Quantitative Heat Effects in An Inert Atmosphere", Fuel Processing Technology, 15, pp45-57 (1987)

44. Elsermann, W., Johnson, P. and Conger, W. L., "Estimating Thermodynamic Properties of Coal, Char, Tar and Ash", Fuel processing Technology, 3, pp39-53 (1980)

45. Merrick, D., "The Thermal Decomposition of Coal: Mathematical Models of The Chemical and Physical Changes", in Volborth, A.(ed), "Coal Science and Chemistry", Elsevier (1987)

46. Francis, H. E. and Lloyd, W. G., CQ Spring, pp21-25 (1983) 

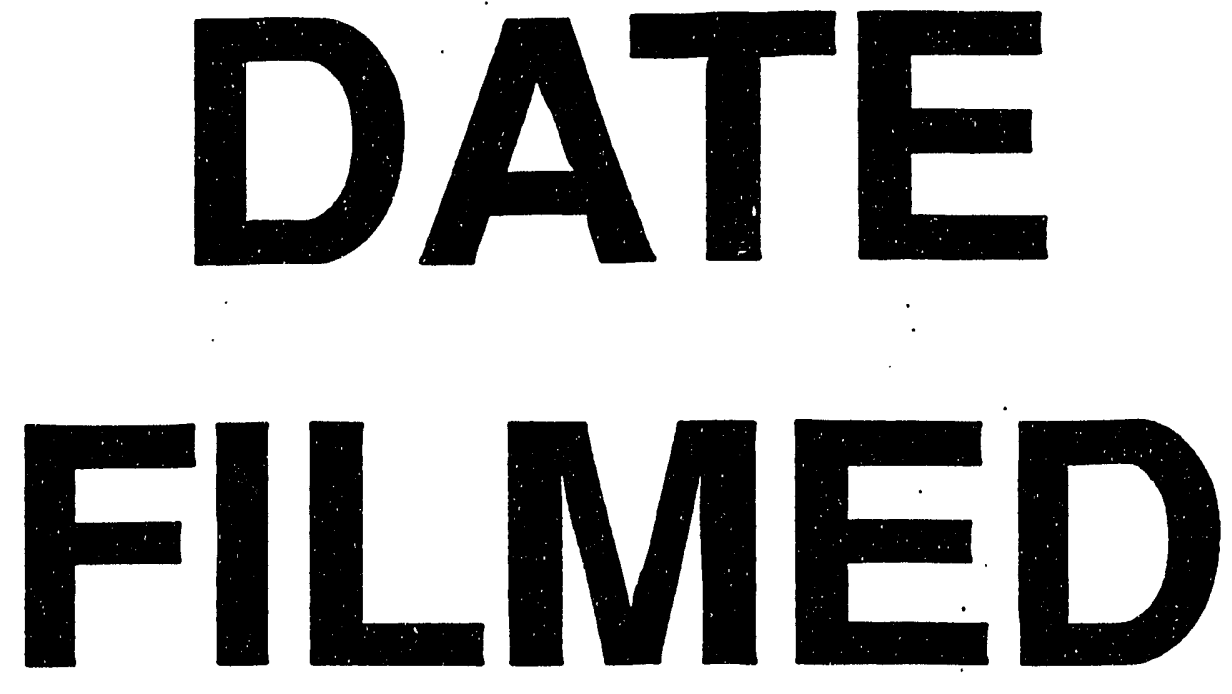

$10 / 20 / 93$
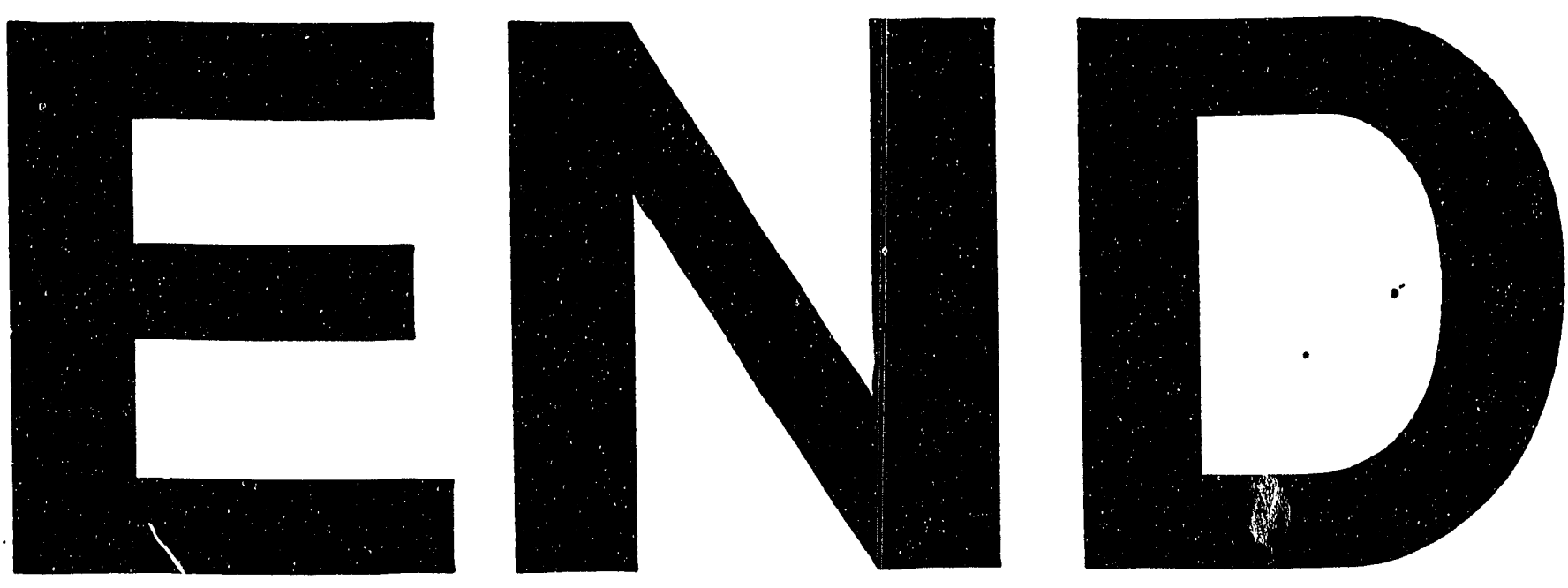
